\author{
UNIVERSIDADE DE SÃO PAULO \\ INSTITUTO DE ENERGIA E AMBIENTE \\ PROGRAMA DE PÓS-GRADUAÇÃO EM CIÊNCIA AMBIENTAL
}

RAFAEL DE CARVALHO SPOSITO

FATORES DETERMINANTES DA VIABILIDADE DA COLETA DE MÚLTIPLOS PRODUTOS FLORESTAIS NÃO MADEIREIROS:

ESTUDO EM SETE LOCALIDADES DA AMAZÔNIA CENTRAL 
RAFAEL DE CARVALHO SPOSITO

\section{FATORES DETERMINANTES DA VIABILIDADE DA COLETA DE MÚLTIPLOS PRODUTOS FLORESTAIS NÃO MADEIREIROS: ESTUDO EM SETE LOCALIDADES DA AMAZÔNIA CENTRAL}

Dissertação apresentada ao Programa de PósGraduação em Ciência Ambiental do Instituto de Energia e Ambiente da Universidade de São Paulo para obtenção do título de Mestre em Ciência Ambiental.

Orientadora: Prof ${ }^{\mathrm{a}}$. Dr ${ }^{\mathrm{a}}$. Carla Morsello

Versão Original 
AUTORIZO A REPRODUÇÃO E DIVULGAÇÃO TOTAL OU PARCIAL DESTE TRABALHO, POR QUALQUER MEIO CONVENCIONAL OU ELETRÔNICO, PARA FINS DE ESTUDO E PESQUISA, DESDE QUE CITADA A FONTE.

\section{FICHA CATALOGRÁFICA}

Sposito, Rafael de Carvalho.

Fatores determinantes da viabilidade da coleta de múltiplos produtos florestais não madeireiros: estudo em sete localidades da Amazônia central/ Rafael de Carvalho Sposito; orientadora : Carla Morsello- São Paulo, 2016.

107f.: il.; $30 \mathrm{~cm}$.

Dissertação (Mestrado em Ciência Ambiental) - Programa de Pós-

Graduação em Ciência Ambiental - Instituto de Energia e Ambiente da Universidade de São Paulo. 


\section{FOLHA DE APROVAÇÃO}

Nome: SPOSITO, Rafael de Carvalho

Título: Fatores determinantes da viabilidade da coleta de múltiplos produtos florestais não madeireiros: estudo em sete localidades da Amazônia central.

Dissertação apresentada ao Programa de PósGraduação em Ciência Ambiental do Instituto de Energia e Ambiente da Universidade de São Paulo para obtenção do título de Mestre em Ciência Ambiental.

Aprovado em:

\section{Banca examinadora}

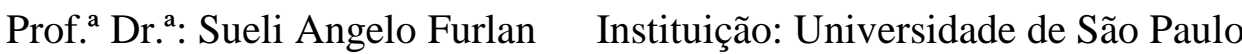

Julgamento:

Assinatura:

Dr. ${ }^{a}$ Nelissa Peralta Bezerra

Instituição: Instituto de Desenvolvimento Sustentável Mamirauá

Julgamento: Assinatura:

Prof. ${ }^{\text {a }}$ Dr. ${ }^{\text {a }: ~ C a r l a ~ M o r s e l l o ~}$ Instituição: Universidade de São Paulo

Presidente

Assinatura: 
Dedico a todos os habitantes da RDS Mamirauá:

pessoas, plantas e animais. 


\section{AGRADECIMENTOS}

Muitas pessoas colaboraram direta ou indiretamente para o desenvolvimento desta pesquisa, desde o planejamento do projeto até a coleta e análise dos dados, e a elaboração da dissertação.

Agradeço enormemente a todos os moradores das sete comunidades da RDS Mamirauá que participaram do estudo, especialmente aos que, por mais de uma vez, deixaram seus afazeres de lado para me guiar pelas matas, lagos, rios e paranás de Mamirauá, assim como aos que participaram das entrevistas. A todos que me acolheram em suas casas, sempre tão gentil e alegremente, oferecendo um armador para atar minha rede e compartilhando de suas estórias, ensinamentos, peixe, farinha, café e açaí, dentre outros produtos florestais não madeireiros. Estejam certos de que as experiências vividas com vocês em Batalha de Baixo, Costa da Ilha, São José do Maiana, Terra Nova, Triunfo, Capote e Santa Teresa estarão pra sempre guardadas em minha memória e coração. O meu mais profundo agradecimento e reverência ao Sr. Lourival, dona Creuza e suas filhas Lolita e Isaura, que me acolheram em Fonte Boa-AM (minha porta de entrada para a RDS Mamirauá), como um verdadeiro membro da família, dando todo o suporte logístico, técnico e afetivo necessário para o sucesso dos trabalhos de campo de 2014.

Agradeço à minha família por todo apoio e incentivo que me deram durante os três anos de mestrado. Além disso, faço um agradecimento especial à minha mãe, Bete, pela revisão de português e redação de toda a dissertação. Os eventuais erros gramaticais ou problemas de clareza contidos neste documento são de minha inteira responsabilidade, já que modifiquei diferentes partes do texto após já terem sido revisadas, e não as submeti a uma nova revisão. Agradeço também à minha prima Beatriz, que me ajudou pronta e gentilmente com a tradução do resumo para o inglês. Agradeço à Anelize, que no meu primeiro ano de mestrado se tornou minha namorada, no segundo, minha noiva, e no terceiro, minha esposa. Sempre tão companheira, fez com que me sentisse amparado, material e emocionalmente, em todos momentos, bons e difíceis, pelos quais passei durante essa caminhada.

Agradeço aos amigos e ex-colegas do Instituto Mamirauá, em especial: Juliana Leoni, que revisou uma das primeiras versões do projeto, dando boas sugestões; Emílio Higashikawa, Jezenias, Kitão e Israel, que ajudaram com a coleta dos dados ecológicos, sendo companheiros até debaixo dos vigorosos temporais amazônicos e das incontáveis ferroadas de carapanã, com certeza a parte mais dura de todo o trabalho de campo; Alessandra Stremel, pelas dicas e informações acerca da socioeconomia das famílias de Mamirauá, que foram 
importantes para elaborar parte dos questionários utilizados nas entrevistas; Sandro Regatieri, pelas informações demográficas das comunidades estudadas, importantes para o planejamento do delineamento da pesquisa; Alex Coelho, pelas valiosas dicas de logística e por todo o apoio dado durante os trabalhos de campo realizados em 2014; João Paulo Borges e Maria Cecília Gomes, por terem me recebido tão amorosamente em sua casa em Tefé-AM, onde tive todas as condições necessárias para trabalhar, descansar e me divertir enquanto não estava na Reserva Mamirauá ou em Fonte Boa; Soldado e Bianca, por também terem me hospedado com carinho, nos últimos dias que estive em Tefé. Agradeço também aos amigos de outras instituições, que contribuíram pontualmente com algumas sugestões metodológicas, como o Camarão e a Raquel dos Santos. À Alice Brites que ajudou em vários momentos da pesquisa, sobretudo com as análises dos dados e com a revisão de boa parte dos textos e gráficos produzidos.

Agradeço à Carla Morsello, que se fez presente com sua cuidadosa orientação e me ajudou a dar mais um importante passo na carreira. Aos professores membros do comitê de orientação do PROCAM: Luiz Carlos Beduschi, Alexandre Adalardo e Sueli Furlan, que com seus preciosos comentários e sugestões me ajudaram a alcançar meus objetivos no mestrado.

E por último, agradeço ao Instituto de Desenvolvimento Sustentável Mamirauá, pelo apoio financeiro, técnico e logístico dado a esta pesquisa, que foi imprescindível para a realização dos trabalhos de campo e coleta dos dados. Agradeço ainda à Coordenação de Aperfeiçoamento de Pessoal de Nível Superior (CAPES) e à Fundação de Amparo à Pesquisa do Estado de São Paulo (FAPESP) pelas bolsas concedidas. 


\section{RESUMO}

SPOSITO, R. C. Fatores determinantes da viabilidade da coleta de múltiplos produtos florestais não madeireiros: estudo em sete localidades da Amazônia central. 2016. 107 f. Dissertação (Mestrado em Ciência Ambiental) - Programa de Pós-Graduação em Ciência Ambiental - Instituto de Energia e Ambiente da Universidade de São Paulo, São Paulo, 2016.

O uso múltiplo florestal é apontado na literatura científica como mais uma das estratégias win-win de conservação e desenvolvimento local. Porém, pode haver limitações, as quais ainda não foram totalmente elucidadas. A ausência de múltiplos produtos florestais não madeireiros (PFNM) disponíveis em um contexto local e a falta do interesse e capacidade das pessoas de coletarem tais produtos restringe o sucesso dessa estratégia. Este estudo teve, portanto, o objetivo de avaliar como diferentes fatores afetam esses aspectos citados e, consequentemente, a viabilidade da coleta de múltiplos PFNM, assim como o potencial de geração de renda monetária. Foram avaliados fatores ambientais, socioeconômicos, culturais e de percepção no contexto de sete localidades da Reserva Mamirauá, na Amazônia Central. A disponibilidade (ocorrência e abundância) dos PFNM fornecidos por cinco espécies de importância comercial na região (frutos de açaí, buriti e camu-camu, e sementes de andiroba e murumuru), o potencial econômico desses PFNM e os fatores ambientais foram avaliados no nível da localidade. O interesse e a capacidade das pessoas coletarem os múltiplos PFNM, bem como o fator de percepção (gosto pela coleta), foram avaliados no nível do indivíduo. Já os fatores socioeconômicos e culturais foram avaliados no nível da unidade doméstica. Para avaliar a disponibilidade, foram estabelecidos um total de 24 transectos entre as sete localidades, onde também foram estimados três fatores ambientais (radiação solar, topografia e quantidade de matéria orgânica no solo). O potencial econômico foi estimado a partir da abundância das espécies, da taxa anual da produção de frutos e sementes e do preço dos produtos. O interesse e a capacidade dos indivíduos de coletar, bem como os fatores socioeconômicos, culturais e de percepção (gosto pela coleta) foram estimados através de survey, por meio de entrevistas. Ao todo foram realizadas 195 entrevistas, sendo 75 no nível da unidade doméstica e 120 no nível do indivíduo. Notou-se que a ocorrência e abundância das espécies variaram entre as localidades, sendo que apenas E. precatoria e A. murumuru são abundantes em todas as localidades. Além disso, a disponibilidade dos PFNM também varia de acordo com a frutificação das espécies, que pode ser baixa em determinado ano. Portanto, a disponibilidade de PFNM pode ser o primeiro fator limitante para geração de renda 
monetária com a coleta de múltiplos PFNM. As variações nos fatores ambientais parecem afetar a concentração dos indivíduos das espécies, que possuem distribuição agregada. Em todas as localidades, a maioria dos indivíduos declarou interesse em coletar os cinco PFNM pesquisados, exceto o murumuru. Além das pessoas terem mais interesse em coletar os produtos que são mais consumidos e vendidos, o gosto pela coleta também é importante. Por último, a maioria dos indivíduos das sete localidades é apta a coletar todos os produtos avaliados, apesar das dificuldades envolvidas na coleta. Portanto, os resultados sugerem que os principais fatores limitantes para a coleta de múltiplos PFNM nas sete localidades da RDS Mamirauá estão relacionados a pouca quantidade de árvores ou palmeiras e à falta de interesse em coletar, que é desencadeada, por sua vez, pela falta do gosto de coletar, assim como pelo não costume de consumir e pela dificuldade de comercializar os PFNM.

Palavras-chave: coleta, produtos florestais não madeireiros, disponibilidade, interesse, capacidade, açaí, murumuru, buriti, andiroba, camu-camu, Mamirauá. 


\begin{abstract}
SPOSITO, R. C. Determinant factors for the feasibility of collecting multiple non-timber forest products: a study in seven sites at central Amazon. 2016. 107 f. Dissertation (Master in Environmental Science) - Graduate Program in Environmental Science, Universidade de São Paulo, São Paulo 2016.
\end{abstract}

The use of multiple forest resources has been pointed in the scientific literature as one of the most win-win strategies for conservation and local development. However, the limitations of this approach have not been completely determined. The unavailability of diverse non-timber forest products (NTFP) in a local context as well as the lack of motivation and ability of people to collect such products limits the success of this strategy. In this regard, our study aimed to evaluate the contribution of different factors to the above mentioned aspects, including the feasibility of the collection of multiple NTFP and its potential generation of monetary income. We evaluated the environmental, the socioeconomic, the cultural and the perception factors in seven sites of the central Amazon, at Mamirauá Reserve. In a local context, the economic potential and availability (presence and abundance) of NTFP provided by fruits and seeds of five important species found specifically in that region (açaí, buriti, camu-camu, andiroba and murumuru) were examined. In an individual level, we evaluated the personal motivation and ability of collecting the multiple NTFP, in addition to the perception factor (characterized by the pleasure of collecting). Further, we investigated the socioeconomic and cultural factors in the context of the domestic units. In order to measure the availability, 24 transects where established in seven Amazon sites. Environmental factors such as solar radiation, topography and the amount of organic compounds in the soil were also accessed. In order to estimate the economic potential, we considered the abundance of the species, the annual rate of fruits and seeds production and the product prices. To better address the individual motivation and ability in collecting the products and the socioeconomic, cultural and perception factors, surveys and interviews were performed. A total of 195 interviews were done: 75 at the domestic unit level and 120 at the individual level. Our study demonstrates that the presence and abundance of the species vary among the different localities, being the E. precatoria and A. murumuru the common species found in all the localities. Moreover, the availability of NTFP vary seasonally, according to the characteristics of fructification of every species. Hence, the availability of the NTFP might be the first limiting factor compromising the generation of monetary income. Changes in the 
environmental factors were found to affect the concentration of the individual of the species, which show an aggregated distribution. In all the localities, the vast majority of the subjects demonstrated to be interested in collecting the species, except the murumuru. We observed a higher motivation of people in collecting that products with a higher consumption and commercial rates. Finally, we found that a significant amount of subjects in the seven sites were able to collect all the products evaluated, regardless the difficulties underlain the collection process. In conclusion, our data suggest that the main limiting factors for the collection of multiple NTFPs in the seven localities of the Mamirauá RDS are related to a small number of trees or palms and the lack of motivation in collecting, which is triggered in turn by the lack of pleasure of collecting as well as for the non-habit of consuming and for the difficulty of commercializing.

Keywords: collect, non-timber forest products, availability, motivation, ability, açaí, murumuru, buriti, andiroba, camu-camu, Mamirauá. 


\section{LISTA DE FIGURAS}

Figura I.1 - Área de estudo evidenciando os núcleos povoados das sete localidades

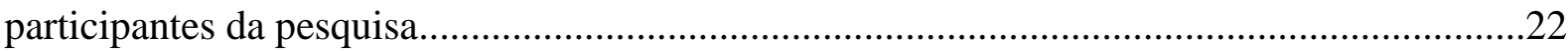

Figura I.2 - Frutos de murumuru flutuando na várzea após a queda.

Figura I.3 - Sementes de murumuru sendo trabalhadas por moradora da RDS Mamirauá para

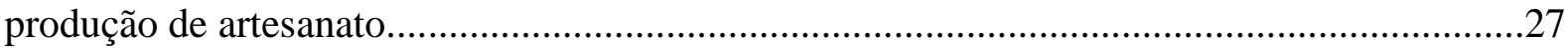

Figura I.4 - Frutos de andiroba abertos com suas sementes expostas.....................................28

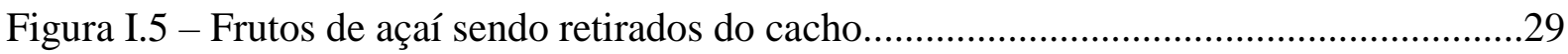

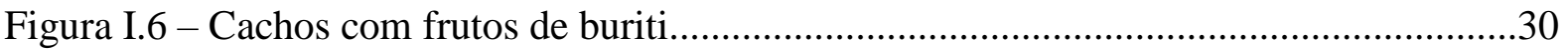

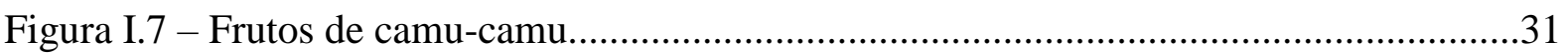

Figura I.8 - Escala utilizada para o entrevistado indicar o nível de interesse em coletar cada

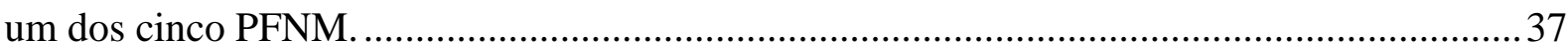

Figura II.1.a - Variação na altura de inundação entre as localidades e os transectos preferenciais

Figura II.1.b - Variação na profundidade do folhiço entre as localidades e os transectos preferenciais

Figura II.1.c - Variação na abertura de dossel entre as localidade e os transectos preferenciais

Figura II.1 - Variação dos fatores ambientais entre as localidade e os transectos preferenciais

Figura II.2 - Proporção da ocorrência das espécies por localidade.

Figura II.3 - Proporção das abundâncias médias das espécies por parcela nas sete localidades

Figura II.4 - Melhor mês para coletar os PFNM de acordo com as unidades domésticas entrevistadas.

Figura II.5 - Variação do potencial econômico por parcela entre os transecto preferenciais. .53 Figura II.6.a - Frequência relativa dos diferentes níveis de interesse em coletar açaí nas sete localidades.

Figura II.6.b - Frequência relativa dos diferentes níveis de interesse em coletar murumuru nas sete localidades.

Figura II.6.c - Frequência relativa dos diferentes níveis de interesse em coletar buriti nas cinco localidades.

Figura II.6.d - Frequência relativa dos diferentes níveis de interesse em coletar andiroba nas sete localidades.

Figura II.6.e - Frequência relativa dos diferentes níveis de interesse em coletar camu-camu nas sete localidades.

Figura II. 6 - Frequência relativa dos diferentes níveis de interesse (i.e. de -4 a 4) em coletar os cinco PFNM nas sete localidades.

Figura II.7 - Frequência relativa dos indivíduos interessados em coletar os cinco PFNM

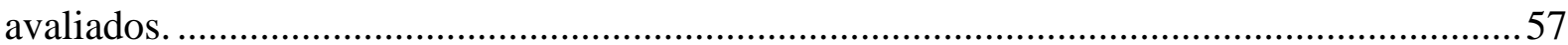

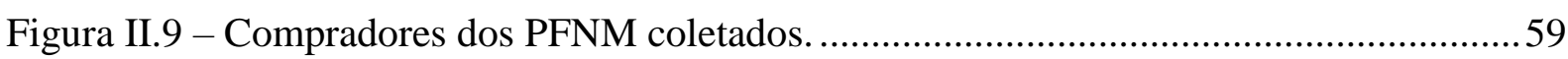


Figura II.8.a - Frequência relativa dos diferentes níveis de gosto pela coleta de açaí nas sete localidades.

Figura II.8.b - Frequência relativa dos diferentes níveis de gosto pela coleta de murumuru nas sete localidades.

Figura II.8.c - Frequência relativa dos diferentes níveis de gosto pela coleta de buriti nas sete localidades.

Figura II.8.d - Frequência relativa dos diferentes níveis de gosto pela coleta de andiroba nas sete localidades.

Figura II.8.e - Frequência relativa dos diferentes níveis de gosto pela coleta de camu-camu nas sete localidades

Figura II.8 - Frequência relativa dos diferentes níveis de gostar (i.e. de -4 a 4) para a coleta dos cinco PFNM nas sete localidades.

socioeconômicos, culturais e de percepção, com o interesse em coletar os cinco PFNM de importância econômica.

Figura II.10 - Proporção de indivíduos aptos e não aptos a coletar os cinco PFNM de importância comercial avaliados.

Figura II.11 - Variação da capacidade dos indivíduos em coletar os cinco PFNM avaliados. 66 Figura II.12 - Capacidade de coleta de homens e mulheres estimada pelo número médio de latas.

Figura II.13 - Diferença entre capacidade de coleta e quantidade coletada por produto. 67 Figura II.14 - Percepção sobre a quantidade de frutos e sementes produzidos pelas árvores em 2014.

Figura II.15 - Possíveis combinações de coleta dos PFNM, segundo os entrevistados...........68

Figura II.16 - Tempo médio gasto na coleta de uma lata de cada PFNM. ..............................69

Figura II.17 - Tempo médio gasto por homens e mulheres na coleta de uma lata de cada PFNM.

Figura II.18 - Frequência com que os entrevistados se dedicam à coleta dos PFNM. 


\section{LISTA DE TABELAS}

Tabela I.1 - Informações relacionadas aos critérios de seleção das localidades estudadas. ....23

Tabela I.2 - Número de transectos estabelecidos em cada localidade.

Tabela I.3 - Alturas e diâmetros mínimos considerados para a definição das fases adultas reprodutivas e número de indivíduos amostrados nos diferentes anos

Tabela I.4 - Definição e estatística descritiva das variáveis empregadas para testar a associação dos fatores socioeconômicos e do gosto pela coleta com o interesse dos indivíduos coletarem os cinco PFNM de importância comercial.

Tabela II.1 - Preço médio, em reais, de venda dos PFNM por unidade comercial.

Tabela II. 2 - Resultados das regressões multinível da associação dos fatores socioeconômicos e de percepção, com o interesse em coletar os cinco PFNM de importância 


\section{SUMÁRIO}

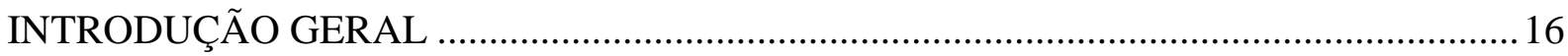

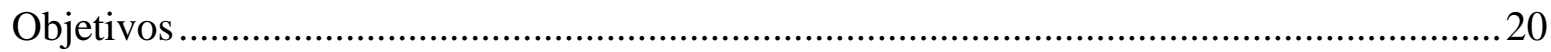

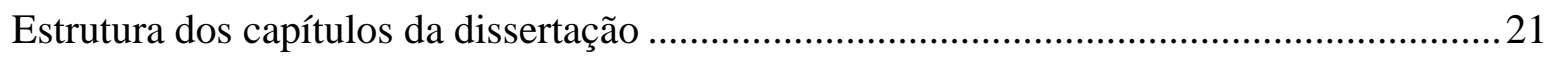

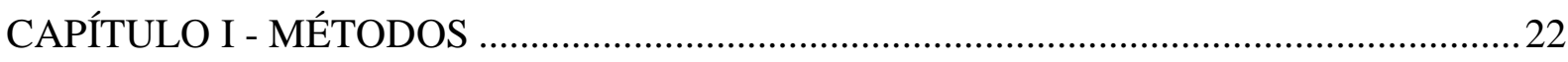

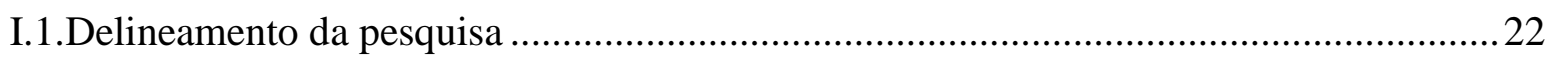

I.2.Caracterização da área de estudo e das localidades................................................... 23

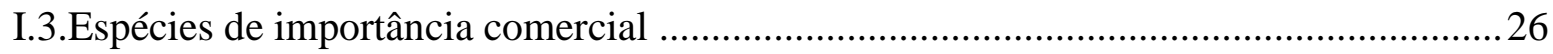

I.4.Técnicas de amostragem, coleta e análise dos dados ................................................... 31

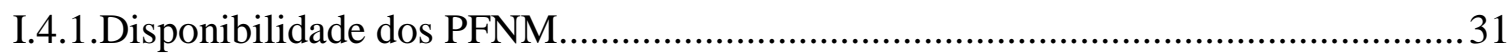

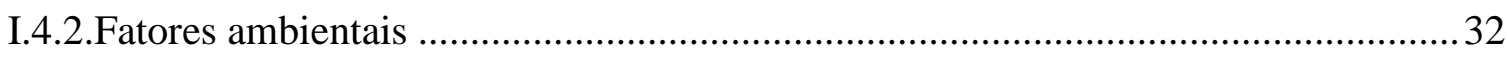

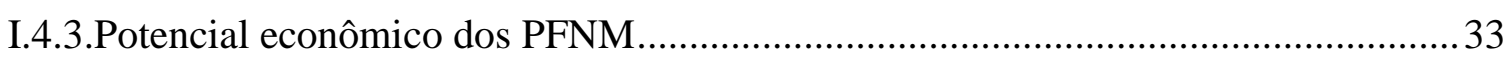

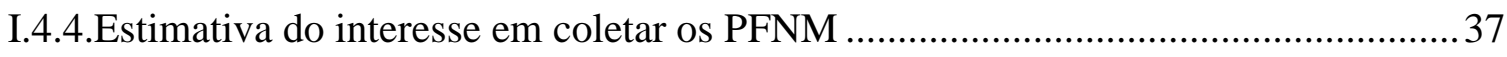

I.4.5.Associação dos fatores socioeconômicos e de percepção com o interesse.................37

I.4.6.Estimativa da capacidade, aptidão e habilidade de coleta ........................................ 40

I.4.7.Aprovação do survey por comitê de ética ............................................................. 41

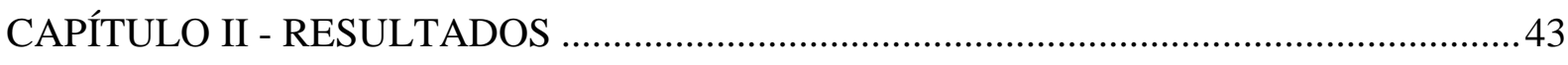

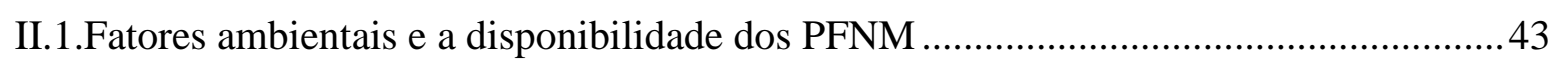

II.1.1.Topografia, matéria orgânica e radiação solar..................................................... 43

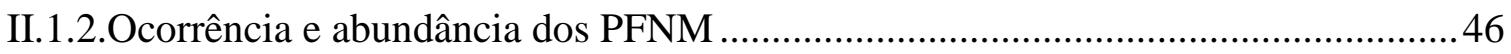

II.2.Potencial econômico dos múltiplos PFNM ...............................................................50

II.2.1.Frutificação e produção de sementes ............................................................... 50

II.2.2.Potencial econômico dos diferentes PFNM e localidades......................................51

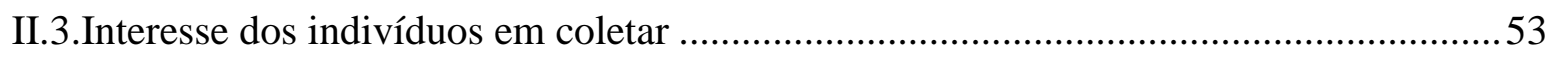

II.4.Fatores socioeconômicos, culturais e de percepção ...................................................57

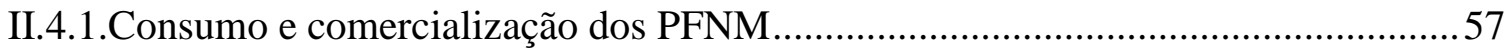

II.4.2.Origem, identidade, renda e riqueza das unidades domésticas..............................60

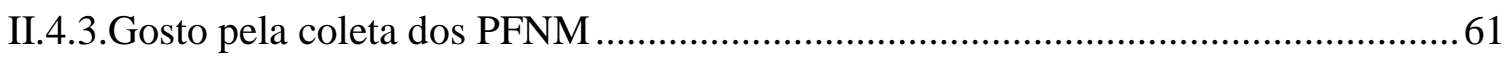

II.5.Associação dos fatores socioeconômicos e de percepção com o interesse ....................64

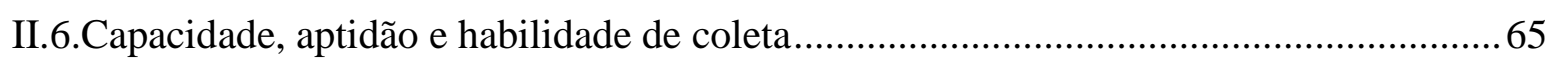

CAPÍTULO III - DISCUSSÃO E CONCLUSÕES ............................................................. 71

III.1.Discussão dos principais resultados encontrados ....................................................... 71 
III.1.1.Disponibilidade e potencial econômico dos PFNM ............................................... 71

III.1.2.Interesse em coletar múltiplos PFNM de importância comercial ..........................76

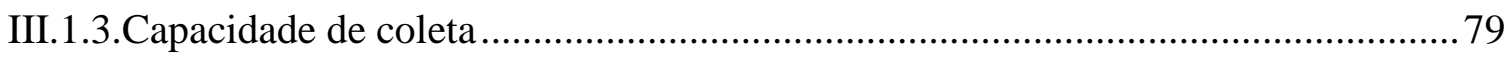

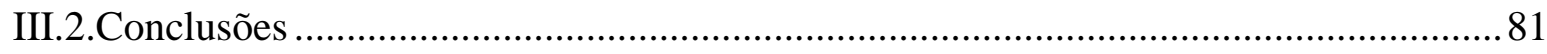

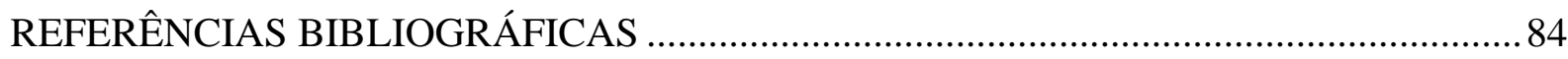

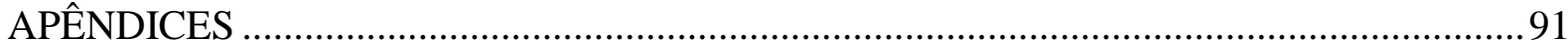




\section{INTRODUÇÃO GERAL}

O argumento de que é preciso incentivar a conservação de florestas de forma utilitária popularizou-se a partir da década de 1980 (PETERS et al., 1989), quando ganhou força o discurso em favor do uso e da comercialização de produtos florestais, em particular dos Produtos Florestais Não Madeireiros (PFNM), ou seja, todos os produtos de origem florestal com exceção da madeira. Segundo essa visão, a exploração de PFNM seria uma forma de alavancar o desenvolvimento das regiões detentoras de florestas e, ao mesmo tempo, conservar a diversidade biológica (PANAYOTOU; ASHTON, 1992; RUIZ PÉREZ; ARNOLD, 1996). Três razões principais fundamentam essa visão. Primeiro, os PFNM são um importante meio de contribuir para a subsistência e o bem-estar das populações que vivem em ambientes de floresta. Isso porque são produtos acessíveis para grande parte da população, inclusive aqueles mais vulneráveis que fazem uso destes produtos para o próprio consumo ou obtenção de renda monetária (KAR; JACOBSON, 2012). Segundo, ainda que impactos ecológicos da exploração de PFNM sejam frequentes (TICKTIN, 2004), são menores que aqueles relativos a outras formas de uso do solo, como a exploração madeireira ou a agropecuária (SHANLEY, 2002). Por fim, o aumento da exploração comercial de PFNM pode conferir maior valor monetário às florestas, e dessa forma, aumentar os incentivos para mantê-las em pé (ARNOLD; PÉREZ, 2001).

Motivadas por essas proposições, muitas organizações têm se empenhado em desenvolver políticas e projetos de incentivo ao uso e à comercialização de PFNM ao redor do mundo (NEUMANN; HIRSCH, 2000; SHACKLETON et al., 2011), e após cerca de vinte anos da implementação de vários desses projetos, diversos estudos vêm avaliando os resultados dessas experiências. De maneira geral, as evidências acumuladas demonstram que não existe situação ideal ou um produto específico cuja comercialização possa promover automaticamente a conservação das florestas e o desenvolvimento socioeconômico dos seus habitantes (BELCHER; SCHRECKENBERG, 2007).

Do ponto de vista da conservação, observa-se que, frequentemente, melhor infraestrutura para exploração, maior demanda e preços mais elevados dos produtos florestais, assim como maior proximidade ao mercado, podem promover a intensificação da coleta (BELCHER et al., 2005). Essa intensificação, por sua vez, pode aumentar os impactos ecológicos diretos, como reduções nas taxas de sobrevivência, crescimento, reprodução e variabilidade genética da população explorada (BOOT; GULLISON, 1995; TICKTIN, 2004). 
Podem ainda provocar impactos indiretos, como alterações da composição e estrutura da vegetação, alterações na paisagem (e.g., pela construção de estradas) e efeitos secundários na fauna associada à espécie explorada (TICKTIN, 2004; SHACKLETON et al., 2011).

Em termos econômicos, os PFNM são considerados muito importantes para o consumo doméstico de habitantes de áreas florestais, representando fontes de alimento, fibras, óleos, dentre outros (BELCHER; SCHRECKENBERG, 2007). Podem, além disso, contribuir significativamente com a renda monetária familiar (SCHRECKENBERG et al., 2006), ou representar até mesmo a única fonte monetária para algumas comunidades ou subgrupos, como as mulheres (SOUSA, 2009). Contudo, os valores comerciais alcançados são em geral baixos, pois muitas vezes os produtos servem de matéria-prima para pequenas indústrias ligadas a mercados menos exigentes, o que tende a limitar o valor de venda (BELCHER; SCHRECKENBERG, 2007). O retorno financeiro potencial também é limitado por fatores ecológicos, como baixa densidade e grande sazonalidade na oferta dos recursos (SHACKLETON et al., 2011).

Sendo assim, diferentes estratégias têm sido sugeridas para incrementar a renda monetária e, concomitantemente, minimizar os impactos ecológicos negativos da exploração de PFNM (e.g. CLAY; CLEMENT, 1993; BELCHER; SCHRECKENBERG, 2007). Dentre elas destacam-se: (i) o armazenamento e beneficiamento do produto ainda nas comunidades coletoras, aumentando a quantidade do produto e o retorno financeiro para os manejadores (BELCHER; SCHRECKENBERG, 2007); (ii) o estabelecimento de parcerias entre comunidades e empresas que podem garantir a venda do produto e propiciar transferência de tecnologia ou auxílio na produção (ROS-TONEN et al., 2006) e, por fim, (iii) o manejo florestal de uso múltiplo que permite diversificar a produção (GUARIGUATA et al., 2012). No entanto, as duas primeiras estratégias, dependendo da forma como são conduzidas, demonstraram ainda estar associadas a impactos sociais e ecológicos negativos, como a diminuição do tempo dedicado a atividades sociais e culturais, e/ou o aumento da pressão de caça (MORSELLO et al., 2012). Já a última tem recebido atenção crescente na literatura científica nos últimos anos, sendo tema de várias publicações recentes na área (e.g. GARCÍAFERNÁNDEZ et al., 2008; KELES; BAŞKENT, 2011; GUARIGUATA et al., 2012).

O uso múltiplo dos recursos florestais consiste na extração ou produção de diferentes produtos e serviços ambientais, como madeira, PFNM e captação de carbono, por exemplo. Alguns autores também se referem a essa estratégia como equivalente à diversificação da produção florestal (GUARIGUATA et al., 2012), que também ocorre quando se exploram múltiplos PFNM (SHACKLETON, 2005). Proponentes dessa estratégia argumentam que 
manejar produtos e serviços variados pode: aumentar as alternativas capazes de gerar renda ao longo do ano; aumentar a capacidade de adaptação às oportunidades, às ameaças e aos riscos do mercado (CLAY; CLEMENT, 1993) e, por fim, favorecer o acesso a uma variedade de produtos que também servem para a subsistência (BELCHER; SCHRECKENBERG, 2007). Paralelamente, o uso múltiplo seria menos impactante em termos ecológicos, pois a pressão de coleta se diluiria por diferentes espécies (HOMMA; SCHWARTZMAN, 1992). Ainda, segundo alguns autores, as florestas manejadas para o uso de múltiplos recursos podem ser tão efetivas para a conservação biológica quanto às unidades de conservação de proteção integral, ao menos no que se refere à contenção do desmatamento (PORTER-BOLLAND et al., 2012).

Por outro lado, vários fatores podem limitar a implantação e, consequentemente, os resultados positivos do manejo florestal de múltiplos produtos. Primeiro, aspectos relacionados à distribuição espacial (i.e. ocorrência e abundância) das espécies, bem como à sazonalidade da oferta de diferentes PFNM (e.g., frutas, sementes) podem inviabilizar a coleta de múltiplos PFNM simultaneamente, ao não favorecer a disponibilidade de vários produtos em um mesmo contexto e período do ano (GARCÍA-FERNÁNDEZ et al., 2008). Segundo, dificuldades de comercialização, como por exemplo, falta de comprador ou de preço justo pago pelos produtos, podem fazer com que as pessoas não se interessem pela coleta dos PFNM para fins comerciais (NEUMANN; HIRSCH, 2000). Terceiro, a falta de aptidão e habilidade, por exemplo, podem limitar a capacidade das pessoas coletarem múltiplos PFNM (TICKTIN; SHACKLETON, 2011).

Esse contexto nos mostra que, apesar de o uso múltiplo estar sendo apontado na literatura científica como mais uma das estratégias win-win de conservação e desenvolvimento local, pode também haver limitações, as quais ainda não foram totalmente elucidadas. Todavia, é lógico pensar que sem múltiplos PFNM disponíveis em um contexto local, sem interesse e capacidade das pessoas de coletarem tais produtos, não haverá sucesso na promoção dessa estratégia.

A disponibilidade dos PFNM e, consequentemente seu potencial de gerar renda monetária, é limitada por ao menos quatro aspectos ecológicos principais: (i) a ocorrência de espécies florestais de importância comercial; (ii) a abundância de indivíduos dessas espécies que coocorrem em certa localidade; (iii) a taxa anual de produção de frutos, sementes ou outros produtos comercializáveis; e (vi) a sazonalidade da produção e consequentemente da coleta, ou seja, a época do ano em que os produtos podem ser coletados (KLIMAS et al., 2007; TICKTIN; SHACKLETON, 2011; NEWTON, WATKINSON, et al., 2012). 
Ocorrência e abundância refletem a distribuição espacial das espécies e de seus indivíduos, que pode ser influenciada por diversos fatores ambientais como radiação solar, topografia e matéria orgânica disponível no solo para as plantas (HERRERO-JÁUREGUI et al., 2012; NEWTON, PERES, et al., 2012; VEDEL-SØRENSEN et al., 2013). A produção de frutos, bem como a época em que eles são produzidos também são afetadas pelos mesmos fatores e podem ainda ser influenciadas por doenças, herbivoria e polinização (RATHCKE; LACEY, 1985; BERJANO et al., 2006)

Dentre os fatores ambientais, a radiação solar controla muitos processos do desenvolvimento das plantas, agindo como sinal para a germinação, o crescimento direcionado e a forma delas (LARCHER, 2000). A topografia pode afetar a umidade dos solos, pois terrenos inclinados drenam bem a água, frequentemente causando estresse de umidade para as plantas na encosta ao mesmo tempo em que a água satura os solos nas terras baixas vizinhas. Por sua vez, a quantidade de água no solo altera a disponibilidade de nutrientes, e as variações nas quantidades de matéria orgânica criam gradientes de acidez e nitrogênio disponível. Dentro das possíveis combinações desses fatores, cada espécie mostra diferentes preferências (RICKLEFS, 1996), o que, por sua vez, reflete em diferenças na disponibilidade do conjunto de PFNM.

De maneira geral, a disponibilidade de PFNM em florestas tropicais, como a Amazônia é elevada, sendo que algumas estimativas indicam um rendimento hipotético de mais de 6.000 dólares por hectare ao ano com esses produtos (PETERS et al., 1989). Porém, na prática, o valor monetário obtido é muito inferior a esse potencial, variando nesse mesmo bioma de nove a 17 dólares por hectare ao ano (GRAM, 2001). A grande diferença entre os valores potenciais e adquiridos faz supor que a contribuição de múltiplos PFNM para a geração de renda monetária em um determinado contexto pode, dentre outros fatores, ser limitada pela falta de interesse e ou capacidade das pessoas em coletá-los.

Assumindo que o interesse dos indivíduos em coletar diferentes PFNM é determinado pela utilidade material (i.e., subsistência e econômica) que os produtos possuem, ao menos dois fatores socioeconômicos podem afetar esse interesse: (i) o consumo dos PFNM, que servem como alimento e remédio, entre outros fins (VAN ANDEL, 2006); e (ii) a comercialização dos PFNM, que pode incrementar a renda monetária (DAVIDAR et al., 2008). Empiricamente, nota-se que o interesse das pessoas em coletar determinado PFNM aumenta de acordo com o aumento do consumo daquele produto ou conforme o aumento das possibilidades de sua venda. Além disso, a coleta de PFNM e até mesmo o gosto por essa atividade pode ser transmitida culturalmente através das gerações, assim como ocorre com 
outras práticas produtivas, e esses aspectos por sua vez também podem influenciar o interesse (KIM et al., 2012). Portanto, fatores culturais, como a origem e as atividades dos indivíduos (e.g. pescador, agricultor, coletor, etc.), bem como o fator de percepção individual (i.e., o gosto pela coleta) não podem se desprezados.

Quanto à capacidade de coleta, nem todas as pessoas conseguem coletar determinados produtos. Certos tipos de frutos ou sementes demandam aptidões especiais para serem coletados, como ter que subir em árvores ou palmeiras a vários metros de altura. Além disso, a quantidade de PFNM que um indivíduo consegue coletar em um dia pode ainda estar associada à distância entre a sua casa e a área onde o produto está localizado (NEWTON, WATKINSON, et al., 2012), bem como à condição física ou habilidade do indivíduo, o que reflete no tempo que ele gasta para coletar os produtos de uma árvore ou palmeira. Em geral os homens conseguem coletar maior quantidade e diversidade de produtos, em parte devido a sua maior força física (SUNDERLAND et al., 2014). Dessa forma, para que ocorra o aproveitamento de múltiplos PFNM disponíveis em um certo contexto, é preciso que existam pessoas com aptidão e habilidade para coletá-los.

Em suma, a viabilidade da coleta de múltiplos PFNM depende da disponibilidade de diferentes PFNM, assim como do interesse e da capacidade dos indivíduos coletarem esses produtos. Como visto, esses três aspectos já foram avaliados separadamente em diversos estudos. Porém a falta de evidências empíricas sobre como esses diversos aspectos e fatores variam em conjunto e consequentemente facilitam ou dificultam a coleta de múltiplos PFNM é o que motiva a investigação deste estudo, que visa a responder à seguinte pergunta:

Como fatores ambientais, socioeconômicos, culturais e de percepção afetam a viabilidade da coleta de múltiplos produtos florestais não madeireiros, assim como o potencial de geração de renda monetária?

\section{Objetivos}

O objetivo central desta dissertação foi avaliar como diferentes fatores afetam a viabilidade da coleta de múltiplos produtos florestais não madeireiros, assim como o potencial de geração de renda monetária. Em particular, foram avaliados fatores ambientais, socioeconômicos, culturais e de percepção no contexto da Reserva de Desenvolvimento Sustentável Mamirauá. 
Os objetivos específicos do estudo foram:

(i) Avaliar como os fatores ambientais: altura de inundação, radiação solar e profundidade do folhiço afetam a coleta, em particular em termos da disponibilidade (ocorrência e abundância) de PFNM fornecidos por cinco espécies de importância comercial na região, e se existem diferenças entre localidades quanto a essa disponibilidade;

(ii) estimar o potencial econômico dos PFNM disponíveis para cada uma das localidades e avaliar se existem diferenças entre elas;

(iii) avaliar, no nível do indivíduo, como varia o interesse em coletar os cinco PFNM e sua associação com os fatores socioeconômicos (i.e. consumo e comercialização dos PFNM, renda, riqueza e escolarização) e culturais (i.e., origem e identidade) das unidades domésticas, e de percepção individual (i.e., gosto pela coleta);

(iv) avaliar, no nível do indivíduo, como varia a capacidade de coleta em termos das quantidades possíveis de coleta dos cinco produtos, bem como em termos da aptidão e habilidade de coleta.

\section{Estrutura dos capítulos da dissertação}

Esta dissertação está organizada em três capítulos, além desta introdução geral. O primeiro, apresenta os métodos e, sendo assim, o delineamento e a área de estudo, seguido da descrição das espécies investigadas e das técnicas de amostragem, coleta e análise dos dados. O segundo, apresenta os resultados, isto é, descreve a variação dos fatores ambientais, socioeconômicos, culturais e de percepção, e de que maneira esses fatores afetam a disponibilidade dos PFNM nas localidades estudadas, o interesse e a capacidade dos indivíduos de coletar os PFNM. Por fim, o terceiro capítulo discute os resultados encontrados e apresenta as conclusões. 


\section{CAPÍTULO I - MÉTODOS}

Neste capítulo são apresentados o delineamento da pesquisa, a área de estudo, a descrição das espécies investigadas e as técnicas de amostragem, coleta e análise dos dados.

\section{I.1. Delineamento da pesquisa}

Para avaliar como os fatores ambientais de diferentes localidades ribeirinhas em áreas de floresta de várzea da Amazônia e como os fatores socioeconômicos e culturais das unidades domésticas dessas localidades afetam a viabilidade da coleta de múltiplos PFNM e a geração de renda monetária, foram selecionadas sete localidades da Reserva de Desenvolvimento Sustentável (RDS) Mamirauá.

A seleção foi realizada de maneira não probabilística, mas contemplou localidades dispostas ao longo de grande extensão da RDS, variando quanto aos tipos de ambientes (chavascal, várzea baixa e várzea alta), quanto ao número de habitantes e distância do centro urbano mais próximo (figura I.1 e tabela I.1). Por localidade, considerou-se neste estudo o núcleo povoado por um conjunto de unidades domésticas e a área utilizada por elas para as práticas tradicionais de agricultura, pesca, extrativismo e caça.

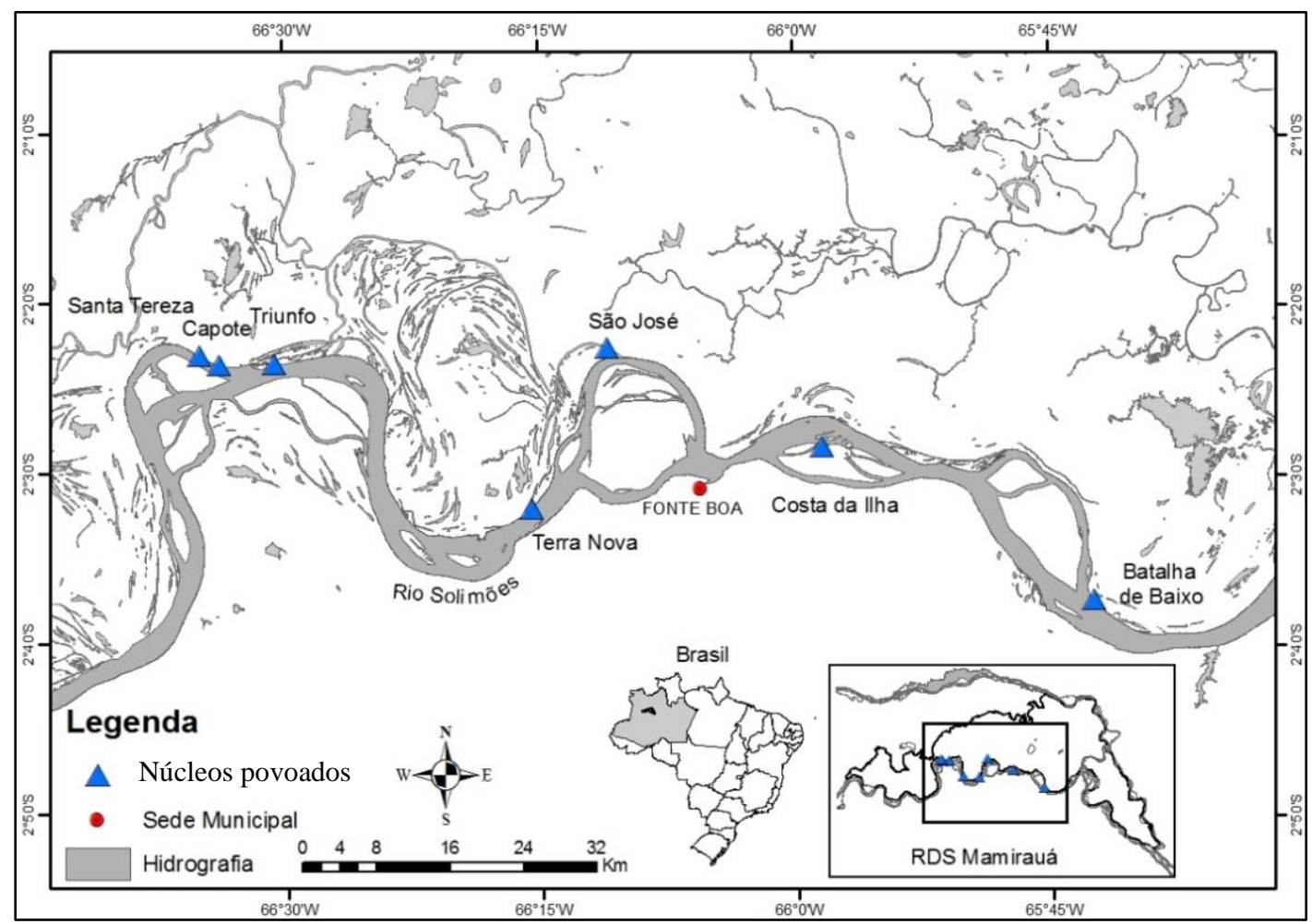

Figura I.1 - Área de estudo evidenciando os núcleos povoados das sete localidades participantes da pesquisa. Fonte: Elaboração própria. 
Tabela I.1 -Informações relacionadas aos critérios de seleção das localidades estudadas.

\begin{tabular}{lcccc}
\hline Localidade & $\begin{array}{l}\mathbf{N}^{\mathbf{o}} \text { de unidades } \\
\text { domésticas }\end{array}$ & $\mathbf{N}^{\mathbf{0}}$ de habitantes & $\begin{array}{l}\text { Distância ao } \\
\text { centro urbano } \\
\text { mais próximo }\end{array}$ & $\begin{array}{l}\text { Área de uso } \\
\text { aproximada (ha) }\end{array}$ \\
\hline Batalha de Baixo & 30 & 170 & $3 \mathrm{~h}$ & 25.000 \\
Costa da Ilha & 27 & 170 & $1 \mathrm{~h}$ & 18.000 \\
São José & 35 & 200 & $2 \mathrm{~h} 30$ & 15.000 \\
Terra Nova & 6 & 45 & $2 \mathrm{~h} 30$ & 10.000 \\
Trinfo & 9 & 85 & $4 \mathrm{~h}$ & 5.000 \\
Capote & 6 & 35 & $5 \mathrm{~h}$ & 3.000 \\
Santa Tereza & 9 & 50 & $5 \mathrm{~h}$ & 3.000 \\
\hline
\end{tabular}

Nota: Elaboração própria.

A disponibilidade (ocorrência e abundância) dos PFNM fornecidos por cinco espécies de importância comercial na região, o potencial econômico desses PFNM e os fatores ambientais foram avaliados no nível da localidade.

O interesse e a capacidade das pessoas coletarem os múltiplos PFNM, bem como o gosto pela coleta, foram avaliados no nível do indivíduo.

Já os fatores socioeconômicos e culturais foram avaliados no nível da unidade doméstica, isto é, um grupo de pessoas que compartilham a maior parte dos aspectos de consumo (i.e. utilização de recursos e serviços) e trabalho para assegurar sua reprodução material (SCHMINK, 1984).

\section{I.2. Caracterização da área de estudo e das localidades}

A RDS Mamirauá é uma área protegida localizada na região do Médio Rio Solimões, estado do Amazonas, Brasil. O clima local é tropical úmido, com temperatura média anual de $27^{\circ} \mathrm{C}$, pluviosidade anual média de $3.000 \mathrm{~mm}$, com picos de precipitação entre dezembro e maio. Com 1.124.000 ha, a RDS Mamirauá é composta por florestas de várzea, isto é, florestas alagáveis influenciadas pelo regime hidrológico de rios de águas brancas ricas em sedimentos e nutrientes, cuja amplitude média de inundação é de cerca de 10,8 metros (WITTMANN et al., 2004). A inundação e a consequente deposição anual de sedimentos trazidos dos Andes definem a topografia da várzea, flora e até mesmo os padrões de ocupação humana (QUEIROZ, 2005).

A topografia característica de Mamirauá condiciona a ocorrência de variados ambientes aquáticos, desde o habitat de água aberta dos rios e braços de rios, até as florestas alagadas. Diferenças no tempo e na altura dos alagamentos devido às variações no relevo da

\footnotetext{
${ }^{1}$ Tempo aproximado de viagem em canoa com motor rabeta (meio de transporte comumente utilizado pelos moradores da RDS Mamirauá).
} 
várzea, levam ao desenvolvimento de três tipos de vegetação florestal: o chavascal, a várzea baixa e a várzea alta. Segunda Wittmann et al. (2010), o chavascal consiste em área de vegetação baixa, pantanosa, sendo inundado anualmente durante cerca de seis a oito meses a uma profundidade superior a seis metros. A várzea baixa corresponde à transição do chavascal para as áreas florestais da várzea, estabelecendo-se onde a média anual de inundação é maior que três metros, com períodos de alagamento superiores a 50 dias por ano, tendo sub-bosque frequentemente mais limpo. Já a várzea alta corresponde aos terrenos mais elevados da várzea, com terras sujeitas à inundação anual que duram no máximo quatro meses, com profundidade de até três metros. As florestas de várzea alta contêm a maior riqueza de espécies dentre os ambientes de várzea e, estruturalmente, são as mais parecidas com as florestas de terra firme.

A ocupação humana mais recente de Mamirauá data do início do século XX, sendo que antes disso a região era habitada por diversos grupos indígenas. $\mathrm{O}$ aumento do número de assentamentos no Médio Solimões ocorreu devido à queda da produção de borracha, que fez com que comerciantes e seringueiros abandonassem os seringais localizados a oeste da região e passassem a ocupar as várzeas de Mamirauá, produzindo lenha para os navios a vapor, além de comercializarem pirarucu, peixe-boi e tartaruga. A partir dos anos de 1970 se iniciou um processo de estruturação social dos assentamentos, promovido pela Igreja Católica, seguindo o modelo de comunidades de base, ou seja, localidades que possuem uma liderança política eleita pelos moradores (IDSM, 2010).

A maioria dos 207 núcleos povoados atuais da RDS Mamirauá, cujo número de habitantes varia entre 35 e 600, localiza-se nas margens dos rios Solimões e Japurá. A população atual da RDS compreende mais de 10.000 pessoas vivendo dentro da Reserva ou imediatamente em seu entorno (QUEIROZ, 2011), incluindo os habitantes de seis terras indígenas já homologadas (quatro sobrepostas à RDS) e 45 em processo de reconhecimento pela Fundação Nacional do Índio (FUNAI) (informação pessoal² ${ }^{2}$.

A economia dos moradores da RDS Mamirauá se baseia na combinação da produção e coleta para subsistência de itens alimentares (e.g., peixe e farinha de mandioca) e de uso próprio (e.g. canoas, remos, cestas), assim como a venda de parte desses mesmos itens (e.g., peixe e farinha) que é importante para a obtenção de outros bens de consumo, como os produtos industrializados. As atividades produtivas mais importantes, a pesca e a agricultura, são reconhecidas pela população como sua principal identidade econômica. Contudo, pensões

\footnotetext{
${ }^{2}$ Informação fornecida por Nelissa Bezerra Peralta em março de 2016.
} 
e aposentadorias, além de benefícios sociais (bolsa família, bolsa floresta e seguro defeso) e salários (de professor e agentes de saúde) também são importantes fontes de renda monetária, contribuindo com cerca de metade da renda familiar (LIMA, 2010).

Na RDS Mamirauá existe o manejo comunitário (i.e., que visa o uso sustentável) de diferentes recursos naturais, assessorado especialmente pelo Instituto de Desenvolvimento Sustentável Mamirauá (IDSM). As atividades de manejo surgiram em concordância com os objetivos da RDS, ou seja, de evitar o escasseamento dos recursos naturais e, ao mesmo tempo, promover a melhoria na qualidade de vida das populações locais da Reserva através da geração de renda monetária. Os programas de manejo mais expressivos são o de pesca, de madeira, de ecoturismo e de artesanato.

Entre as 77 localidades da RDS Mamirauá onde o IDSM atuava em 2005, 49 estavam diretamente envolvidas com esses programas, que foram bem sucedidos no que diz respeito ao aumento de renda doméstica e ao fortalecimento das ações coletivas, através da organização comunitária (LIMA, 2010). Embora os produtos manejados exijam mais esforço de organização e produção quando comparado à exploração livre ou ilegal dos recursos naturais, o aumento na renda média anual proporcionado pelas atividades de manejo faz com que estas sejam bem-vindas para grande número de famílias. Nota-se que os jovens adultos passaram a se interessar por essas novas atividades de trabalho, além da pesca e da agricultura de subsistência. Além disso, as mulheres passaram a ter mais oportunidades de contribuir com a renda monetária familiar ao participarem das atividades de manejo, principalmente as ligadas ao artesanato (MOURA; CASTRO, 2012). É com esse olhar que muitas famílias encaram as atividades de manejo, ou seja, como uma possível alternativa de geração de renda, de maneira que o manejo de múltiplos PFNM se insere nessa perspectiva.

Os habitantes de Mamirauá utilizam uma variedade de PFNM com diferentes propósitos, notadamente frutos, cascas de árvores, fibras e óleos, cujo destino é, sobretudo, o consumo familiar. Eventualmente, alguns PFNM são também comercializados nas cidades mais próximas como Fonte Boa, Jutaí e Tefé. São principalmente produtos como frutos de açaí (Euterpe precatoria Mart.) e buriti (Mauritia flexuosa L.f.), e em algumas localidades da RDS destaca-se também a produção de artesanatos, como cestarias feitas com fibras da palha do cauaçu (Calathea lutea) e arumã (Ischnosiphon spp.).

Em 2010, a renda média bruta anual familiar adquirida com atividades de pesca, agricultura, extrativismo florestal, produção de artesanatos, benefícios sociais e salários alcançou $\mathrm{R} \$ 9.047,00$, equivalente a $\mathrm{R} \$ 754,00$ mensais. A abundância de recursos naturais cujo acesso é garantido pela RDS é crucial para a vida de seus moradores e usuários, 
conferindo a eles um grau de autonomia econômica que os moradores de cidades e de regiões rurais fora de Reservas não têm (PERALTA; LIMA, 2014).

\section{I.3. Espécies de importância comercial}

Cinco espécies de importância comercial na região das sete localidades foram selecionadas a partir de entrevistas informais realizadas previamente, que identificaram os produtos que já haviam sido comercializados em ao menos uma ocasião pelos habitantes locais. Os produtos selecionados foram frutos e sementes fornecidos por três tipos de palmeira (i.e., família Arecaceae) e duas espécies arbóreas (famílias Myrtaceae e Meliaceae).

Das cinco espécies selecionadas, Astrocaryum murumuru e Carapa guianensis fornecem sementes (murumuru e andiroba, respectivamente), enquanto Euterpe precatoria, Mauritia flexuosa e Myrciaria dubia fornecem frutos (açaí, buriti e camu-camu, respectivamente). Além de serem amplamente utilizadas por populações indígenas e ribeirinhas modernas da Amazônia, são espécies úteis há séculos, pois sua atual distribuição e abundância, especialmente no caso das palmeiras, estão associadas a assentamentos de populações humanas pré-colombianas (TER STEEGE et al., 2013; CLEMENT et al., 2015). As espécies são descrita a seguir.

Astrocaryum murumuru Mart. ou murumuru é uma palmeira comum em todos os estados amazônicos, sendo comum em florestas de várzea alta. Apresenta estipe solitário de até 20 metros com espinhos pretos em abundância, folhas com cerca de sete metros de comprimento com folíolos regularmente arranjados e frutos ovais com 4 x $8 \mathrm{~cm}$ de dimensão, às vezes espinhosos (WITTMANN et al., 2010). Frutifica por períodos extensos, de fevereiro a setembro, e os frutos são importante fonte de alimento para a fauna, sendo dispersos por animais como, porco-espinho, cutia, macacos, esquilo vermelho, outros roedores e aves (figura I.2). A germinação de sementes e plântulas é maior em clareiras. Das folhas podem ser extraídas fibras para a confecção de artesanato, como cestas, chapéus e redes, mas o produto de maior interesse econômico derivado desta espécie é o óleo extraído da amêndoa que pode ser empregado na alimentação (óleo para cozinhar), em cosmética (cremes, fragrâncias e perfumes) e saboaria (WITTMANN et al., 2010; RIOS; PASTORE JÚNIOR, 2011). O aparecimento de compradores das sementes in natura do murumuru já foi mencionado por moradores de algumas localidades da RDS Mamirauá, sendo 2006 o ano mais recente desse episódio de comercialização local (figura I.3). 


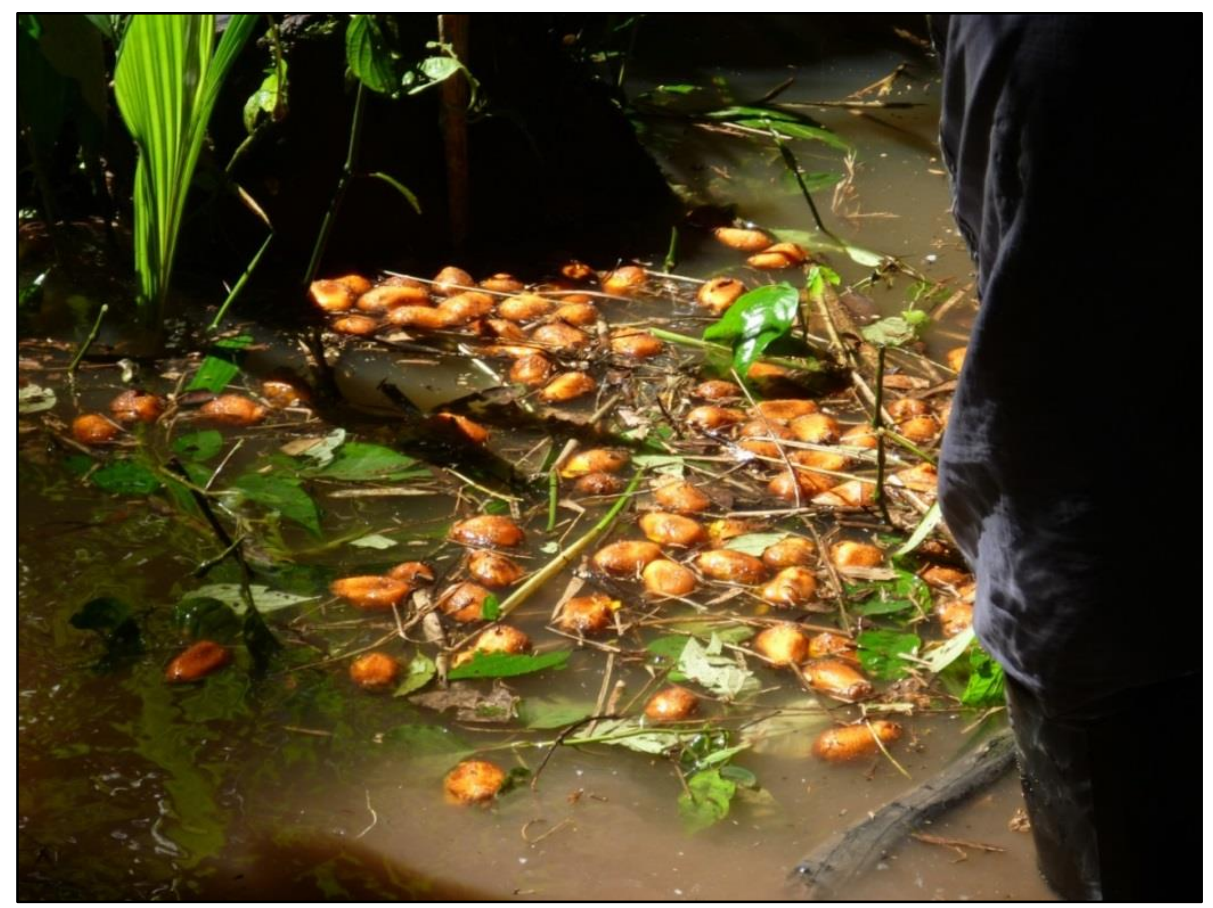

Figura I.2 - Frutos de murumuru flutuando na várzea após a queda.

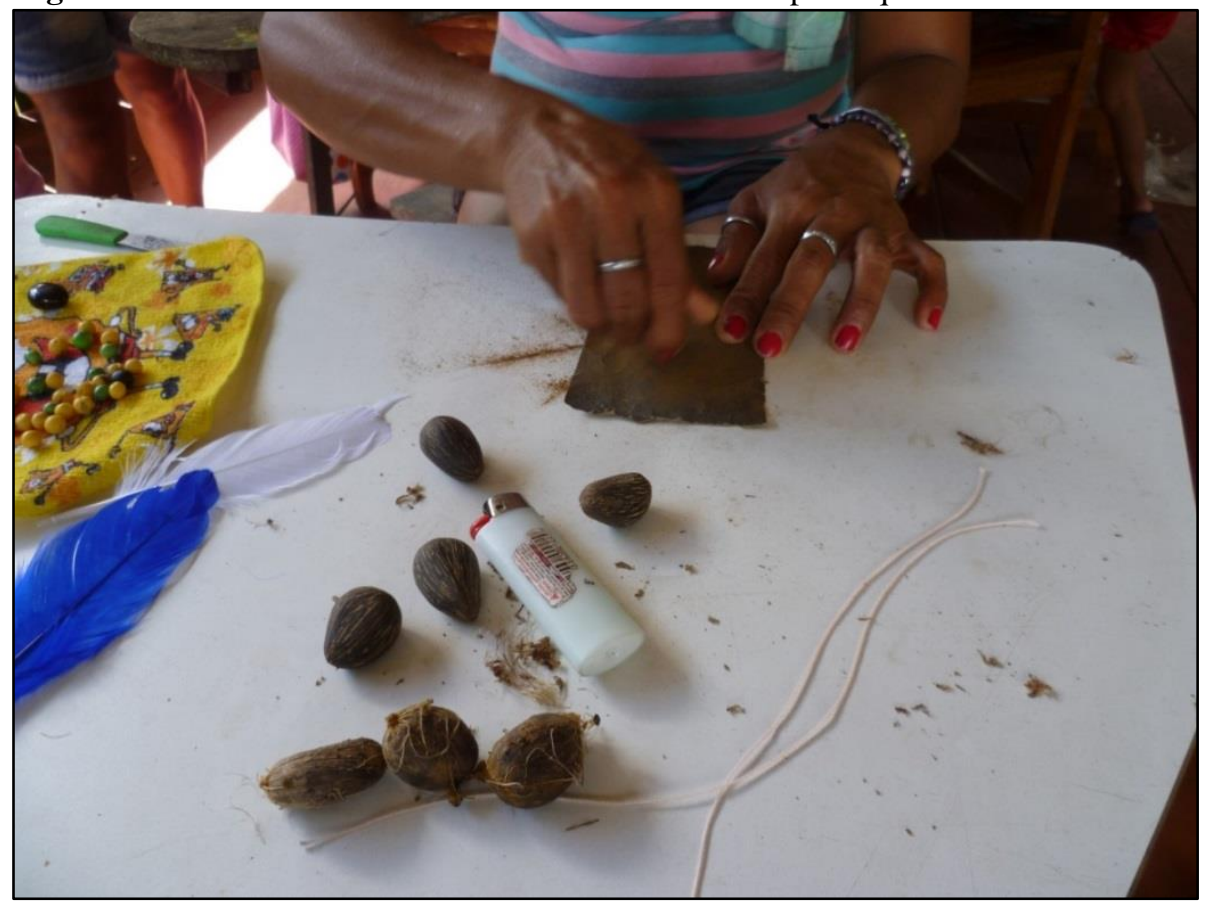

Figura I.3 - Sementes de murumuru beneficiadas por moradora da RDS Mamirauá para produção de artesanato (colares) - isqueiro usado para queimar o fio encerado.

Carapa guianensis Aubl. ou andiroba, da família Meliaceae, é uma árvore que pode atingir mais de 30 metros de altura e dois metros de diâmetro, ocorrendo em maior densidade em florestas de várzea alta. Apresenta folhas compostas alternadas e inflorescência do tipo panícula de cor branca ou creme. Estudo realizado na RDS Amanã, contígua a RDS Mamirauá, identificou que a espécie floresce o ano inteiro com dois picos bem definidos, de 
abril a agosto e de novembro a fevereiro. Os frutos são cápsulas globosas que se partem com o impacto da queda liberando sementes de coloração marrom, as quais são dispersadas de março a julho (MELLINGER, 2006) (figura I.4). Segundo Medina (2005) e Klimas et al. (2007), a produção varia, sendo encontradas estimativas desde 15 até $200 \mathrm{~kg}$ de sementes por árvore, com variações anuais nessa produção, bem como na proporção de árvores que frutificam podem ocorrer dependendo do tipo florestal. O óleo extraído das sementes é utilizado na produção de cosméticos e sabonetes, e na medicina tradicional como repelente contra insetos e cicatrizante (MELLINGER, 2006). A casca é amarga com coloração avermelhada ou acinzentada e tem uso medicinal contra febre e vermes. A madeira da andiroba possui importância comercial (MEDINA, 2005), muito embora seu corte seja proibido na RDS Mamirauá para garantir o fornecimento dos produtos não madeireiros que a árvore oferece.

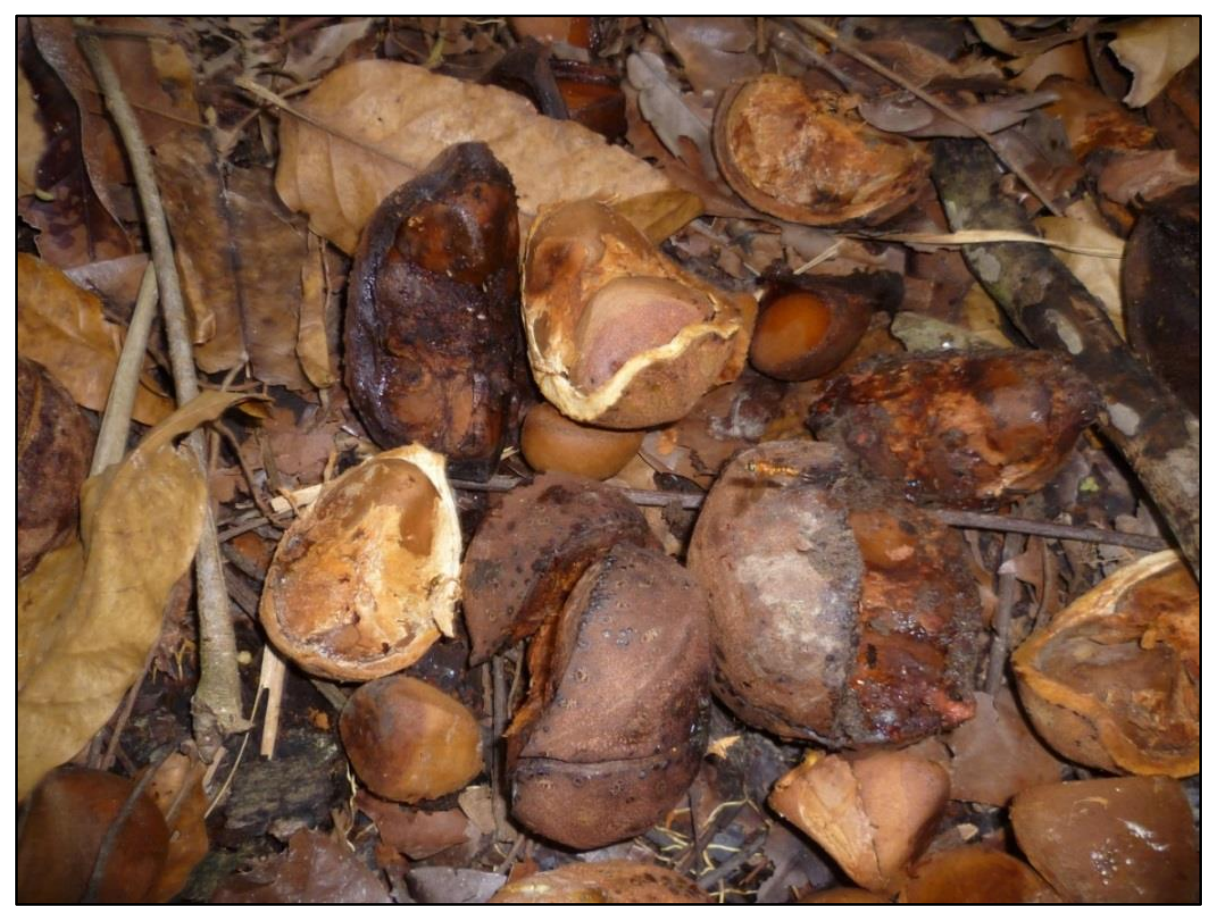

Figura I.4 - Frutos de andiroba abertos com suas sementes expostas.

Euterpe precatoria Mart. ou açaí é uma palmeira que ocorre em ambientes alagados ou não, mas frequentemente acompanha as beiras de rios e paranás (braços de rio), sendo comum na várzea alta. Apresenta estipe solitário ou raramente agrupado com altura média de 20 metros e folíolos regularmente arranjados. Produz inflorescências com frutos globosos, de preto a roxo quando maduros dispersos por aves (WITTMANN et al., 2010). Frutifica entre os meses de março e julho. Em florestas alagáveis já foram encontrados até 57 indivíduos produtivos por hectare, cuja produção pode atingir mais de 270 quilos de frutos por hectare 
(MEDINA, 2005). O fruto de açaí é o produto mais consumido da palmeira e é o que popularizou a espécie através do "vinho do açaí", considerado típico da Amazônia e também já conhecido em mercados nacionais fora da Amazônia, assim como no exterior (MÁRIO MENEZES, 2005). Na RDS Mamirauá, o fruto é um importante item da dieta dos moradores, sendo significativo para sua segurança alimentar (WITTMANN et al., 2010). Além disso, açaí é o fruto mais comercializado pelos moradores da reserva (figura I.5). Além dos frutos, esta palmeira fornece ainda outros produtos de utilidade para as pessoas. A raiz pode ser utilizada como remédio contra problemas hepáticos e renais, o estipe serve como viga para casas, as folhas podem ser utilizadas para cobrir as casas e para confecção de vassouras, o palmito pode ser extraído para alimentação, e das sementes podem ser feitos artesanatos, como colares, brincos e pulseiras. (MEDINA, 2005; WITTMANN et al., 2010).

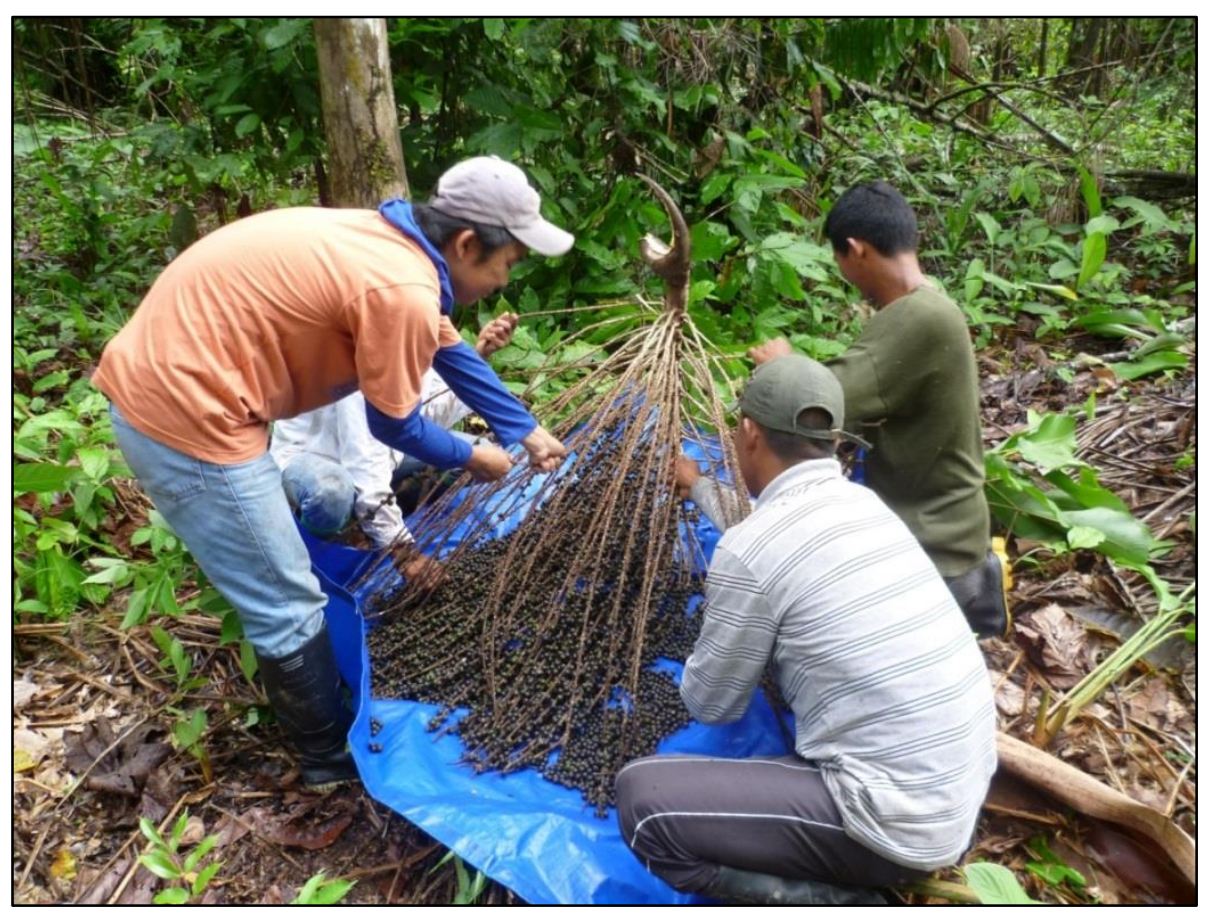

Figura I.5 - Frutos de açaí sendo retirados do cacho.

Mauritia flexuosa L.f. ou buriti é uma palmeira abundante em áreas permanentemente pantanosas de várzea alta da Amazônia ocidental, especialmente próximas à foz dos cursos de água, onde formam grandes populações, frequentemente monoespecíficas. Possui estipe liso que pode alcançar mais de 20 metros de altura, folhas grandes com a palma dividida em múltiplos folíolos e inflorescência com comprimento de dois metros. O buriti é uma espécie dioica, isto é, apresenta indivíduos masculinos e femininos em proporções semelhantes. Frutifica de março a julho com frutos elípticos cobertos por escamas marrons a avermelhadas, e mesocarpo oleoso amarelo ou alaranjado (figura I.6). Uma palmeira de buriti pode produzir 
de 40 a 360 quilos de frutos, que são o produto mais consumido desta palmeira. A polpa, que contém a maior reserva de carotenos conhecida no reino vegetal, pode ser consumida in natura ou utilizada para produzir geleias, doces, sucos e sorvetes (CLAY et al., 2000; MEDINA, 2005; WITTMANN et al., 2010). Na medicina popular, o fruto é utilizado para combater resfriados e recuperar crianças desnutridas. A gordura da polpa também é empregada em saboaria (REVILLA, 2002). A dispersão natural é feita pela água e pela fauna (e.g. veado, anta, queixada, macacos, jabuti, peixes e aves, como papagaios e araras). Das folhas secas são feitos artesanatos, como esteiras, cestos e redes. O óleo extraído das sementes pode ser usado como combustível para a geração de energia elétrica, além de servir como matéria-prima para cosméticos (cremes e sabonetes). O tronco é utilizado na construção de casas, e na medicina tradicional o fruto é utilizado para combater resfriados (RIOS; PASTORE JÚNIOR, 2011).

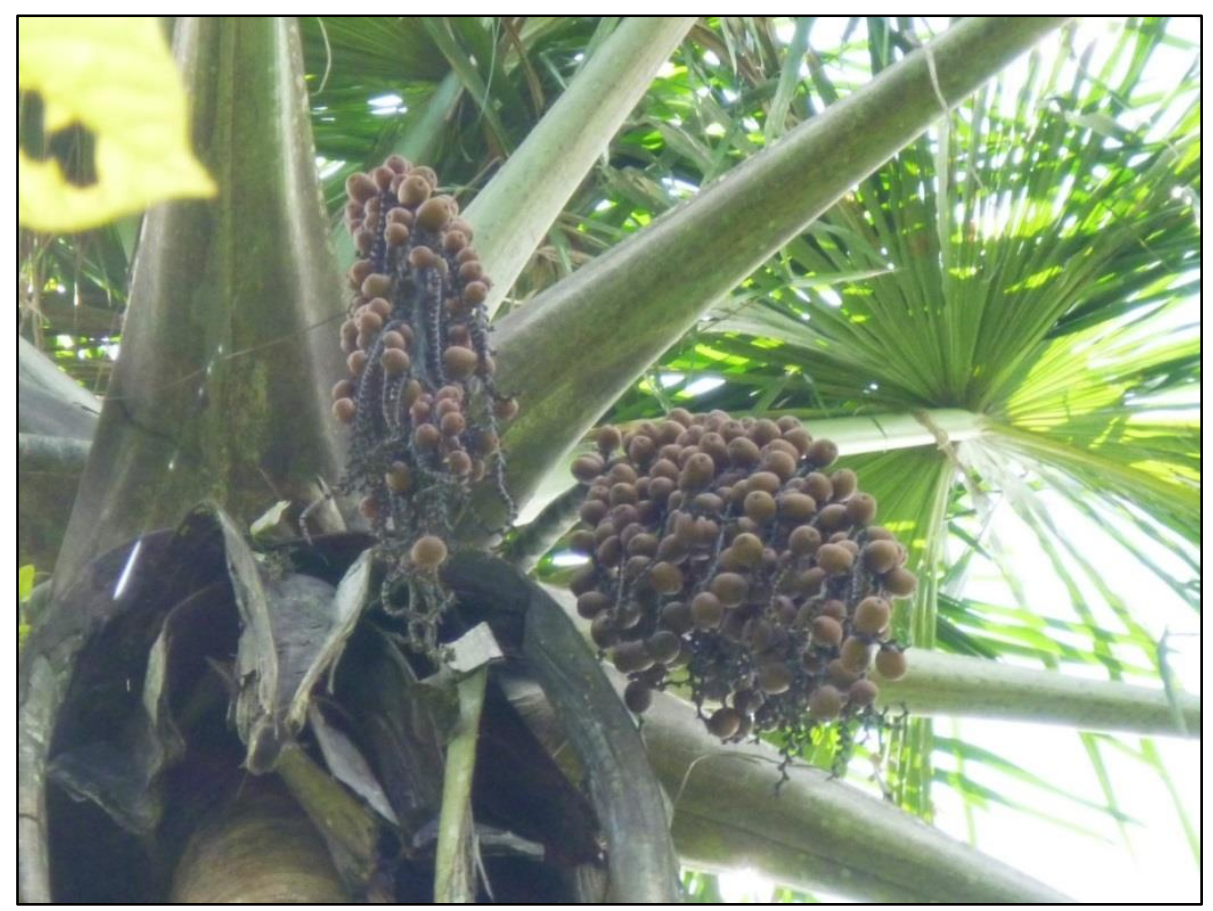

Figura I.6 - Cachos com frutos de buriti.

Myrciaria dubia (Kunth) McVaugh ou camu-camu, família Myrtaceae, é uma árvore de pequeno porte da várzea baixa, frequente na beira de lagos em cotas de inundação entre 6-8 metros, preferencialmente em águas mistas ou pretas. Apresenta ritidoma marrom escuro, desprendendo-se em cascas. Suas folhas são simples, pequenas e elípticas, e suas flores brancas estão organizadas em inflorescências axilares. Frutifica no período das cheias, entre fevereiro e junho e os frutos são bagas redondas e globosas, vermelhas e pretas quando 
maduras (figura I.7). As sementes, envoltas por polpa transparente a amarelada, são dispersadas principalmente por peixes. Em florestas de várzea do Peru constatou-se que nesta espécie a produção de frutos aumenta conforme o tamanho dos indivíduos, podendo produzir entre 9,5 e 12,7 toneladas de frutos por hectare ao ano (PETERS; VASQUEZ, 1987). A polpa do fruto é consumida in natura e também utilizada para suco, geleias e sorvete, e possui as maiores quantidades de vitamina $\mathrm{C}$ já registradas entre todas as frutas conhecidas. (WITTMANN et al., 2010).

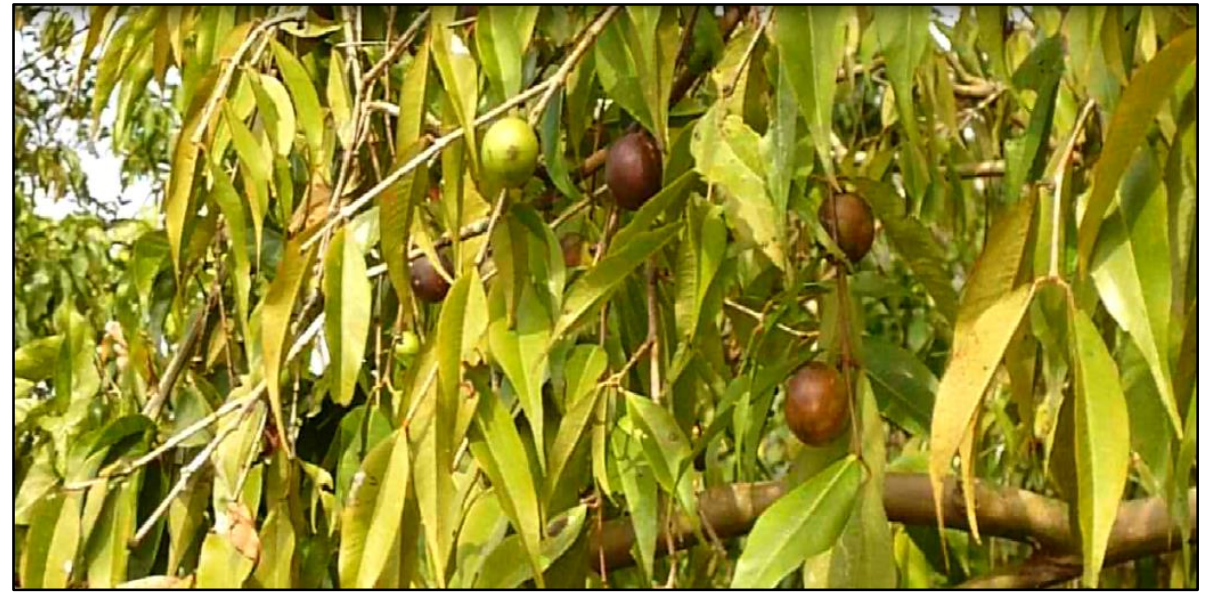

Figura I.7 - Frutos de camu-camu.

\section{I.4. Técnicas de amostragem, coleta e análise dos dados}

\section{I.4.1. Disponibilidade dos PFNM}

Para avaliar a disponibilidade dos PFNM, ou seja, a ocorrência das cinco espécies de importância comercial, bem como as respectivas abundâncias em cada uma das sete localidades alvo da pesquisa, foi estimada a presença/ausência das espécies e o número de indivíduos de cada uma delas. Para isso, foi adotado o procedimento de amostragem preferencial ao invés de aleatório, pois um dos objetivos da pesquisa era avaliar, a partir dessas informações, o potencial econômico dos múltiplos PFNM. Dessa forma, era importante amostrar aquelas áreas onde, segundos os moradores, eles já coletam ou coletariam os produtos para uso próprio ou para comercializarem, descartando as áreas consideradas por eles como inapropriadas. As áreas consideradas apropriadas foram identificadas por meio de entrevistas informais com informantes-chave, sendo estes moradores das próprias localidades estudadas e conhecedores da distribuição espacial das espécies na localidade que habitam. 
Dessa forma, os valores estimados correspondem à ocorrência e abundância nas áreas onde os produtos são ou seriam preferencialmente coletados para serem comercializados.

Em cada localidade foram estabelecidos de dois a cinco transectos de um hectare cada, com 10 metros de largura e 1.000 metros de comprimento, totalizando 24 transectos amostrados entre as sete localidades. O número (i.e. mínimo dois e máximo cinco) e forma dos transectos foram definidos em concordância com o procedimento sugerido por Hall e Bawa (1993) para estimar ocorrência e abundância de espécies fornecedoras de PFNM de importância econômica. Em cada localidade o número de transectos variou devido ao tamanho das áreas onde os moradores coletam ou coletariam os produtos para comercializarem (tabela I.2).

Tabela I.2 - Número de transectos estabelecidos em cada localidade.

\begin{tabular}{|c|c|c|}
\hline Localidades & $\begin{array}{l}N^{0} \text { de transectos } \\
\text { estabelecidos }\end{array}$ & Espécies preferenciais \\
\hline Capote & 2 & E. precatoria e A. murumuru \\
\hline Santa Teresa & 2 & E. precatoria e A. murumuru \\
\hline Triunfo & 3 & E. precatoria e A. murumuru \\
\hline Batalha de Baixo & 4 & E. precatoria, A. murumuru e C. guianensis \\
\hline São José & 4 & E. precatoria e A. murumuru \\
\hline Terra Nova & 4 & $\begin{array}{l}\text { E. precatoria, A. murumuru, C. guianensis e } \\
\text { M. dubia }\end{array}$ \\
\hline Costa da Ilha & 5 & $\begin{array}{l}\text { E. precatoria, A. murumuru, C. guianensis e } \\
\text { M. flexuosa }\end{array}$ \\
\hline Total & 24 & \\
\hline
\end{tabular}

Em cada transecto foram contabilizados todos os indivíduos de Euterpe precatoria, Carapa guianensis e Myrciaria dubia com DAP $\geq 5 \mathrm{~cm}$, e todos os indivíduos de Astrocaryum murumuru e Mauritia flexuosa com altura $\geq 3 \mathrm{~m}$.

\section{I.4.2. Fatores ambientais}

Três fatores ambientais (i.e. radiação solar, topografia e quantidade de matéria orgânica disponível no solo) foram avaliados a fim de se investigar como eles afetam a disponibilidade (ocorrência e a abundância) das cinco espécies de importância comercial. Para isso, cada um dos 24 transectos estabelecidos foi dividido em 20 parcelas de 10 metros de largura por 50 metros de comprimento, ou seja, uma área de $500 \mathrm{~m}^{2}$ ou 0,05 hectares por parcela, onde os fatores foram estimados.

Os três fatores selecionados estão entre os principais fatores ambientais que afetam a ocorrência e a abundância das espécies. Áreas de floresta que recebem maior radiação solar possuem menor riqueza e abundância de espécies arbóreas tolerantes à sombra 
(TABARELLI; MANTOVANI, 1999). A radiação solar que entra na floresta é regulada principalmente pela abertura do dossel (TABARELLI; MANTOVANI, 1999). Assim sendo, cada parcela foi classificada em três categorias: (i) sem clareira, (ii) com clareira e (iii) no limite de clareira. Foram consideradas clareiras aberturas no dossel $\geq 50 \mathrm{~m}^{2}$ (ASTURIZAGA, 2005).

Terrenos mais elevados, fora do alcance efetivo das cheias, podem apresentar maior abundância e riqueza de espécies, já que um número menor de espécies são adaptadas aos ambientes saturados de água (CARDOSO; SCHIAVINI, 2002). Na floresta de várzea o principal descritor da topografia é a altura da inundação que indica a elevação do terreno, que foi estimada a partir da distância, em metros, entre o chão e a marca da água deixada durante a cheia de 2013 (ano anterior à coleta deste dado) visível no tronco das árvores (WITTMANN et al., 2004).

Maiores quantidades de matéria orgânica no solo podem favorecer maior abundância de espécies por aumentar a quantidade de nutrientes e as possibilidades de germinação e sobrevivência das sementes ao diminuir as chances de descoberta dessas sementes por predadores (SORK, 1983). A quantidade de matéria orgânica no solo pode ser descrita pela profundidade do folhiço, ou seja, pela altura da serapilheira, a qual foi estimada em centímetros com o uso de régua, a partir da profundidade encontrada no ponto central de cada parcela.

\section{I.4.3. Potencial econômico dos PFNM}

\section{I.4.3.1. Frutificação e produção de sementes}

As cinco espécies foram avaliadas quanto à taxa anual, em quilos, da produção de frutos e sementes. Para as palmeiras E. precatoria e $M$. flexuosa a produção foi estimada a partir do número de cachos produzido por indivíduo e o peso de frutos por cacho, enquanto para A. murumuru considerou-se o número de cachos produzido por indivíduo e o peso de sementes por cacho. Para M. dubia a estimativa de produção por indivíduo foi feita a partir da contagem de frutos presentes em um quarto da área da copa selecionado aleatoriamente, e da pesagem de 30 frutos para se estimar o peso médio de um fruto. Por fim, o número de frutos contados foi multiplicado por quatro (toda a copa) e pelo peso médio do fruto. Para $C$. guianensis estimou-se o peso de sementes produzido por indivíduo a partir do peso das sementes não danificadas localizadas sob a copa de cada árvore. 
Os dados utilizados para estimar a taxa anual de produção provêm de dois eventos distintos de coleta, o primeiro realizado em 2011 e o segundo em 2014, ambos durante os meses de abril e maio. Em 2011, buscou-se amostrar de maneira sistemática 30 indivíduos de cada espécie de palmeira e 10 indivíduos de cada espécie arbórea, porém o total de indivíduos com frutos encontrados foi inferior ao tamanho amostral planejado. A amostragem sistemática consistiu em, a partir do primeiro indivíduo com fruto encontrado, localizar outros indivíduos com frutos, distantes ao menos 100 metros entre si. A vantagem desse procedimento de amostragem é que ele não depende de uma listagem da população investigada e pode ser realizado em menos tempo do que uma amostragem aleatória. Por outro lado, a produção pode ser superestimada, pois os indivíduos com mais frutos podem ser encontrados mais facilmente.

Em 2014, buscou-se estimar a produção de frutos e sementes a partir de 30 indivíduos adultos de cada espécie, sorteados dentre aqueles presentes nos transectos estabelecidos para estimar a ocorrência e abundância. Os indivíduos foram classificados como adultos em função da altura ou diâmetro à altura do peito (DAP), a depender da espécie (tabela I.3).

Tabela I.3 - Alturas e diâmetros mínimos considerados para a definição das fases adultas reprodutivas e número de indivíduos amostrados nos diferentes anos.

\begin{tabular}{cccccc}
\hline Espécie & Hábito & $\begin{array}{c}\text { Altura } \\
(\mathbf{m})\end{array}$ & $\begin{array}{c}\text { DAP } \\
(\mathbf{m})\end{array}$ & \multicolumn{2}{c}{$\begin{array}{c}\text { Tamanho amostral } \\
\left(\mathbf{n}^{\mathbf{0}} \text { de indivíduos }\right)\end{array}$} \\
& & & & 2011 & 2014 \\
\hline E. precatoria & palmeira & $10^{\mathrm{a}}$ & n.a. & 30 & 30 \\
A. murumuru & palmeira & $8^{\mathrm{a}}$ & n.a. & 25 & 21 \\
M. flexuosa & palmeira & $9^{\mathrm{a}}$ & n.a. & 6 & 10 \\
C. guianensis & árvore & n.a. & $0,30^{\mathrm{b}}$ & 9 & 2 \\
M. dubia & árvore & n.a. & $0,05^{\mathrm{c}}$ & 0 & 0 \\
\hline Nota: a= adaptado de Henderson $(1995) ; \mathrm{b}=$ Pinto et al $(2012) ; \mathrm{c}=$ Peters e Vasques
\end{tabular}

(1987); n.a= não se aplica.

Apesar de a amostragem probabilística realizada em 2014 demandar mais tempo de trabalho de campo, as estimativas de produção a partir dela são mais confiáveis. Além disso, essa técnica de amostragem permitiu estimar a proporção de indivíduos adultos que realmente frutificam num determinado ano, dado que nem todos os indivíduos adultos sorteados frutificaram durante o período de coleta dos dados.

A decisão de incluir os dados de frutificação de ambos os anos para estimar a taxa anual de produção de frutos e sementes decorreu especialmente do pequeno número de indivíduos das espécies $M$. flexuosa, C. guianensis e M. dubia que produziram frutos tanto em 2011 como em 2014. Ao utilizar os dados coletados nos dois anos, a produção de frutos de mais indivíduos foi incluída na amostra, permitindo avaliar melhor a variabilidade por 
indivíduo, assim como eventuais flutuações de produção que ocorrem de um ano para outro, aumentando, portanto a confiabilidade das estimativas.

Os meses em que os PFNM estão disponíveis para a coleta foram identificados através de survey $^{3}$, por meio de entrevistas realizadas com 75 unidades domésticas distribuídas entre as sete localidades. Nas quatro localidades com menos de dez unidades domésticas, todas as unidades foram incluídas na amostra, enquanto nas três localidades mais populosas (tabela I.1), 15 unidades foram sorteadas para compor a amostra. Cada unidade doméstica foi representada por seu chefe autointitulado (homem ou mulher) sorteado no momento da entrevista, o qual foi perguntado sobre qual ou quais eram os melhores meses do ano para se coletar cada um dos cinco produtos avaliados.

\section{I.4.3.2. Valor monetário dos PFNM disponíveis}

A estimativa do potencial econômico dos cinco PFNM avaliados foi feita em duas etapas. Primeiramente, foi calculado o potencial econômico de cada espécie em cada uma das parcelas (i.e. a mesma unidade amostral utilizada para avaliar os fatores ambientais) através da fórmula:

$$
\mathrm{P}_{\mathrm{ec} i}=\mathrm{A}_{\mathrm{i}} \cdot \mathrm{P}_{\mathrm{i}} \cdot \mathrm{F}_{\mathrm{i}} \cdot \mathrm{V}_{\mathrm{i}},
$$

onde $\mathrm{P}_{\mathrm{ec}}$ corresponde ao potencial econômico em reais $(\mathrm{R} \$$ ) de cada uma das cinco espécies $i$ em cada uma das parcelas amostradas; A é a abundância de indivíduos adultos da espécie na parcela; P corresponde à produção anual média, em quilos, de fruto ou semente de um indivíduo; F é a proporção de indivíduos adultos que frutificaram em 2014; e V é o valor monetário do quilo do produto. Posteriormente, foram somados os potenciais econômicos de cada espécie por parcela, obtendo-se o potencial econômico dos múltiplos PFNM por parcela. Por fim, para comparar o potencial econômico entre as localidades, foi calculado o potencial econômico médio das parcelas agrupadas por localidade.

O valor monetário do quilo de cada um dos cinco produtos foi obtido através de entrevistas com informantes-chave, incluindo o vice-presidente da Associação de Moradores da Reserva Mamirauá e um membro da equipe da Fundação Amazônia Sustentável (FAS) atuante na região da RDS Mamirauá. A FAS é uma organização não governamental que tem como missão promover o desenvolvimento sustentável, a conservação ambiental e a melhoria

\footnotetext{
${ }^{3}$ Coleta sistemática de dados através de perguntas diretas, com preenchimento de uma matriz de dados equivalentes entre todas as unidades amostrais (DE VAUS, 2013).
} 
da qualidade de vida de comunidades ribeirinhas do Estado do Amazonas. Ambos informantes conheciam os preços praticados no ano de 2014 em Fonte Boa, a cidade mais próxima, onde o açaí, buriti e camu-camu são comumente comercializados, bem como os preços em mercados regionais, como na Reserva Extrativista do Médio Juruá, onde as sementes de andiroba e murumuru são comercializadas. Os valores indicados por cada informante não variaram. 


\section{I.4.4. Estimativa do interesse em coletar os PFNM}

O interesse das pessoas coletarem os PFNM de importância comercial foi estimado no nível do indivíduo, através de survey, por meio de entrevistas. Para isso, foi utilizada uma amostra de 120 indivíduos, distribuídos entre 75 unidades domésticas pertencentes às sete localidades alvo da pesquisa, as mesmas unidades cujos chefes responderam sobre os melhores meses para coletar os PFNM .

Dentre cada unidade doméstica amostrada foram sorteados dois indivíduos, sendo um homem e uma mulher, acima de 15 anos de idade. Essa idade foi escolhida, pois é aquela a partir da qual os moradores da região já costumam coletar PFNM por conta própria, segundo entrevistas informais realizadas previamente à pesquisa. As 120 pessoas amostradas (60 homens e 60 mulheres), corresponderam a $80 \%$ do número previsto, pois nem todas as unidades domésticas contaram com a presença de mais de um membro acima de 15 anos.

O interesse foi estimado a partir de uma escala ordinal de nove pontos, variando de - 4 a +4 (figura I.8). Para isso, o entrevistado indicava seu nível de interesse em coletar cada produto, sendo que os valores negativos correspondiam a falta crescente de interesse (de -1 a 4), o zero representava indiferença, enquanto os valores positivos indicavam o interesse crescente pela coleta $(\mathrm{de}+1 \mathrm{a}+4)$. Cada indivíduo entrevistado respondeu sobre seu interesse em coletar somente os produtos existentes na área de uso de sua localidade, conforme seu conhecimento.

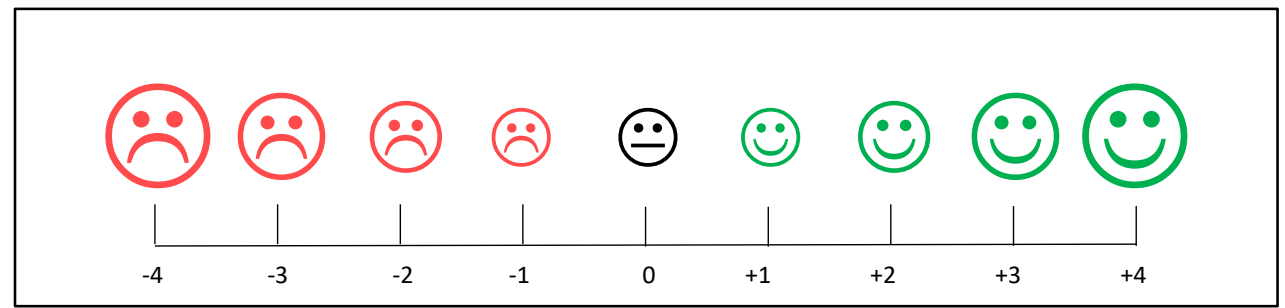

Figura I.8 - Escala utilizada para o entrevistado indicar o nível de interesse em coletar cada um dos cinco PFNM.

\section{I.4.5. Associação dos fatores socioeconômicos, culturais e de percepção com o interesse}

Para avaliar a associação dos fatores socioeconômicos, culturais e de percepção com o interesse dos indivíduos em coletar os cinco PFNM de importância comercial, foram 
consideradas como variáveis explicativas, dois fatores socioeconômicos (consumo e a comercialização de cada um dos PFNM), dois culturais (origem e identidade dos indivíduos) e um de percepção (gosto pela coleta). Para os fatores socioeconômicos e culturais foram criadas uma série de variáveis dummy correspondentes às diferentes observações. Porém, as duas variáveis dummy relacionadas à origem do chefe da unidade doméstica (i.e., "comunidade ribeirinha" e "cidade"), assim como as oito relacionadas à identidade do chefe (i.e., pescador, agricultor, dona de casa, agente de saúde, aposentado, auxiliar administrativo, carpinteiro, pastor e zelador de escola) inicialmente incluídas nos modelos, foram excluídas, pois quase não variaram e pioravam o ajuste dos modelos.

Foram ainda controlados os fatores de confusão que poderiam distorcer a interpretação da associação entre os fatores investigados e o interesse. Os fatores de confusão corresponderam à renda total (subsistência e monetária), riqueza e escolaridade, sendo que os valores de renda foram ajustados para valores mensais. Conforme demonstrado por Davidar (2008), unidades domésticas com renda, riqueza e escolaridade mais baixas tendem a mostrar maior interesse em coletar produtos florestais.

A correlação entre as variáveis explicativas foi avaliada com base nos coeficientes de correlação de Pearson aos pares, adotando a correção de Sidák para múltiplas correlações (HAMILTON, 2012). Com variáveis muito relacionadas não se consegue separar o efeito específico de cada uma sobre o interesse e, neste caso, um dos procedimentos comumente adotados é a omissão da variável que apresenta colinearidade, isto é, correlação com outras variáveis. Como não houve colinearidade, já que os coeficientes de correlação foram inferiores à $0.5(\mathrm{p}<0.1)$, todas as variáveis foram consideradas nas análises (DORMANN et al., 2013). A tabela I.4 sumariza todas as variáveis adotadas nos modelos.

Tabela I.4 - Definição e estatística descritiva das variáveis empregadas para testar a associação dos fatores socioeconômicos e do gosto pela coleta com o interesse dos indivíduos coletarem os cinco PFNM de importância comercial.

\begin{tabular}{|c|c|c|c|c|c|c|}
\hline Variáveis & Descrição (unidade) & Obs. & $\overline{\mathbf{X}}$ & D.P & Mín. & Máx. \\
\hline \multicolumn{7}{|l|}{ Explicativas } \\
\hline $\begin{array}{l}\text { Consumo dos } \\
\text { cinco PFNM } \\
\text { por unidade } \\
\text { doméstica }\end{array}$ & $\begin{array}{l}\text { Se consome cada produto } \\
(0=\text { não; } 1=\operatorname{sim})\end{array}$ & 75 & n.a. & n.a. & 0 & 1 \\
\hline $\begin{array}{l}\text { Venda dos } \\
\text { cinco PFNM } \\
\text { por unidade } \\
\text { doméstica }\end{array}$ & $\begin{array}{l}\text { Se já vendeu alguma vez } \\
\text { cada produto }(0=\text { não; } 1=\operatorname{sim})\end{array}$ & 75 & n.a. & n.a. & 0 & 1 \\
\hline $\begin{array}{l}\text { Gosto de } \\
\text { coletar açaí }\end{array}$ & $\begin{array}{l}\text { Gosto do indivíduo em } \\
\text { coletar açaí (de } 1 \text { a } 9)\end{array}$ & 69 & 7,4 & 1,8 & 1 & 9 \\
\hline $\begin{array}{l}\text { Gosto de } \\
\text { coletar }\end{array}$ & $\begin{array}{l}\text { Gosto do indivíduo em } \\
\text { coletar murumuru (de } 1 \text { a } 9 \text { ) }\end{array}$ & 35 & 6,6 & 1,8 & 1 & 9 \\
\hline
\end{tabular}




\begin{tabular}{|c|c|c|c|c|c|c|}
\hline Variáveis & Descrição (unidade) & Obs. & $\overline{\mathbf{X}}$ & D.P & Mín. & Máx. \\
\hline \multicolumn{7}{|l|}{ murumuru } \\
\hline $\begin{array}{l}\text { Gosto de } \\
\text { coletar buriti }\end{array}$ & $\begin{array}{l}\text { Gosto do indivíduo em } \\
\text { coletar buriti (de } 1 \text { a } 9)\end{array}$ & 69 & 7,3 & 1,4 & 3 & 9 \\
\hline $\begin{array}{l}\text { Gosto de } \\
\text { coletar } \\
\text { andiroba }\end{array}$ & $\begin{array}{l}\text { Gosto do indivíduos em } \\
\text { coletar andiroba (de } 1 \text { a } 9)\end{array}$ & 86 & 7,5 & 1,6 & 1 & 9 \\
\hline $\begin{array}{l}\text { Gosto de } \\
\text { coletar camu- } \\
\text { camu } \\
\text { Dependente }\end{array}$ & $\begin{array}{l}\text { Gosto do indivíduo em } \\
\text { coletar camu-camu (de } 1 \text { a } 9 \text { ) }\end{array}$ & 77 & 7,2 & 1,5 & 2 & 9 \\
\hline $\begin{array}{l}\text { Interesse em } \\
\text { coletar açaí }\end{array}$ & $\begin{array}{l}\text { Interesse de coletar açaí no } \\
\text { próximo período produtivo } \\
\text { (de } 1 \text { a 9) }\end{array}$ & 120 & 7,1 & 1,6 & 1 & 9 \\
\hline $\begin{array}{l}\text { Interesse em } \\
\text { coletar } \\
\text { murumuru }\end{array}$ & $\begin{array}{l}\text { Interesse de } \quad \text { coletar } \\
\text { murumuru no próximo } \\
\text { período produtivo }(\text { de } 1 \text { a } 9)\end{array}$ & 120 & 4,8 & 2,6 & 1 & 9 \\
\hline $\begin{array}{l}\text { Interesse em } \\
\text { coletar buriti }\end{array}$ & $\begin{array}{l}\text { Interesse de coletar buriti no } \\
\text { próximo período produtivo } \\
\text { (de } 1 \text { a 9) }\end{array}$ & 76 & 6,8 & 2,0 & 1 & 9 \\
\hline $\begin{array}{l}\text { Interesse em } \\
\text { coletar } \\
\text { andiroba }\end{array}$ & $\begin{array}{l}\text { Interesse de coletar andiroba } \\
\text { no próximo período } \\
\text { produtivo (de } 1 \text { a } 9)\end{array}$ & 100 & 7,2 & 1,8 & 1 & 9 \\
\hline $\begin{array}{l}\text { Interesse em } \\
\text { coletar camu- } \\
\text { camu } \\
\text { Controles }\end{array}$ & $\begin{array}{l}\text { Interesse de coletar camu- } \\
\text { camu no próximo período } \\
\text { produtivo (de } 1 \text { a } 9)\end{array}$ & 94 & 6,6 & 2,1 & 1 & 9 \\
\hline $\begin{array}{l}\text { Renda da } \\
\text { unidade } \\
\text { doméstica }\end{array}$ & $\begin{array}{l}\text { Renda mensal total } \\
\text { (subsistência e monetária) } \\
(\mathrm{R} \$)\end{array}$ & 75 & $\mathrm{R} \$ 3.640,00$ & $\mathrm{R} \$ 1.553,58$ & $\mathrm{R} \$ 1.231,50$ & $\mathrm{R} \$ 8.545,00$ \\
\hline $\begin{array}{l}\text { Riqueza da } \\
\text { unidade } \\
\text { doméstica }\end{array}$ & $\begin{array}{l}\text { Bens de patrimônio } \\
\text { doméstico e equipamentos de } \\
\text { trabalho }(\mathrm{R} \$)\end{array}$ & 75 & $\mathrm{R} \$ 8.521,00$ & $\mathrm{R} \$ 5.248,56$ & $\mathrm{R} \$ 515,00$ & $\mathrm{R} \$ 26.230,00$ \\
\hline $\begin{array}{l}\text { Escolaridade } \\
\text { do chefe da } \\
\text { unidade } \\
\text { doméstica }\end{array}$ & Anos completos de estudo & 75 & 3,7 & 3,3 & 0 & 11 \\
\hline
\end{tabular}

Notas: Obs. $=\mathrm{N}^{\circ}$ de observações. $\bar{X}=$ média; D.P.= desvio padrão; Mín.= valor mínimo; Máx.= valor máximo n.a.= não se aplica.

Para avaliar associação dos fatores socioeconômicos e de percepção (i.e. variáveis explicativas) com o interesse dos indivíduos em coletar cada um dos PFNM (i.e. variáveis dependentes), foram empregados modelos multinível com efeitos aleatórios. Esses modelos são apropriados para analisar dados de natureza hierárquica, levando em conta a possível dependência entre as observações múltiplas de uma unidade amostral. Considerar a hierarquia dos dados permite obter estimativas dos coeficientes da regressão mais próximas à realidade, pois ignorar a correlação entre as unidades amostrais poderia inflar o nível de significância das análises (GOLDSTEIN, 2011).

Os modelos adotados foram de dois níveis, sendo que o primeiro correspondeu às observações múltiplas do interesse dos indivíduos, enquanto o segundo, que representa o 
maior nível por agrupar o primeiro, correspondeu às unidades domésticas, inseridas como fatores aleatórios. Foram utilizadas regressões logísticas múltiplas, devido à natureza da variável dependente (categórica ordinal), sendo que em cada regressão foram incluídas as variáveis controle (fatores de confusão). Os valores das variáveis dependentes incluídas nos modelos foram transformados em escala positiva para melhorar o ajuste dos modelos, assim como foi feito com a variável "gosto de coletar", sendo para isso adicionado o valor cinco às estimativas originais.

Todas as análises foram feitas com o software Stata v.13.1.

Além das variáveis empregadas nos modelos, foram também avaliadas outras variáveis com o objetivo de descrever os aspectos de consumo e comercialização dos PFNM. No caso do consumo foi avaliada a finalidade do uso de cada produto (e.g. alimentação, remédio, artesanato, etc.) e no caso da comercialização foi avaliado: mês e ano em que foi feita a última venda; onde foi feita a venda (na própria localidade ou na cidade); para quem venderam (atravessador ou consumidor final); a forma como o produto foi vendido (in natura ou beneficiada); a unidade pela qual venderam (e.g. saca, litro, dúzia, etc.); o preço pelo qual venderam cada unidade; se tiveram alguma despesa exclusiva para realizar a venda do produto (e.g. gasto com transporte ou beneficiamento); e o valor da despesa.

Todas as variáveis avaliadas, com exceção do gosto, foram estimadas no nível da unidade doméstica, através de survey, por meio de entrevistas. Cada uma das 75 unidades domésticas incluídas na amostra, como descrito na seção anterior, foi representada por seu chefe autointitulado (homem ou mulher) sorteado no momento da entrevista. O gosto pela coleta dos PFNM foi estimado, assim como o interesse, no nível do indivíduo e a partir de uma escala ordinal de nove pontos. Nos casos em que os entrevistados declararam não gostar de coletar (nível negativo de -1 a -4) foi ainda perguntado o motivo.

\section{I.4.6. Estimativa da capacidade, aptidão e habilidade de coleta}

A capacidade, aptidão e habilidade de coleta foram avaliadas no nível do indivíduo, através de survey, por meio de entrevistas aplicadas a mesma amostra utilizada para avaliar o interesse, ou seja, 120 indivíduos.

A capacidade foi estimada pelo número de latas (18 litros) que o entrevistado declarou que acredita ser capaz de coletar em um ano considerado por ele de boa frutificação, ou seja, com grande produção de frutos e sementes. Assim como o interesse, cada indivíduo entrevistado respondeu sobre sua capacidade de coletar somente os produtos existentes na 
área de uso de sua localidade, conforme seu conhecimento. Dessa mesma forma foi avaliada a aptidão e habilidade.

Para aptidão, foi perguntado ao entrevistado se ele consegue ou não coletar cada produto, sendo que para os que não conseguem ou nunca conseguiram foi perguntado o motivo. Já a habilidade foi estimada pelo tempo, em minutos, que o entrevistado gastou para coletar uma lata (18 litros) de cada produto no último período de frutificação anterior à entrevista, sem considerar o tempo gasto no percurso até a área de coleta.

O survey ainda incluiu uma questão relacionada à frequência com que os entrevistados coletam PFNM, incluindo os cinco produtos de importância comercial. Cada entrevistado escolheu a frequência que melhor representava sua dedicação, dentre sete categorias apresentadas: nunca; poucas vezes; uma vez por mês; uma vez a cada 15 dias; uma vez por semana; mais de uma vez por semana; todos os dias. Essa questão teve o intuito de conhecer o quanto eles comumente se dedicam a esta atividade.

\section{I.4.7. Aprovação do survey por comitê de ética}

No total, 195 entrevistas foram realizadas, sendo 120 no nível do indivíduo e 75 no nível da unidade doméstica. Porém, antes da coleta dos dados utilizados neste estudo, os questionários utilizados nas entrevistas foram testados através de uma pesquisa piloto, em uma localidade da RDS Mamirauá que não fazia parte da pesquisa, mas que apresentava características semelhantes às localidades-alvo do estudo, com relação à origem, identidade e modo de vida das pessoas. O questionário no nível da unidade doméstica foi aplicado em 12 unidades e o referente ao indivíduo foi aplicado em 12 indivíduos. Com base na pesquisa piloto, algumas perguntas foram reajustadas e só então se iniciou a coleta de dados na área de estudo.

A realização das entrevistas tanto no nível do indivíduo, quanto no nível da unidade doméstica se deu posteriormente à aprovação da proposta da pesquisa pelo Comitê de Ética em Pesquisa do IDSM, uma organização social que atua como uma das unidades de pesquisa do Ministério de Ciência, Tecnologia e Inovação do governo federal e é cogestora da RDS Mamirauá. Cumpriu-se ainda a exigência de se apresentar um Termo de Consentimento Livre e Esclarecido (TCLE) a cada unidade doméstica entrevistada. Esse termo, assinado pelo chefe da unidade, serviu para esclarecer os objetivos da pesquisa, bem como para obter o consentimento do chefe para a realização da entrevista. O TCLE e os protocolos de coleta 
dados do survey (i.e. questionários utilizados para as entrevistas) encontram-se nos apêndices A e $\mathrm{B}$, respectivamente. 


\section{CAPÍTULO II - RESULTADOS}

Os resultados são apresentados em seis partes, sendo que a primeira descreve os fatores ambientais e a disponibilidade (ocorrência e abundância) das espécies de importância comercial nas localidades estudadas. A segunda, descreve o potencial econômico dos cinco PFNM nas sete localidades. A terceira, descreve o interesse das pessoas em coletar os cinco PFNM. A quarta, descreve os fatores socioeconômicos e culturais das unidades domésticas, e o fator de percepção (gosto) individual. A quinta, avalia a associação desses fatores com o interesse dos indivíduos em coletar os PFNM. Por último, a sexta parte descreve a capacidade, aptidão e habilidade das pessoas em coletar os PFNM de importância comercial.

\section{II.1.Fatores ambientais e a disponibilidade dos PFNM}

\section{II.1.1. Topografia, matéria orgânica e radiação solar}

Dentre os três fatores ambientais avaliados (topografia, quantidade de matéria orgânica no solo e radiação solar), a radiação solar foi o fator que menos variou dentre todas as parcelas amostradas, com mais da metade destas (64,1\%) não apresentando clareira. Já a topografia, representada pela altura da inundação, variou bastante entre as parcelas amostradas, de 0,28 a 3,10 m, com altura média de inundação de 1,40 m (D.P.=0,59 m). A quantidade de matéria orgânica, representada pela profundidade do folhiço também variou bastante entre as parcelas amostradas, de 0,00 a 13,50 cm, com profundidade média de 4,20 $\mathrm{cm}(\mathrm{D} . \mathrm{P} .=2,50 \mathrm{~cm})$.

Com relação à variação dos fatores ambientais entre as localidades, a altura média de inundação variou em até cerca de duas vezes, de 0,98 a 1,80 m, assim como a profundidade média do folhiço: de 2,41 a 5,59 cm. A ausência de clareira predominou em cinco das sete localidades, e nas duas com maior radiação solar, 53\% e 57\% das parcelas amostradas, respectivamente, continham clareira e ou estavam no limite de clareira.

A altura média de inundação encontrada na localidade onde ocorreram mais espécies foi intermediária $(1,36 \mathrm{~m})$ às alturas médias de inundação encontradas nas três localidades com menos espécies (de 0,98m a 1,50m). Já a profundidade do folhiço, que nas três localidades com menos espécies atingiu no máximo $3,60 \mathrm{~cm}$ em média, foi maior na localidade onde ocorreram as cinco espécies $(5,25 \mathrm{~cm}$ em média). E quanto à radiação solar, as parcelas amostradas na localidade com maior número de espécies apresentaram menos clareiras (24\% 
das parcelas amostradas com lareiras) do que as três localidades com duas espécies (32\%, $40 \%$ e $50 \%$ das parcelas amostradas com clareiras).

Entre os transectos preferenciais, ou seja, nas áreas onde determinado produto seria coletado para comercialização por ocorrer em maiores quantidades segundo os habitantes, o transecto preferencial para $M$. flexuosa apresentou os menores valores médios de altura de inundação $(1,05 \mathrm{~m})$ e profundidade do folhiço $(0,40 \mathrm{~cm})$, bem como a maior abertura de dossel, com $70 \%$ das parcelas amostradas com clareira ou no limite de clareira. Por outro lado, o transecto preferencial para M. dubia apresentou os maiores valores médios de altura de inundação $(2,30 \mathrm{~m})$ e profundidade do folhiço $(7,60 \mathrm{~cm})$, bem como a menor abertura de dossel, com 90\% das parcelas sem clareira. Entre os transectos preferencias para as outras espécies, a variação dos fatores ambientais foi menos acentuada (figura II.1).

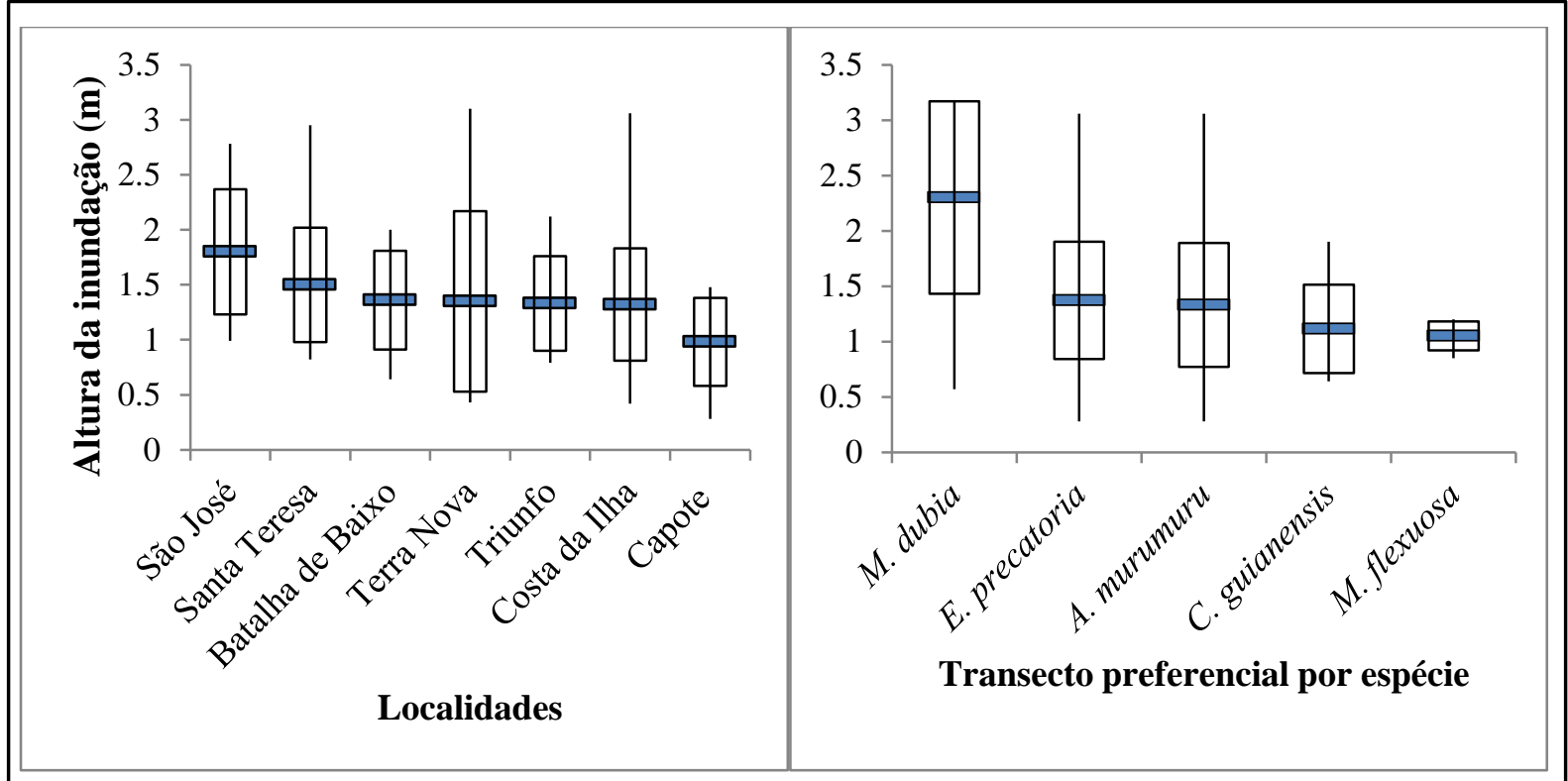

Figura II.1.a - Variação na altura de inundação entre as localidades e os transectos preferenciais. 


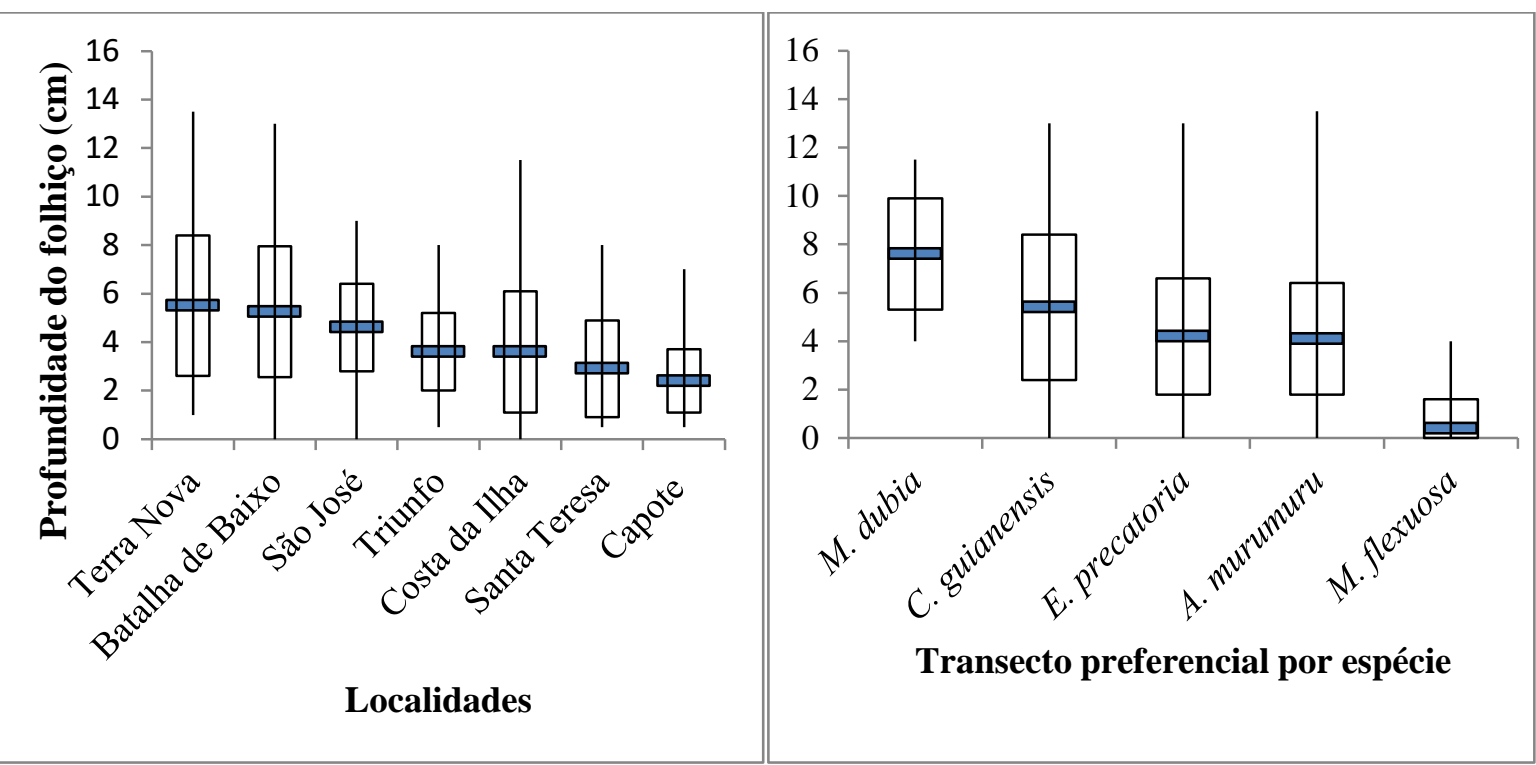

Figura II.1.b - Variação na profundidade do folhiço entre as localidades e os transectos preferenciais.

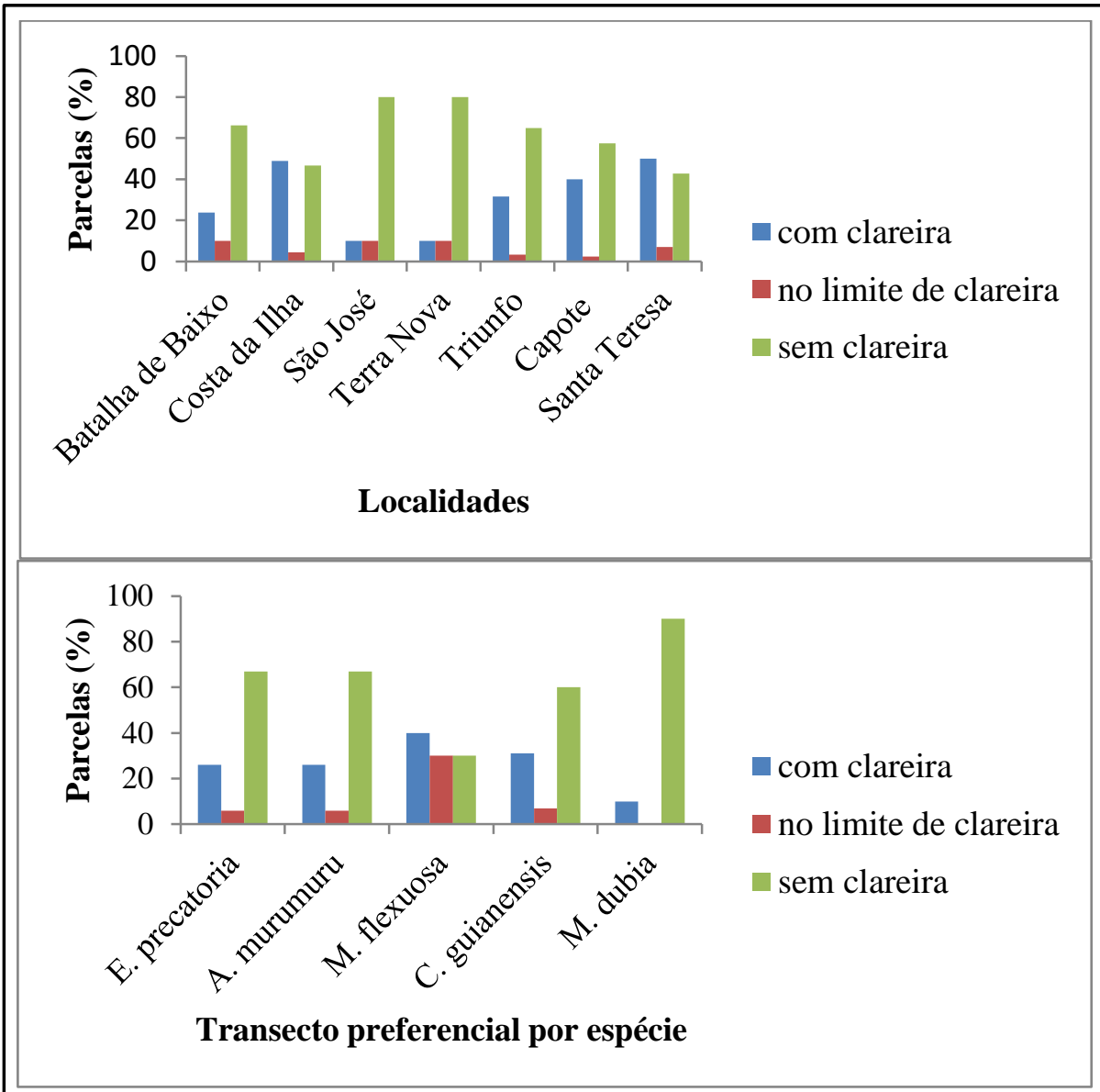

Figura II.1.c - Variação na abertura de dossel entre as localidade e os transectos preferenciais.

Figura II.1 - Variação dos fatores ambientais entre as localidade e os transectos preferenciais. 


\section{II.1.2. Ocorrência e abundância dos PFNM}

No contexto geral das sete localidades, ou seja, considerando todos os transectos amostrados, ocorreram em média 1,5 (D.P.=0,8) espécies por parcela $\left(500 \mathrm{~m}^{2}\right)$ dentre as cinco espécies avaliadas, variando entre nenhuma e no máximo quatro. A moda foi de duas espécies por parcela, observado em 50,9\% destas. Dentre as cinco espécies, E. precatoria foi a mais frequente, tendo ocorrido na maior parte das parcelas amostradas $(79,8 \%)$, seguida por $A$. murumuru que também ocorreu em mais de metade das parcelas $(59,4 \%)$. Já as outras espécies foram mais raras, ocorrendo em pequena porcentagem das parcelas amostradas: $C$. guianensis (13,7\%), M. flexuosa (4,9\%) е M. dubia (2,6\%).

$\mathrm{Na}$ escala da localidade, o número de espécies variou entre dois e cinco, ou seja, uma diferença de até 2,5 vezes entre as localidades estudadas. Em três das sete localidades ocorreram apenas duas espécies, enquanto em apenas uma localidade (Batalha de Baixo) ocorreram as cinco espécies de importância comercial avaliadas. As duas espécies mais comuns, E. precatoria e A. murumuru, estiveram presentes nas sete localidades. Já $C$. guianensis e $M$. flexuosa ocorreram em apenas três, e $M$. dubia apresentou uma distribuição ainda mais restrita, tendo ocorrido somente em duas das localidades amostradas, sendo que em uma delas (Batalha de Baixo) esta espécie ocorreu em somente uma parcela (figura II.2).

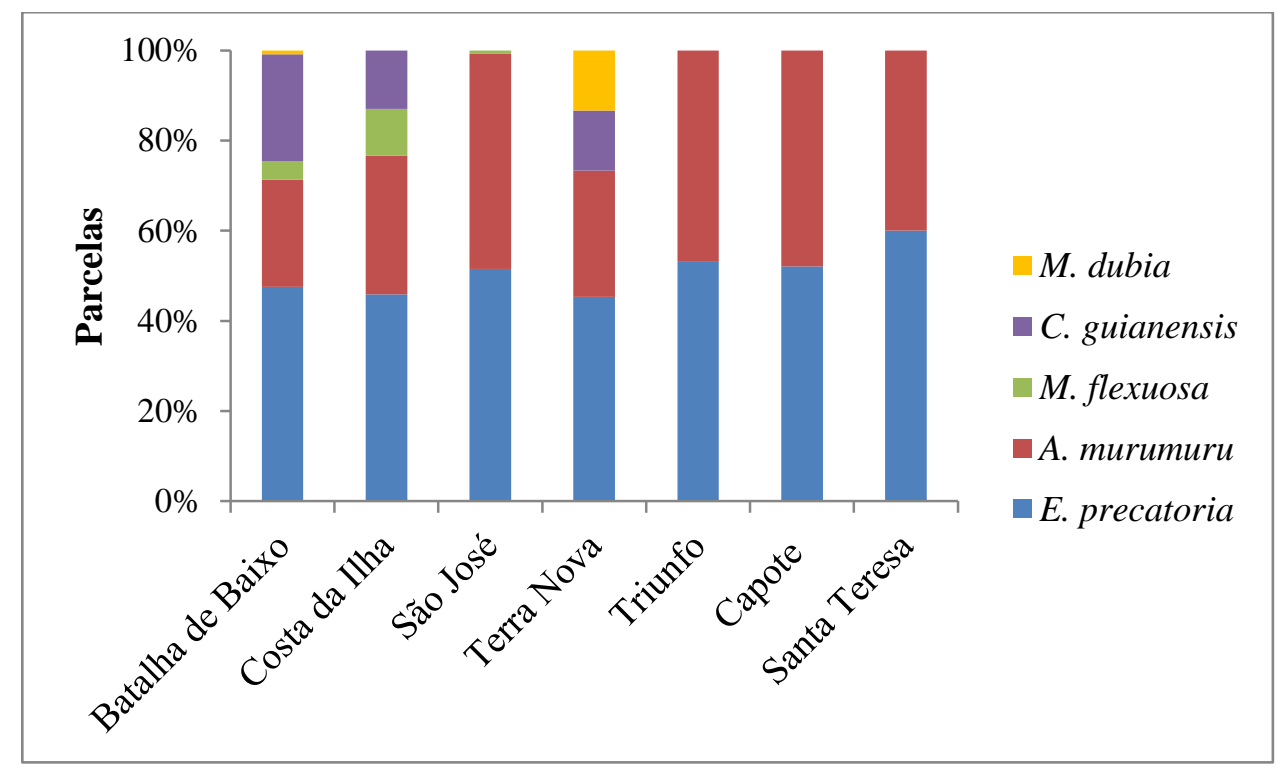

Figura II.2 - Proporção da ocorrência das espécies por localidade

Com relação à coocorrência das espécies, foram nos transectos alocados nas áreas onde o açaí seria coletado para comercialização por ocorrer em maiores quantidades segundo 
os habitantes, que coocorreu o maior número de espécies, isto é, as outras quatro investigadas. Nos transectos alocados nas áreas de maior concentração de $A$. murumuru, assim como de $M$. flexuosa e C. guianensis coocorreram outras três espécies em cada caso. Já no transecto alocado na área de maior concentração de M. dubia, nenhuma das outras quatro espécies investigadas foi encontrada. Isso indica que nos locais onde ocorre E. precatoria em maiores quantidades existe aparentemente maior probabilidade de coocorrerem também as outras espécies avaliadas, o que favoreceria a coleta de múltiplos PFNM nesses locais.

A maior abundância média, isto é, quando considerado indivíduos jovens e adultos das cinco espécies em todos os transectos amostrados nas sete localidades, foi observada para $E$. precatoria, com 3,5 (D.P.=3,1) indivíduos por parcela, seguido por A. murumuru com cerca de metade dessa abundância $(\overline{\mathrm{X}}=1,7$; D.P.=2,1). As outras espécies foram menos abundantes, com menos de um indivíduo em média por parcela: C. guianensis ( $\overline{\mathrm{X}}=0,5$ indivíduo), M. dubia e M. flexuosa $(\overline{\mathrm{X}}=0,1$ indivíduo).

Contudo, para todas as espécies a variação observada entre o número mínimo e máximo de indivíduos por parcela foi bastante grande, evidenciando a distribuição agregada dos indivíduos que é comum para essas espécies. A maior variação encontrada foi para a espécie $M$. dubia que apresentou entre nenhum a 24 indivíduos por parcela, seguido por $E$. precatoria, cuja abundância variou entre nenhum a 19 indivíduos. As outras espécies apresentaram variações inferiores, mas ainda assim, significativas: M. flexuosa entre nenhum a 14, C. guianensis entre nenhum a 12 e A. murumuru entre nenhum a 10 indivíduos por parcela.

Considerando à abundância das espécies em seus respectivos transectos preferenciais, ou seja, nas áreas de maior concentração dos indivíduos que, segundo os habitantes seriam utilizadas para a coleta comercial, $M$. dubia foi a espécie mais abundante, com média de 4,1 indivíduos por parcela, seguido por E. precatoria com média de 3,6 indivíduos por parcela. As outras espécies apresentaram abundâncias médias mais baixas, cerca de metade desses valores: C. guianensis com 2,3, A. murumuru com 2,0 e M. flexuosa com 1,9 indivíduos por parcela. As abundâncias nessas áreas preferenciais de coleta foram até 41 vezes maiores, como no caso de $M$. dubia, em comparação com a abundância média dentre todas as parcelas amostradas, evidenciando mais uma vez a distribuição agregada das espécies.

Na escala da localidade, a variação encontrada entre as abundâncias médias de cada espécie por parcela também foi grande. A abundância média de E. precatoria, a espécie mais abundante em média em todas as localidades, variou em até cerca de três vezes (i.e. de 1,6 a 5,2 indivíduos por parcela). Na localidade com a menor abundância média (Terra Nova) a 
altura média de inundação foi também menor, isto é, $0,15 \mathrm{~m}$ a menos do que o valor encontrado na localidade com maior abundância média (Santa Teresa). Também quanto à radiação solar, as parcelas amostradas em Terra Nova continham cinco vezes menos clareira (10\% das parcelas com clareira) do que as parcelas em Santa Teresa (50\% das parcelas com clareira). Em contraste, a profundidade média do folhiço encontrada em Terra Nova foi quase duas vezes maior do que em Santa Teresa $(5,5 \mathrm{~cm}$ e 2,9cm, respectivamente).

A. murumuru foi a segunda espécie mais abundante em seis das sete localidades, com abundância média variando também em até cerca de três vezes entre as localidades, de 0,8 a 2,7 indivíduos por parcela. Na localidade com menor abundância média (Batalha de Baixo) a altura média de inundação foi $1,36 \mathrm{~m}$, isto é, $0,44 \mathrm{~m}$ mais baixo do que a altura média da inundação nas áreas amostradas da localidade com maior abundância média (São José) que foi de 1,80m. Por outro lado, a profundidade média do folhiço na localidade de menor abundância média foi maior, de 5,25cm contra 4,60cm. Quanto à radiação solar, as parcelas amostradas na localidade com menor abundância média de A. murumuru continham cerca de duas vezes mais clareira ( $24 \%$ das parcelas com clareira) do que as parcelas da localidade com maior abundância média (10\% das parcelas com clareira).

As abundâncias médias de C. guianensis e $M$. dubia variaram de nenhum a 1,3 indivíduos por parcela entre as localidades, sendo que $M$. dubia foi a segunda espécie mais abundante, em média, em uma das sete localidades. No caso de C. guianensis, as alturas médias de inundação nas parcelas amostradas das quatro localidades com valores nulos de abundância variaram entre $0,98 \mathrm{~m}$ e $1,80 \mathrm{~m}$, e a altura média de inundação em Batalha de Baixo, que teve a maior abundância média de C. guianensis foi de $1,36 \mathrm{~m}$, ou seja, um valor intermediário a esses últimos. A profundidade média do folhiço nas localidades de menores abundâncias média variou de 2,40cm a 4,60cm, enquanto em Batalha de Baixo o valor foi superior, 5,25cm. Quanto à radiação solar, as parcelas amostradas nas localidades com valores nulos de abundância variaram quanto à presença de clareira, de $10 \%$ a 50\% das parcelas amostradas com clareira, e em Batalha de Baixo, como dito anteriormente, 24\% das parcelas continham clareira, ou seja, uma proporção intermediária de radiação solar em comparação com as localidades com as menores abundâncias médias. No caso de $M$. dubia, as alturas médias de inundação nas parcelas amostradas das seis localidades com valores nulos de abundância variaram entre $0,98 \mathrm{~m}$ a 1,80 , e a altura média de inundação em Terra Nova, que teve a maior abundância média, foi de 1,50m. A profundidade média do folhiço nas localidades de menores abundâncias média variou de $2,40 \mathrm{~cm}$ a $5,25 \mathrm{~cm}$, enquanto em Terra Nova o valor foi superior, $5,50 \mathrm{~cm}$. 
Apenas M. flexuosa apresentou pequena variação entre as localidades, de nenhum a 0,5 indivíduo em média por parcela.

Considerando as cinco espécies em conjunto e os valores não nulos de abundância, ou seja, somente as abundâncias das espécies que ocorreram em cada localidade, o número médio de indivíduos por parcela foi parecido entre as sete localidades, variando de 5,0 a 6,5 indivíduos das cinco espécies (figura II.3).

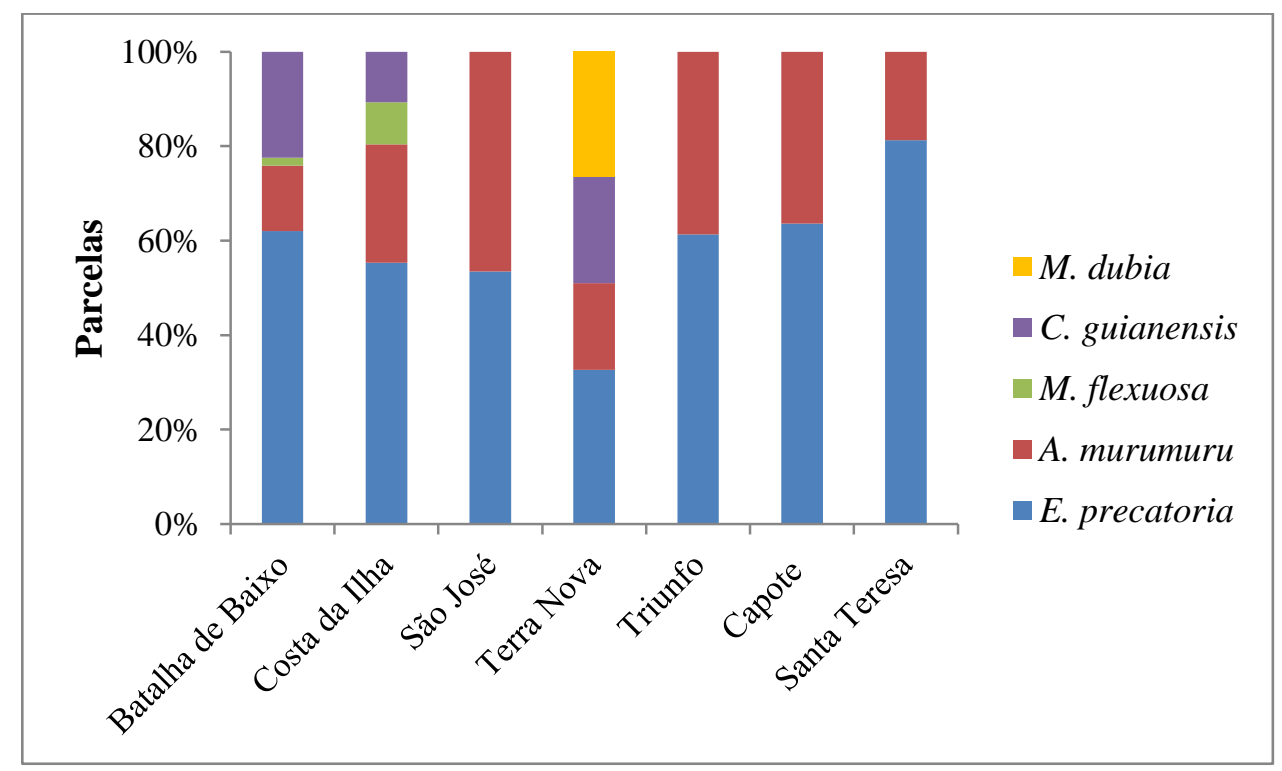

Figura II.3 - Proporção das abundâncias médias das espécies por parcela nas sete localidades.

Dentre todas as parcelas amostradas, mais da metade $(55,2 \%)$ apresentaram poucos indivíduos (i.e. de nenhum a cinco indivíduos por $500 \mathrm{~m}^{2}$ ), sendo que as espécies mais raras, C. guianensis, M. flexuosa e M. dubia estiveram ausentes em grande parte das parcelas: $86,8 \%, 95,2 \%$ e $97,5 \%$, respectivamente. No entanto, em 18,8\% das parcelas amostradas foram observados de 10 a 28 indivíduos das cinco espécies, indicando que apesar de ocorrer em poucos locais, as espécies podem ser bastante abundantes em determinadas ambientes.

A respeito da abundância somente dos indivíduos adultos, ou seja, aqueles capazes de produzir os frutos e sementes de importância comercial, a abundância média encontrada considerando todos os transectos amostrados, seguiu o mesmo padrão de abundância encontrada para todos os indivíduos (i.e. jovens e adultos), ou seja, a maior abundância média foi de E. precatoria, com 2,6 (D.P.=2,7) e a segunda maior foi de A. murumuru, com aproximadamente metade desse valor, isto é, 1,1 (D.P.=1,6) adultos por parcela. Já os adultos das outras espécies foram igualmente mais raros, com 0,1 indivíduo por parcela. 
Considerando a abundância dos adultos de cada espécie em seus respectivos transectos preferenciais, $M$. dubia foi a espécie mais abundante, com 4,1 adultos por parcela, seguido por E. precatoria, com abundância média de 2,8 adultos por parcela. As outras espécies apresentaram valores mais baixos: $M$. flexuosa com 1,6, A. murumuru com 1,3 e $C$. guianensis com cerca metade desses valores, isto é 0,7 , adultos por parcela.

\section{II.2.Potencial econômico dos múltiplos PFNM}

\section{II.2.1. Frutificação e produção de sementes}

Todas as espécies frutificam especialmente no período da cheia, isto é, de fevereiro a julho, com variações de um ou dois meses entre elas. A frutificação de $M$. dubia ocorre pouco mais cedo que as demais, de fevereiro a junho (PETERS; VASQUEZ, 1987), enquanto E. precatoria, M. flexuosa e C. guianensis frutificam de março a julho (CLAY et al., 2000; MÁRIO MENEZES, 2005; MEDINA, 2005). O maior período de frutificação é de $A$. mигитити, que assim como $M$. dubia, também se inicia a partir de fevereiro, mas se estende até setembro (RIOS; PASTORE JÚNIOR, 2011).

Quatro meses (de março a junho) foram percebidos com maior frequência como os melhores para coletar quatro dos cinco PFNM, de acordo com a percepção das 75 unidades domésticas entrevistadas sobre os melhores meses para coletar cada produto, devido tanto a maior disponibilidade de frutos ou sementes, quanto à facilidade de coleta definida pelo regime de cheia da várzea. Nesse período, maio foi mais citado pelas unidades domésticas como o melhor mês para coletar esses produtos: açaí (77\% das unidades), andiroba (30\% das unidades), buriti (56\% das unidades) e camu-camu (62\%). Já murumuru (A. murumuru) foi o único produto cuja coleta pode se estender por todo o ano, com a menor variação entre os meses, sendo fevereiro considerado menos frequentemente como o melhor mês (3\% das unidades) e setembro mais frequentemente o melhor (29\% das unidades) (figura II.4). 


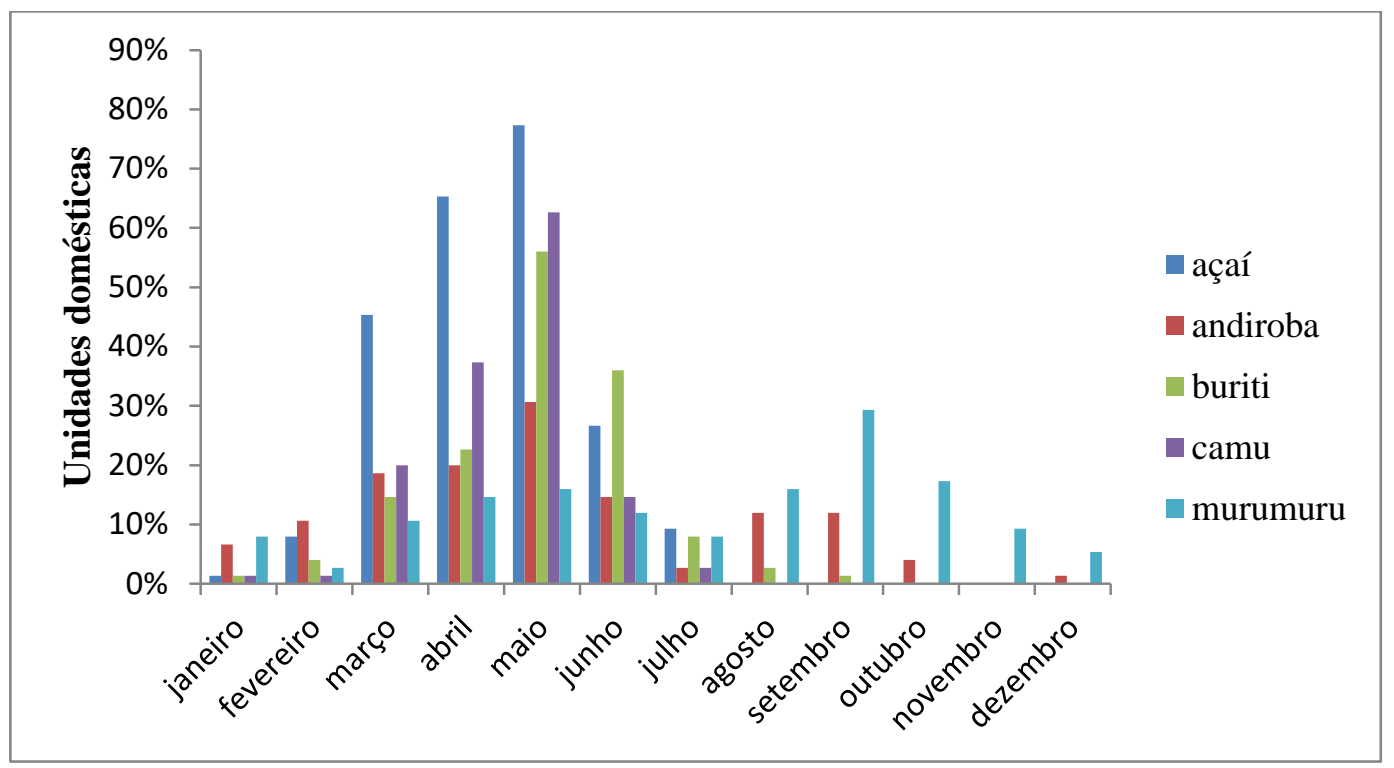

Figura II.4 - Melhor mês para coletar os PFNM de acordo com as unidades domésticas entrevistadas.

Em 2014, menos da metade dos indivíduos adultos amostrados de todas as espécies frutificaram. Os maiores índices de frutificação foram das palmeiras E. precatoria e A. murumuru com $43 \%$ dos indivíduos adultos amostrados frutificando, seguidos por $C$. guianensis com quase a mesma proporção, 40\%. Com valor próximo aos anteriores, $M$. flexuosa teve $33 \%$ dos indivíduos adultos frutificando, enquanto $M$. dubia teve o índice mais baixo, com nenhum dos indivíduos adultos amostrados frutificando.

Dentre as espécies estudadas, M. flexuosa teve a maior produção anual média por árvore, com 71,0 kg (D.P.=29,6), enquanto E. precatoria teve uma produção cerca de três vezes menor, com 21,0 kg (D.P.=15,0) de frutos por árvore. Já entre as espécies fornecedoras de sementes, os números foram bastante inferiores; $C$. guianensis com produção anual média de 5,3 kg (D.P.=4,4) e A. murumuru com 5,2 kg (D.P.=3,4) por árvore.

\section{II.2.2. Potencial econômico dos diferentes PFNM e localidades}

Além da ocorrência e abundância das espécies de importância comercial, e da taxa anual da produção dos frutos e sementes, os preços dos produtos também determinam o potencial econômico da coleta de múltiplos PFNM. O produto mais caro nos mercados regionais (cidade de Fonte Boa e Resex do Médio Juruá) avaliados em 2014 foi o fruto de camu-camu, com o preço de $R \$ 3,00$ por quilo, seguido pelos frutos de buriti, com $R \$ 2,00$ por quilo. Já o preço dos frutos de açaí foi metade do valor mais caro, isto é, $\mathrm{R} \$ 1,50$ por quilo. As 
sementes de andiroba e murumuru foram os produtos mais baratos, com preço de $\mathrm{R} \$ 0,50$ por quilo, ou seja, seis vezes menor do que valor o fruto mais caro.

De acordo com a estimativa da produção anual média de frutos ou sementes por árvore (considerando as árvores que frutificaram em 2011 e ou 2014) e com o preço dos produtos, $M$. flexuosa foi a espécie de maior potencial econômico, com cada árvore rendendo em média $\mathrm{R} \$ 142,00$ ao ano. Apesar de não terem sido encontrados indivíduos de $M$. dubia frutificando na área e período amostrados, esta espécie apresentaria o segundo maior potencial econômico médio, com R $\$ 39,00$ por árvore, caso fosse considerada a produção média de 13,0 quilos de frutos por árvore, encontrada na região do rio Ucayali da Amazônia peruana, por Peters e Vasquez (1987). Este valor, no entanto, é bastante inferior ao encontrado para a primeira espécie, embora similar ao potencial econômico de E. precatoria que teve o terceiro maior potencial econômico, com $\mathrm{R} \$ 31,50$ por árvore. Já $C$. guianensis e A. murumuru apresentaram o menor potencial, com $\mathrm{R} \$ 2,65$ e $\mathrm{R} \$ 2,60$ em média por árvore, respectivamente, ou seja, um potencial econômico cerca de 80 vezes inferior à espécie com a árvore mais rentável em termos de produção de frutos ou sementes. Importante salientar que esses valores correspondem ao potencial econômico por árvore e que o potencial econômico de uma espécie para gerar renda monetária em determinada localidade irá depender ainda da quantidade de árvores presentes na região.

Dentre todas as parcelas amostradas e considerando as cinco espécies, bem como a proporção de árvores que frutificaram em 2014, o potencial econômico anual médio estimado por parcela $\left(500 \mathrm{~m}^{2}\right)$ foi de $\mathrm{R} \$ 42,50$ (D.P. $\left.\mathrm{R} \$ 49,23\right)$, com grande variação nos valores encontrados, indo de zero a $\mathrm{R} \$ 500,13$. Já a variação do potencial econômico médio entre os transectos preferenciais foi menos acentuada, de $\mathrm{R} \$ 0,00$ a $\mathrm{R} \$ 205,15$ por parcela, sendo o transecto preferencial para M. dubia igual a zero, já que não foi encontrado nenhum indivíduo frutificando, e o preferencial para M. flexuosa o de maior potencial (figura II.5). 


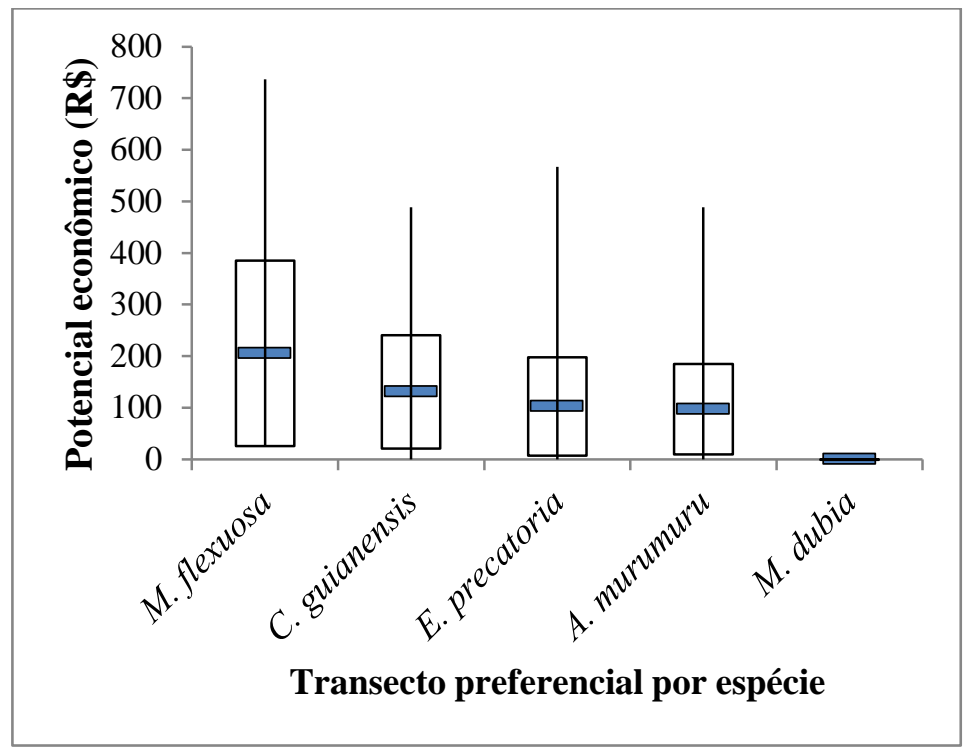

Figura II.5 - Variação do potencial econômico por parcela entre os transecto preferenciais.

Ainda considerando a produção anual média de frutos e sementes, e a proporção de árvores das cinco espécies que frutificaram em 2014, mas observando o potencial econômico médio na escala da localidade, três delas tiveram valores próximos entre si: Santa Teresa com $\mathrm{R} \$ 57,73$ (D.P. R $\$ 39,30$ ), seguida por Batalha de Baixo com R $\$ 49,69$ (D.P. R \$54,99) e Costa da Ilha, com $\mathrm{R} \$ 49,32$ (D.P. R $\$ 73,36$ ) por parcela. Já as outras quatro localidades tiveram valores médios mais baixos: São José com $\mathrm{R} \$ 41,27$ (D.P. $\mathrm{R} \$ 36,05)$, Triunfo com $\mathrm{R} \$ 39,51$ (D.P. $\mathrm{R} \$ 38,90$ ), Capote com $\mathrm{R} \$ 38,83$ (D.P. $\mathrm{R} \$ 27,58$ ) e Terra Nova com o valor mais baixo entre todas, R\$22,14 (D.P. 25,58), ou seja, quase três vezes inferior à média mais alta, visto que essa localidade era a única que contava com transecto preferencial para $M$. dubia, cujo potencial econômico estimado foi zero.

\section{II.3.Interesse dos indivíduos em coletar}

O interesse dos indivíduos em coletar variou tanto quando comparados diferentes PFNM, quanto quando comparado o interesse demonstrado em diferentes localidades considerando o mesmo produto. A variação do interesse em coletar os diferentes produtos pode ser devido aos fatores socioeconômicos, culturais e de percepção avaliados neste estudo. Já a variação entre as localidades, considerando o interesse em coletar um mesmo produto, pode ser causada por diferenças na disponibilidade (ocorrência e abundância das espécies) dos produtos em cada localidade. 
Em duas localidades (Capote e Terra Nova) não foi considerado o interesse em coletar buriti, devido à ausência deste produto na região segundo eles. Sobre a andiroba, em uma localidade (Capote) apenas um indivíduo dentre os dez entrevistados declarou algum nível de interesse em coletar (neste caso, falta de interesse, representado pelo valor -1), já que este é um produto ausente na região, segundo a maioria dos habitantes locais (figura II.6).

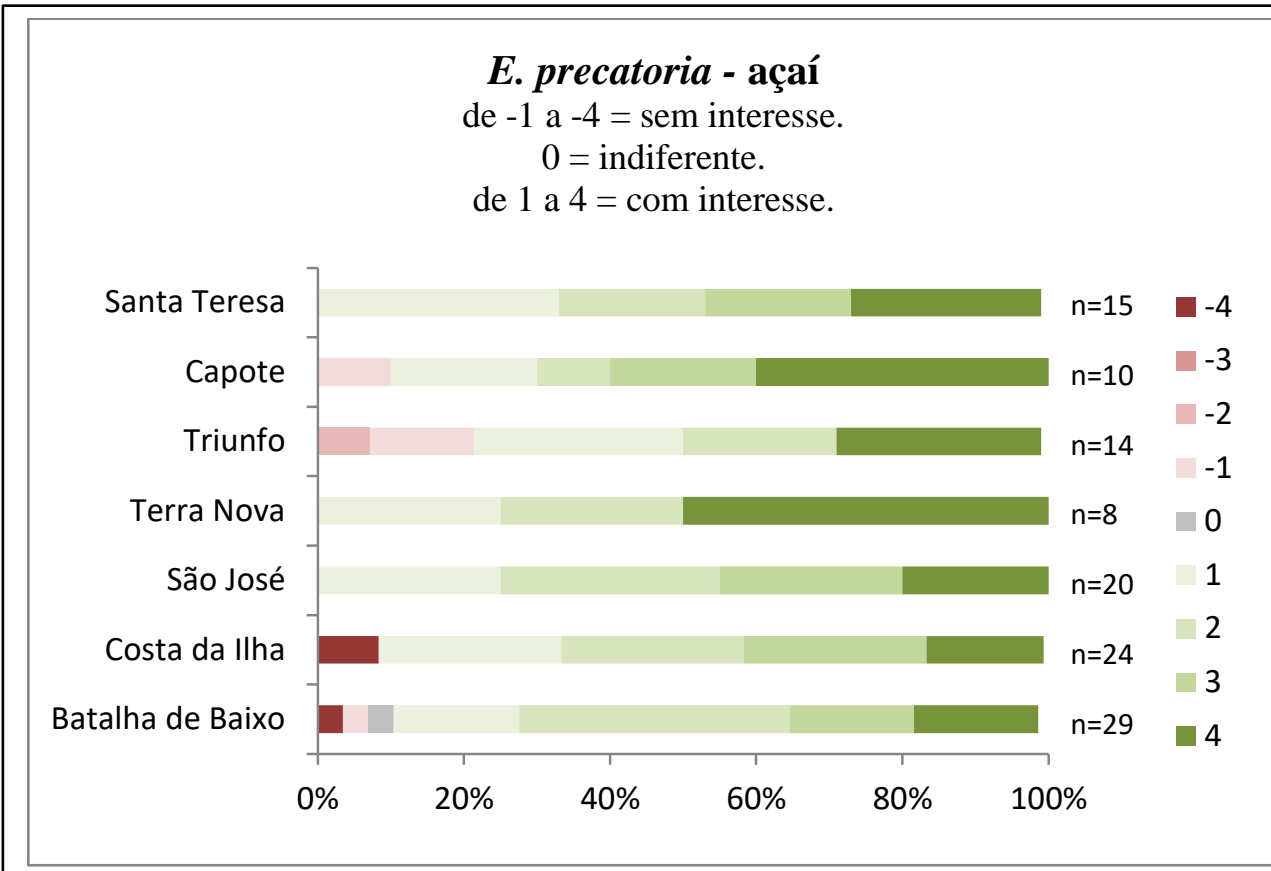

Figura II.6.a - Frequência relativa dos diferentes níveis de interesse em coletar açaí nas sete localidades.

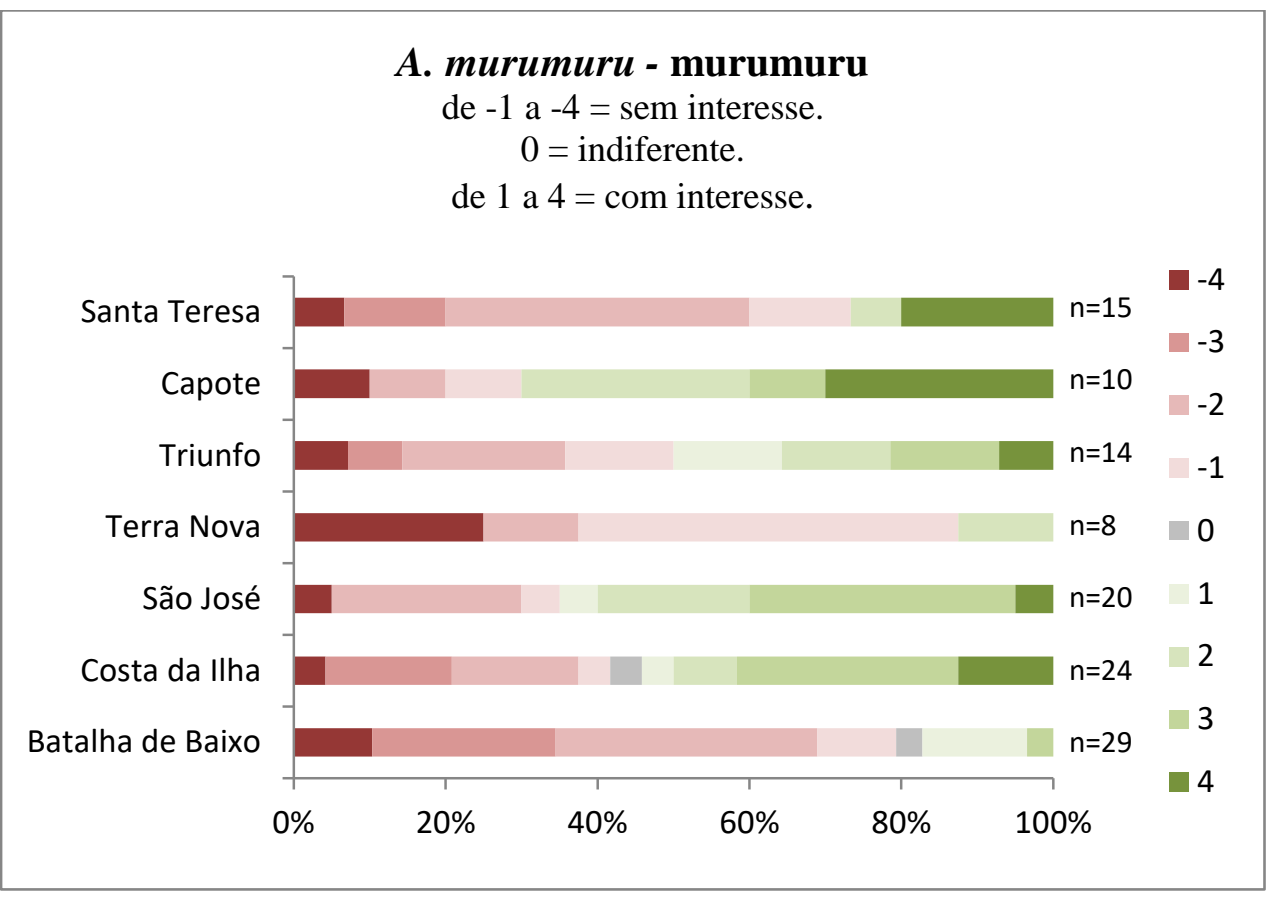

Figura II.6.b - Frequência relativa dos diferentes níveis de interesse em coletar murumuru nas sete localidades. 
M. flexuosa - buriti

de -1 a $-4=$ sem interesse.

$0=$ indiferente.

de 1 a $4=$ com interesse.

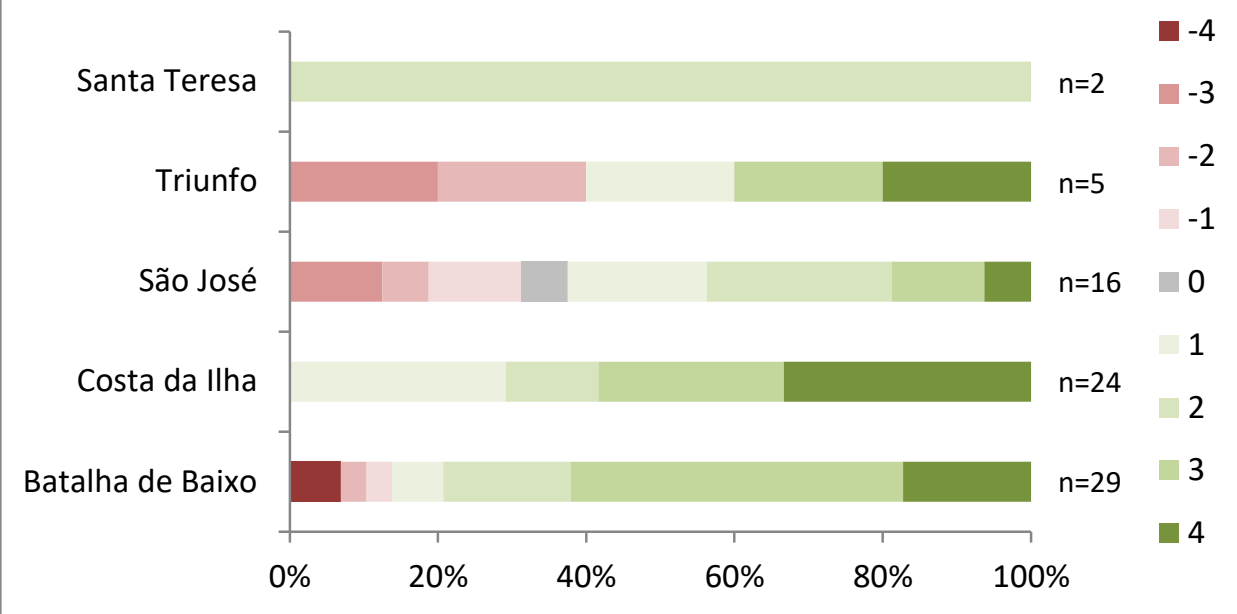

Figura II.6.c - Frequência relativa dos diferentes níveis de interesse em coletar buriti nas cinco localidades.

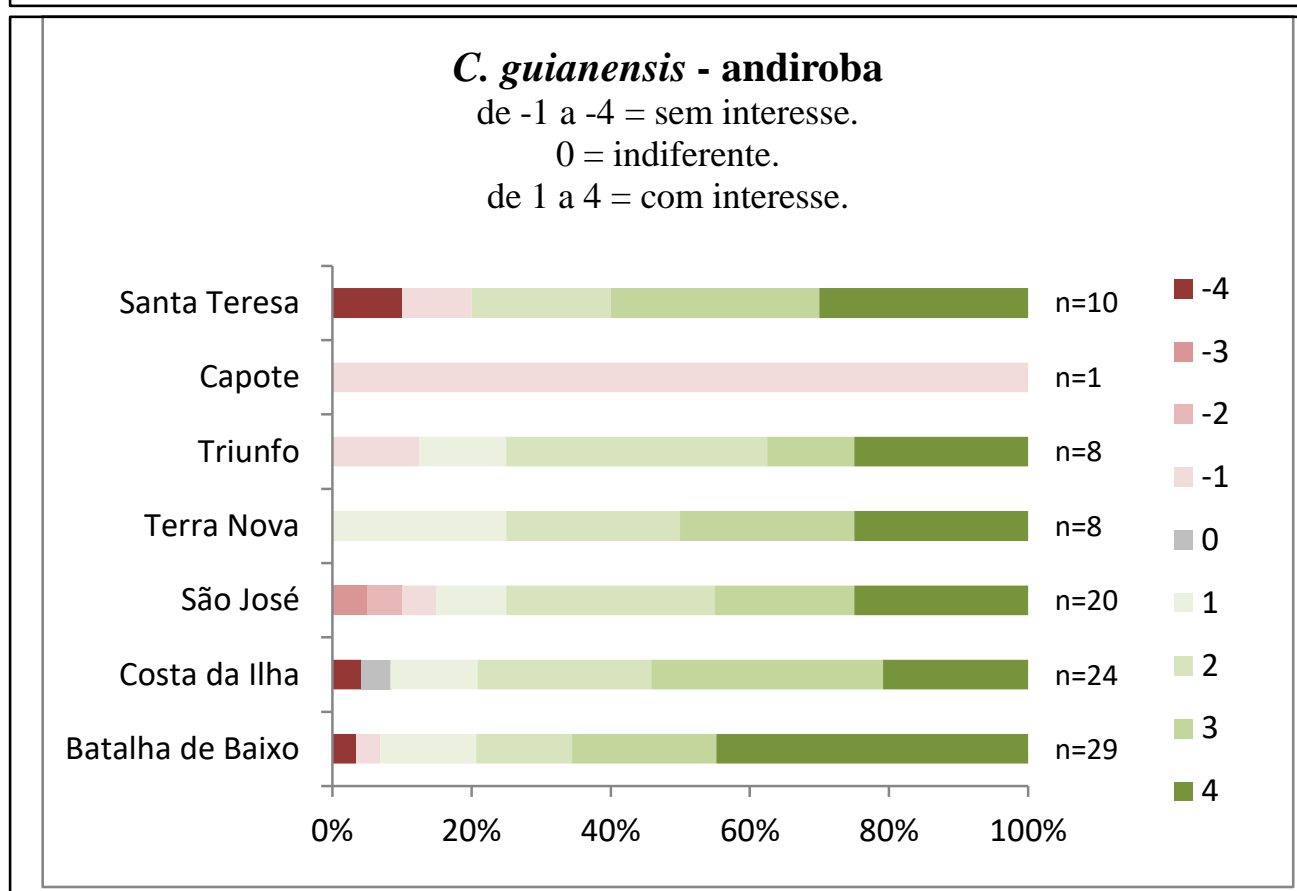

Figura II.6.d - Frequência relativa dos diferentes níveis de interesse em coletar andiroba nas sete localidades. 


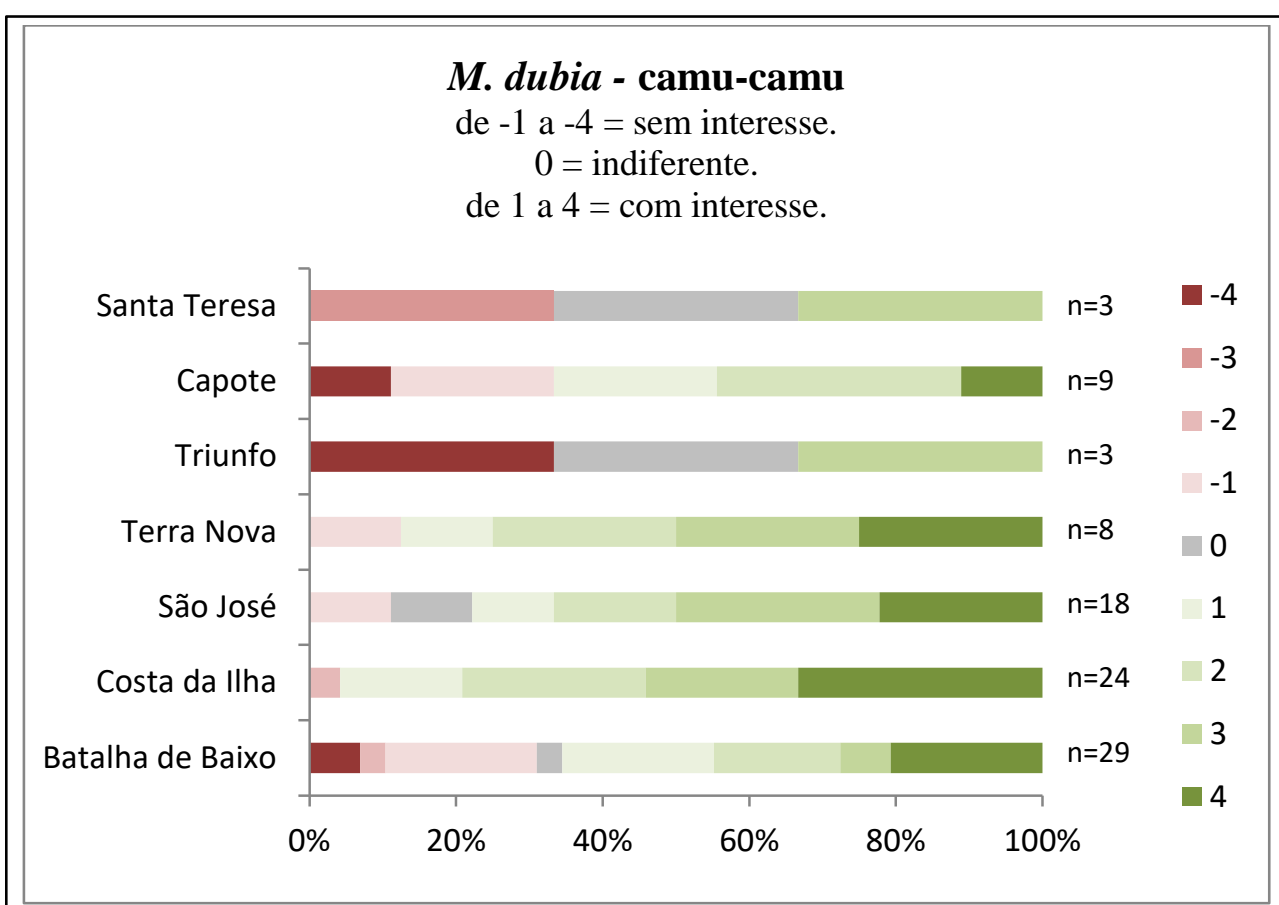

Figura II.6.e - Frequência relativa dos diferentes níveis de interesse em coletar camucamu nas sete localidades.

Figura II. 6 - Frequência relativa dos diferentes níveis de interesse (i.e. de -4 a 4) em coletar os cinco PFNM nas sete localidades. $\mathrm{N}$ = número de indivíduos que declararam interesse em coletar.

Considerando todas as localidades, observou-se que um indivíduo tem mais interesse em coletar entre três e quatro PFNM, dentre os cinco produtos de importância comercial avaliados. Entre as localidades, no entanto, esse número variou em até cinco vezes, possivelmente devido à disponibilidade local dos produtos (ocorrência e abundância das espécies), pois em Triunfo e Santa Teresa, onde ocorreram somente duas das cinco espécies nos transectos amostrados, a maior parte dos entrevistados, $61 \%$ e $80 \%$, respectivamente, declarou interesse em coletar somente um ou dois produtos, enquanto em Costa da Ilha, onde ocorreram quatro espécies nos transectos amostrados, a maior parte dos entrevistados (54\%) declarou interesse em coletar os cinco produtos avaliados. Nas outras cinco localidades esse número variou entre dois e quatros produtos.

O PFNM por cuja coleta houve mais indivíduos interessados foi o açaí, sendo que quase todos os entrevistados $(92,5 \%)$ declararam interesse em coletar este produto direta (subindo na palmeira) ou indiretamente (ajudar na debulha e transporte dos frutos). Por outro lado, murumuru foi o PFNM pelo qual menos pessoas se declararam interessadas em coletar: apenas $41,6 \%$ dos entrevistados, ou seja, menos da metade dos indivíduos entrevistados. Neste caso, quase todos os entrevistados que nunca coletaram murumuru não o fizeram 
porque simplesmente não usam as sementes. Os outros PFNM apresentaram valores intermediários com relação ao número de indivíduos interessados na coleta (figura II.7) e os motivos pelos quais estes produtos nunca foram coletados variaram. No caso do buriti, as pessoas nunca coletaram principalmente por dois motivos: porque têm medo, pois a palmeira é muito alta e é difícil alcançar os frutos ainda no cacho, ou porque existe outra pessoa na família que já coleta. Sobre a andiroba, a presença de outra pessoa na família que já coleta as sementes também foi um dos motivos dos entrevistados nunca terem coletado. Além disso, a pouca quantidade de árvores dessa espécie na maioria das localidades também foi outro motivo pelo qual as pessoas nunca coletaram. Quanto ao camu-camu, o pequeno número de árvores e a falta de costume de consumir os frutos foram os principais motivos dentre as pessoas que nunca coletaram.

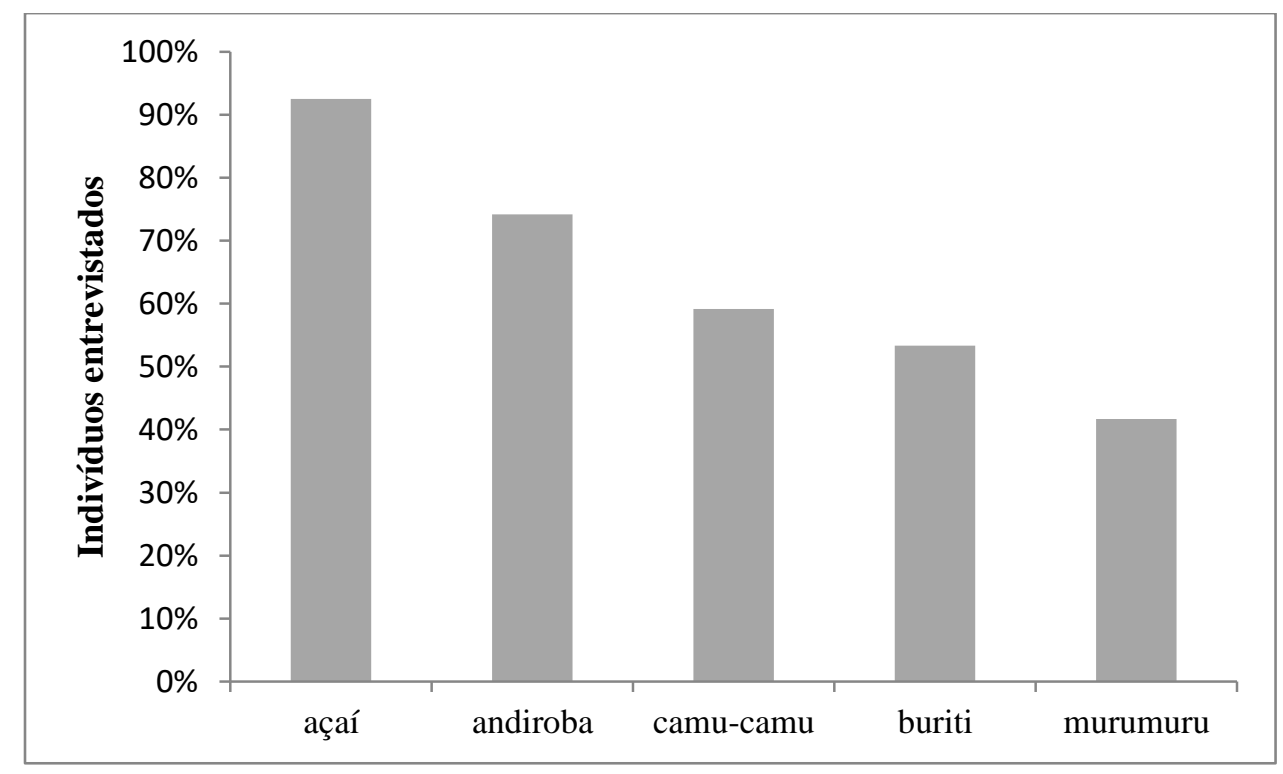

Figura II.7 - Frequência relativa dos indivíduos interessados em coletar os cinco PFNM avaliados.

\section{II.4. Fatores socioeconômicos, culturais e de percepção}

\section{II.4.1. Consumo e comercialização dos PFNM}

Todos os produtos avaliados são amplamente consumidos pelas unidades domésticas entrevistadas, com exceção do murumuru que é utilizado por apenas $12 \%$ das unidades, especialmente para a produção de artesanato, como anéis. O açaí é consumido por todas as unidades domésticas entrevistadas, exclusivamente para alimentação, seguido pela andiroba 
que é consumida por $82 \%$, especialmente como remédio e a seguir, buriti e camu-camu por $76 \%$ e $73 \%$, respectivamente, ambos utilizados para alimentação.

Experiências de comercialização dos cinco PFNM são comuns, sendo que a maior parte das unidades domésticas entrevistadas (80\%) já vendeu ao menos um dos produtos alguma vez ${ }^{4}$. Porém menos da metade delas $(40 \%)$ já vendeu uma maior variedade como dois ou mais produtos: 18,6\% das unidades entrevistadas venderam dois produtos, 14,6\% venderam três, 6,6\% venderam quatro e nenhuma unidade doméstica entrevistada já vendeu os cinco PFNM avaliados. Todos os produtos foram vendidos em 2014, ano em que os dados foram coletados, por pelo menos uma unidade doméstica.

Açaí foi o produto mais comercializado, já tendo sido vendido por mais da metade $(66 \%)$ das unidades domésticas entrevistadas. Os outros quatro foram comercializados por um número consideravelmente menor de unidades domésticas: andiroba, camu-camu e buriti por respectivamente, $26 \%, 25 \%$ e $21 \%$ das unidades, enquanto murumuru foi o menos vendido ( $8 \%$ das unidades entrevistadas).

A maior parte das vendas é feita na cidade, especialmente em Fonte Boa, com exceção do murumuru, cujas sementes foram vendidas na própria localidade onde foram coletadas em $67 \%$ dos casos. Sobre o camu-camu, todas as vendas ocorreram em Fonte Boa. Quanto às unidades domésticas que já venderam buriti, $88 \%$ delas também o fizeram na cidade, e para andiroba e açaí, os valores foram $75 \%$ e $70 \%$, respectivamente.

A maioria das unidades domésticas (88\%) venderam os PFNM exclusivamente para um atravessador, que compra o produto para revender, ou diretamente para o consumidor final, em proporções que variam de um produto para outro, porém $12 \%$ das unidades domésticas entrevistadas venderam determinados produtos (i.e. açaí, buriti e camu-camu) para ambos, atravessador e consumidor final (figura II.9).

\footnotetext{
${ }^{4}$ Para cada produto vendido foi perguntado o mês e o ano em que foi feita a última venda.
} 


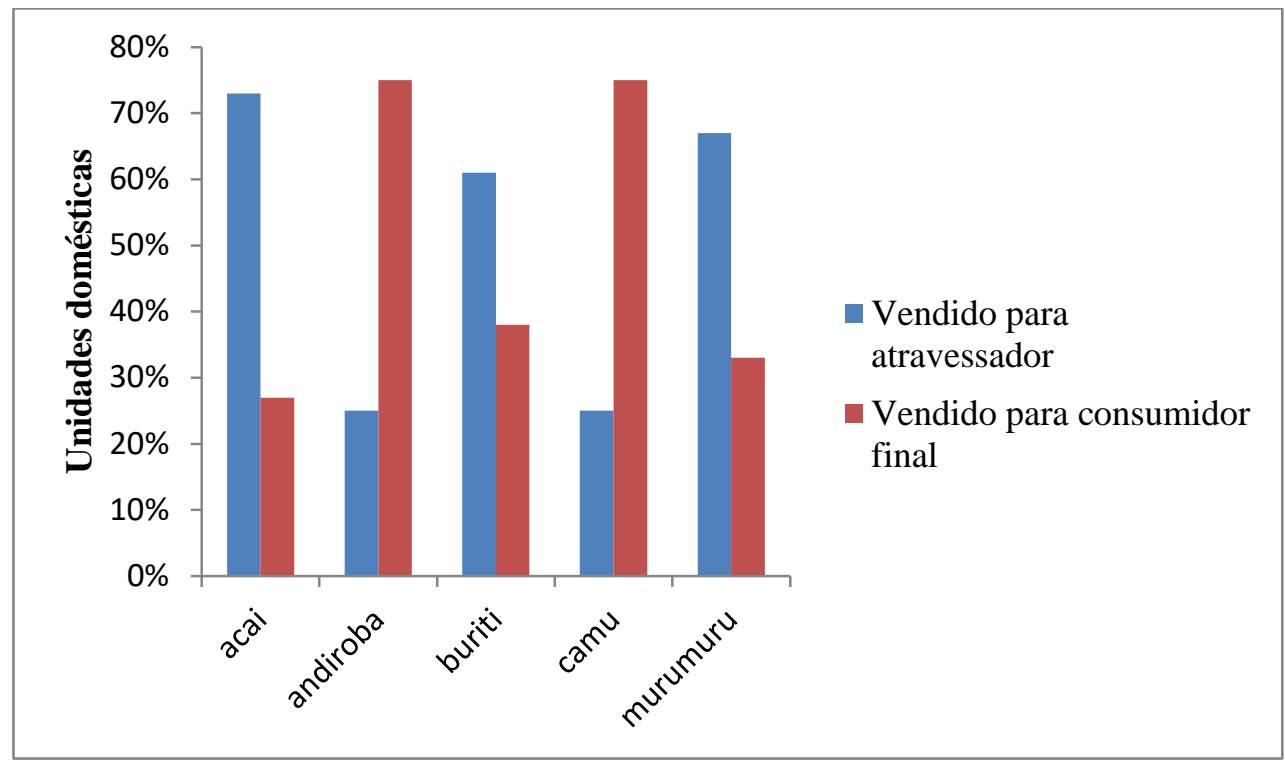

Figura II.9 - Compradores dos PFNM coletados.

Os PFNM são vendidos de diferentes formas (in natura ou beneficiado na forma de vinho como no caso do açaí ou de óleo, no caso da andiroba) e por diferentes unidades comerciais, como saca (80 litros), litro, lata (18 litros), dúzia, ou como artesanato, tal como anel, feito com as sementes do murumuru. Os preços médios de venda variam de acordo com o produto e a unidade comercial (tabela II.1). 
Tabela II.1 - Preço médio, em reais, de venda dos PFNM por unidade comercial.

\begin{tabular}{|c|c|c|c|c|c|c|}
\hline \multirow[b]{2}{*}{ PFNM } & \multirow[b]{2}{*}{$\begin{array}{l}\text { Garrafa } \\
(250 \mathrm{ml})\end{array}$} & \multicolumn{4}{|c|}{ Unidade comercial } & \multirow[b]{2}{*}{ Saca (801) } \\
\hline & & Anel & Dúzia & Lata (181) & Litro & \\
\hline fruto de açaí & - & - & - & $20,40(7,48)$ & - & $48,00(17,43)$ \\
\hline vinho de açaí & - & - & - & - & $3,60(1,20)$ & - \\
\hline semente de andiroba & - & - & - & $15,00^{*}$ & - & - \\
\hline óleo de andiroba & $5,00^{*}$ & - & - & - & $15,55(8,02)$ & - \\
\hline fruto de buriti & - & - & $2.70(2,58)$ & $13,30(5,77)$ & $5,00^{*}$ & $55,00(21,21)$ \\
\hline fruto de camu-camu & - & - & $2,80(1,30)$ & - & $2,75(1,51)$ & - \\
\hline $\begin{array}{l}\text { semente de } \\
\text { murumuru }\end{array}$ & - & $7,00(4,24)$ & - & $3,00(2,82)$ & - & - \\
\hline
\end{tabular}

Nota: Os valores entre parênteses correspondem ao desvio padrão. *Apenas uma venda declarada.

Ao menos $11 \%$ das unidades domésticas assumiram alguma despesa com a comercialização, sobretudo com combustível para o transporte dos produtos, sendo que essa proporção chegou até $78 \%$ das unidades no caso da venda de açaí. O transporte é feito em canoas, as mesmas utilizadas para locomoção das pessoas, de maneira que a capacidade de carga é limitada a poucas sacas (maior unidade comercial). O custo médio com o transporte variou em até dez vezes de uma localidade outra, conforme as distâncias em relação ao local de venda: R\$ 150,00 em Terra Nova; R\$ 100,00 em Capote; R \$ 45,00 em São José, Batalha de Baixo e Santa Teresa; R 21,00 em Triunfo; e R\$ 15,00 em Costa da Ilha.

\section{II.4.2. Origem, identidade, renda e riqueza das unidades domésticas}

Quase todos os chefes das unidades domésticas entrevistadas (93\%) nasceram e viveram pelo menos até os 15 anos de idade em comunidades ribeirinhas, e em sua maioria $(85 \%)$ se identificaram como agricultores ou pescadores. Os $15 \%$ restantes se identificaram como donas de casa, entre outras ocupações, como agente de saúde, zelador de escola e carpinteiro.

Metade dos chefes entrevistados (47\%) completaram apenas o ensino primário (quatro anos de estudo), e uma porção considerável (19\%) nunca frequentou a escola. Apenas 7\% dos chefes das unidades domésticas entrevistados completaram o ensino médio. Por outro lado, mais da metade (67\%) das unidades possuem pelo menos um membro que completou o ensino fundamental (nove anos de estudo) e $27 \%$ das unidades domésticas entrevistadas possuem ao menos um membro que completou o ensino médio.

A renda total (i.e. subsistência e monetária) média das unidades domésticas foi estimada em cerca de $\mathrm{R} \$ 3.640,00$ (D.P. $\mathrm{R} \$ 1.553,58$ ) por mês e a renda monetária média 
mensal $\mathrm{R} \$ 2.494,00$ (D.P. R \$ 1.134,39), ou seja, 68,5\% da renda total. Quanto à riqueza das unidades domésticas, representada pelos bens de patrimônio doméstico e equipamentos de trabalho, o valor médio foi estimado em R \$ 8.521,00 (D.P. R \$ 5.248,56).

\section{II.4.3. Gosto pela coleta dos PFNM}

Assim como o interesse, o gosto dos indivíduos pela coleta (fator de percepção individual) variou tanto entre diferentes PFNM quanto o gosto das pessoas de diferentes localidades pela coleta de um mesmo produto. De maneira geral, ou seja, considerando todas as localidades, há mais pessoas que gostam de coletar os PFNM (nível de gostar entre 1 e 4) do que pessoas que não gostam (nível de gostar entre -1 e -4 ). Os motivos que levam as pessoas a não gostarem de coletar variam de acordo com o produto, podendo ser devido à presença de espinhos na planta e nos frutos, como no caso do murumuru, ou devido a grande altura da palmeira, como no caso do açaí e buriti, em que as pessoas precisam escalar em busca dos frutos. A grande distância de casa até a área de coleta também foi citada como motivo de não se gostar de coletar andiroba e camu-camu.

Na localidade Santa Teresa nenhum dos entrevistados já havia coletado murumuru, sendo assim, o gosto de coleta deste produto nesta localidade não foi avaliado. O mesmo ocorreu para o buriti em outras duas localidades (Capote e Terra Nova) (figura II.8).

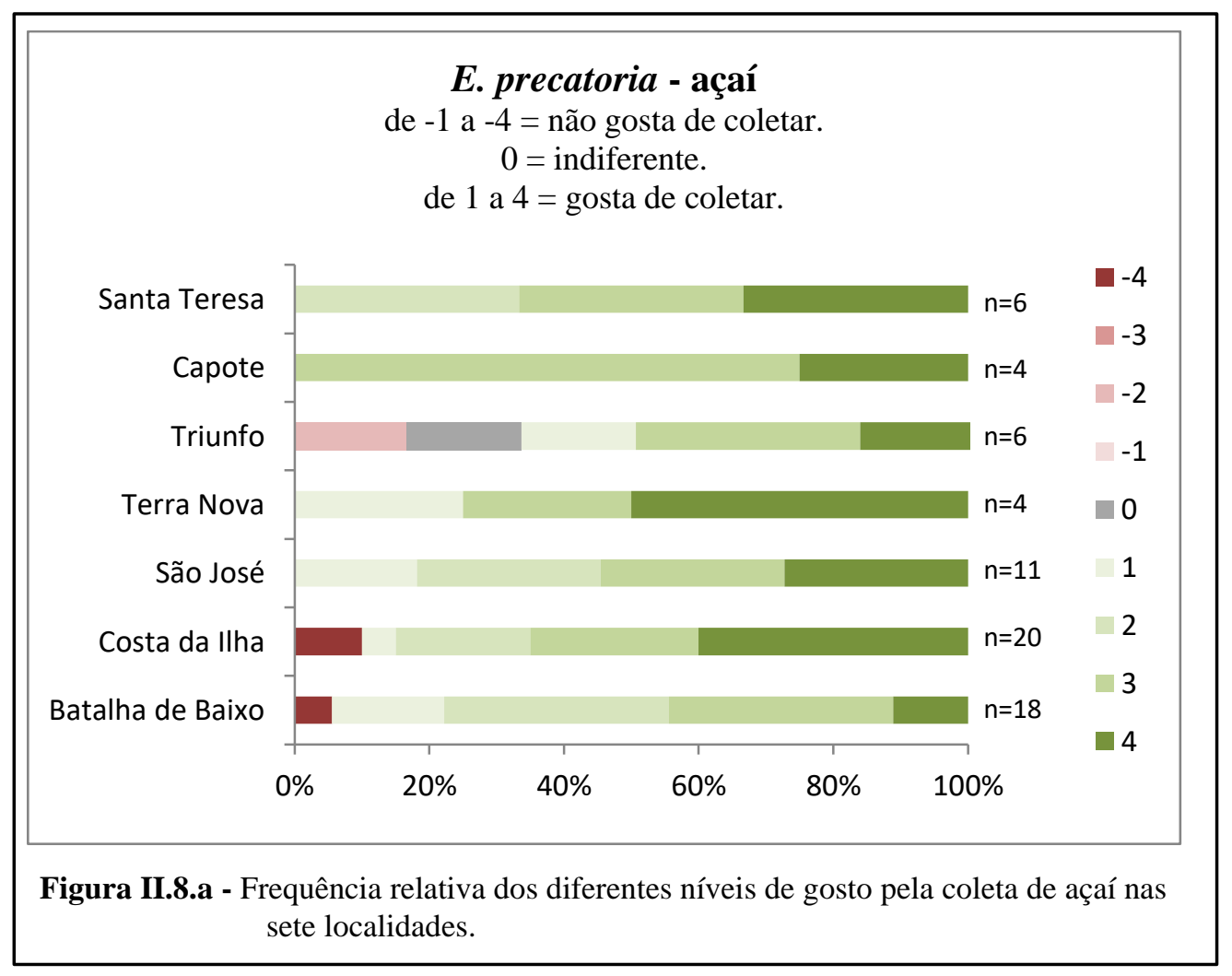




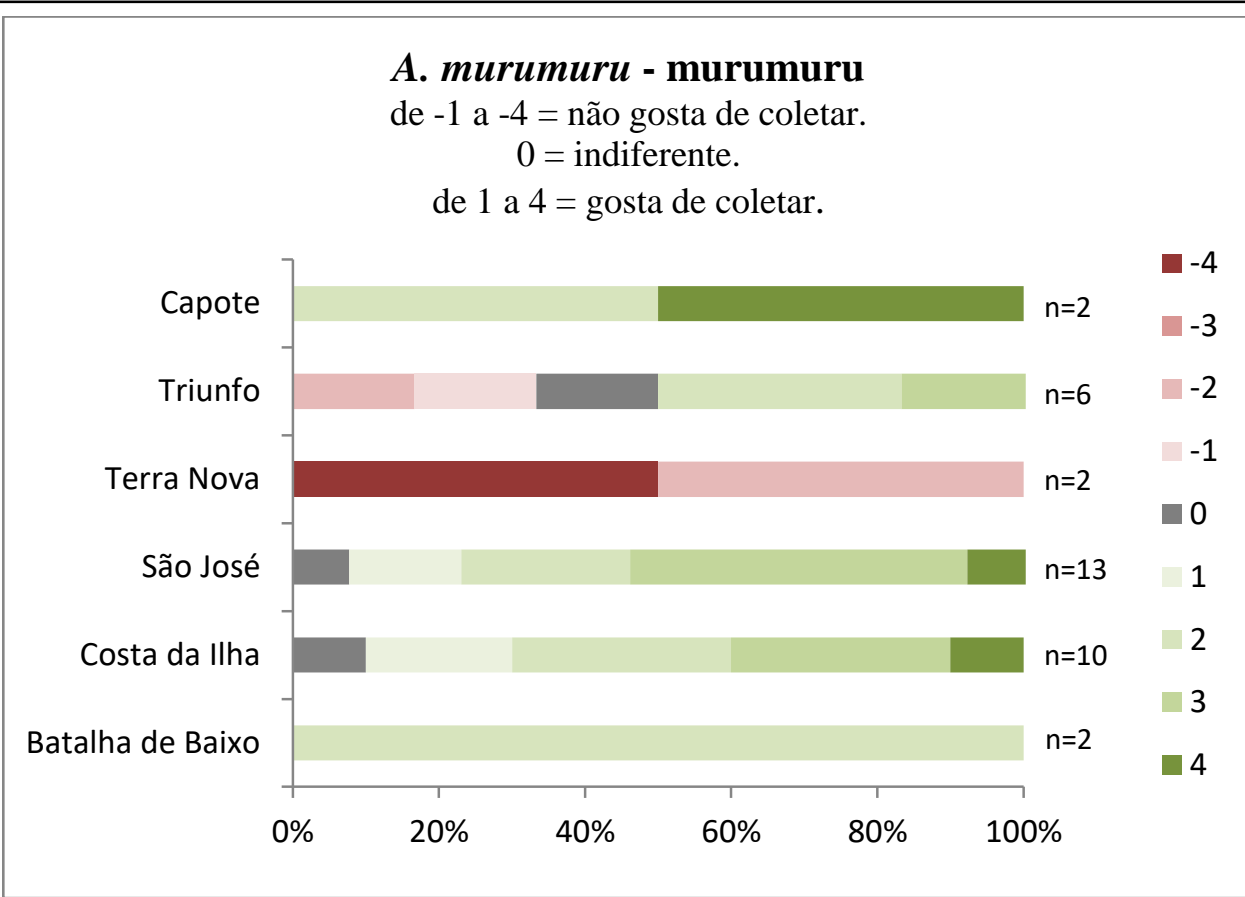

Figura II.8.b - Frequência relativa dos diferentes níveis de gosto pela coleta de murumuru nas sete localidades.

\section{M. flexuosa - buriti}

de -1 a -4 = não gosta de coletar.

$$
0=\text { indiferente. }
$$

de 1 a 4 = gosta de coletar.

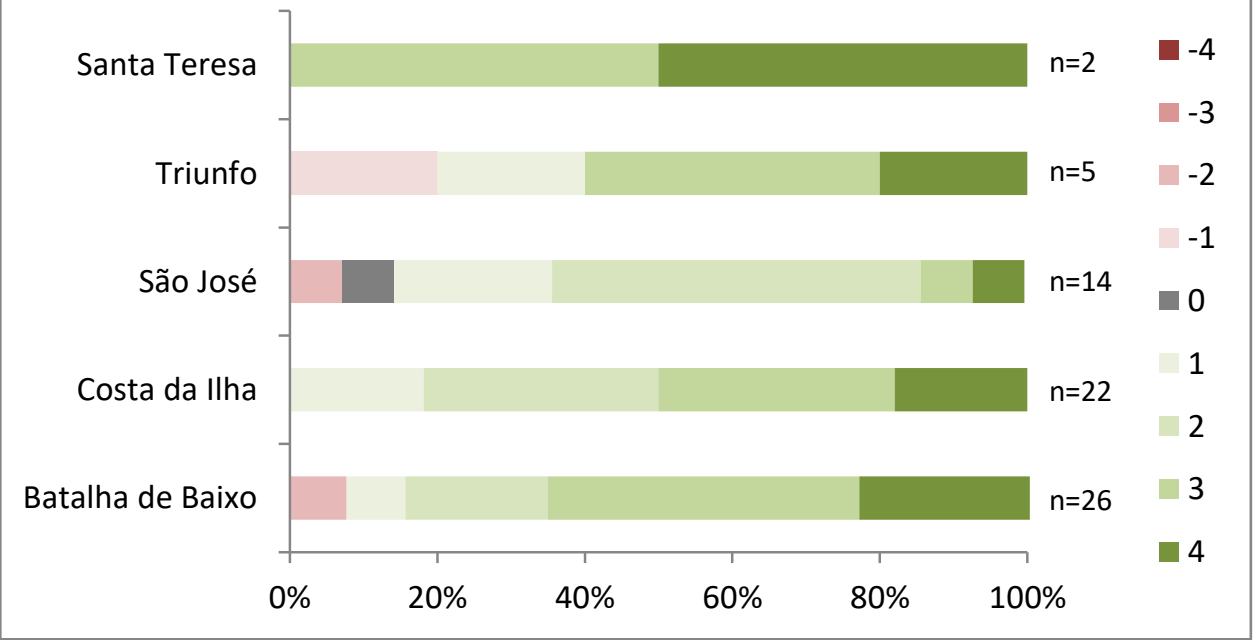

Figura II.8.c - Frequência relativa dos diferentes níveis de gosto pela coleta de buriti nas sete localidades. 


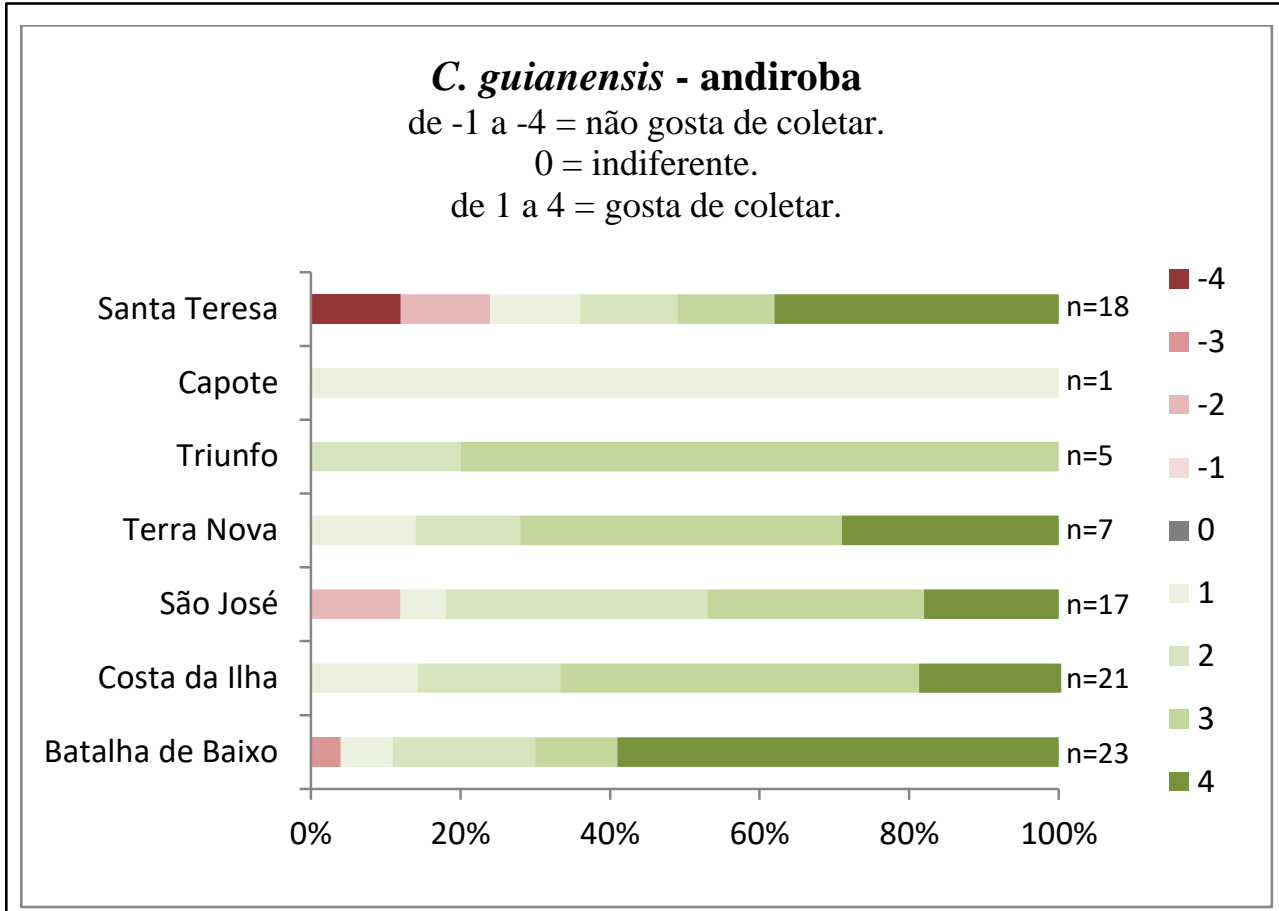

Figura II.8.d - Frequência relativa dos diferentes níveis de gosto pela coleta de andiroba nas sete localidades.

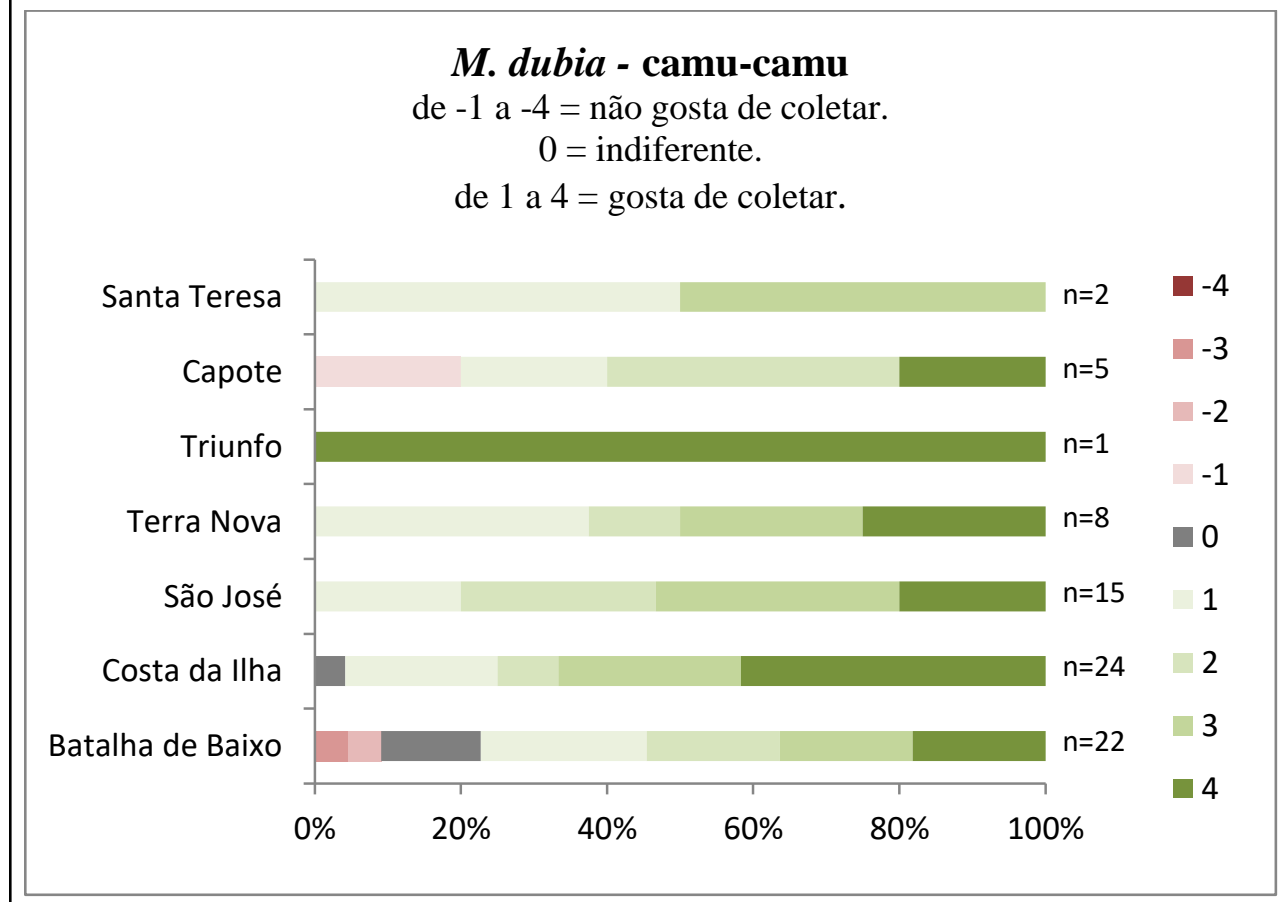

Figura II.8.e - Frequência relativa dos diferentes níveis de gosto pela coleta de camucamu nas sete localidades.

Figura II.8 - Frequência relativa dos diferentes níveis de gostar (i.e. de -4 a 4) para a coleta dos cinco PFNM nas sete localidades. $\mathrm{N}=$ número de indivíduos que declararam gosto pela coleta. 


\section{II.5.Associação dos fatores socioeconômicos e de percepção com o interesse}

A seguir são apresentados os resultados das regressões logísticas multinível, considerando a associação dos fatores socioeconômicos, culturais e de percepção, com o interesse em coletar os cinco PFNM de importância econômica (tabela II.2).

Tabela II.2 - Resultados das regressões multinível da associação dos fatores socioeconômicos e de percepção, com o interesse em coletar os cinco PFNM de importância econômica.

\begin{tabular}{|c|c|c|c|c|c|}
\hline \multirow[b]{2}{*}{ Variáveis } & \multicolumn{5}{|c|}{ Interesse do indivíduo em coletar } \\
\hline & $\begin{array}{l}\text { Açaí } \\
\beta \text { (E.P.) }\end{array}$ & $\begin{array}{l}\text { Murumuru } \\
\beta \text { (E.P.) }\end{array}$ & $\begin{array}{l}\text { Buriti } \\
\beta(\text { E.P.) }\end{array}$ & $\begin{array}{l}\text { Andiroba } \\
\beta \text { (E.P.) }\end{array}$ & $\begin{array}{l}\text { Camu-camu } \\
\beta \text { (E.P.) }\end{array}$ \\
\hline Consumo & 0 (omitido) & $0,623(1,002)$ & $0,106(1,193)$ & $-0,440(0,627)$ & $-0,572(0,650)$ \\
\hline Venda & $0,429(0,582)$ & $0,369(0,817)$ & $0,644(0,508)$ & $0,385(0,509)$ & $0,312(0,563)$ \\
\hline Gosto pela coleta & $1,017^{* * *}(0,206)$ & $1,304^{* * *}(0,325)$ & $1,521^{* * *}(0,257)$ & $1,916^{* * *}(0,286)$ & $1,063^{* * *}(0,190)$ \\
\hline Renda total & $0,000(0,000)$ & $-0,000^{*}(0,000)$ & $-0,000(0,000)$ & $0,000(0,000)$ & $-0,000(0,000)$ \\
\hline Riqueza & $-0,000^{* *}(0,000)$ & $0,000^{*}(0,000)$ & $0,000(0,000)$ & $-0,000(0,000)$ & $0,000(0,000)$ \\
\hline Escolaridade & $-0,048(0,078)$ & $0,133(0,134)$ & $0,012(0,100)$ & $0,009(0,067)$ & $-0,009(0,070)$ \\
\hline Wald $\operatorname{chi}^{2}(13)$ & 27,57 & 22,08 & 37,94 & 46,51 & 32,99 \\
\hline Prob. $>$ chi $^{2}$ & 0,000 & 0,001 & 0,000 & 0,000 & 0,000 \\
\hline $\mathrm{N}$ & 69 & 35 & 69 & 86 & 77 \\
\hline
\end{tabular}

Nota: $* \mathrm{p}<0,10 ; * * \mathrm{p}<0,05 ; * * * \mathrm{p}<0,01$

Para todos os produtos, o gosto pela coleta (fator de percepção) esteve positivamente associado ao interesse em coletar, ou seja, quanto maior o gosto do indivíduo pela coleta, maior seu interesse em coletar: andiroba $(\beta=1,916$; $p<0,01)$, açaí $(\beta=1,017$; $p<0,01)$, camu-camu $(\beta=1,063 ; \mathrm{p}<0,01)$, murumuru $(\beta=1,304 ; \mathrm{p}<0,01)$, buriti $(\beta=1,521 ; \mathrm{p}<$ $0,01)$.

Além do gosto, a renda total e a riqueza da unidade doméstica (fatores socioeconômicos) também estiveram associadas ao interesse em coletar, porém apenas em dois casos: açaí e murumuru, sendo que em ambos a intensidade da associação foi nula. Para o açaí existe uma fraca tendência de que quanto maior a riqueza da unidade doméstica, em termos de bens de patrimônio doméstico e equipamentos de trabalho, menor o interesse em coletar açaí $(\beta=-0,000 ; p<0,05)$. Da mesma forma, para o murumuru, existe uma fraca tendência de que quanto maior a renda total e a riqueza da unidade doméstica, menor o interesse em coletar $(\beta=-0,000 ; p<0.10)$.

Para os outros produtos, nenhum dos fatores investigados, exceto o gosto, esteve associado de maneira significativa ao interesse das pessoas em coletá-los. 


\section{II.6. Capacidade, aptidão e habilidade de coleta}

As unidades domésticas entrevistadas possuem em média sete indivíduos (entre adultos e crianças), dos quais quatro, em média (D.P.=2), costumam coletar diferentes PFNM, incluindo os frutos de importância comercial avaliados. Considerando ainda as pessoas que não têm o costume de coletar, mas que poderiam fazê-lo se quisessem, cada unidade doméstica possui em média cinco pessoas aptas a coletar PFNM em geral, ou seja, a maior parte dos membros das unidades.

A maioria dos indivíduos entrevistados considera-se apta (consegue) a coletar os cinco PFNM de importância comercial, já que no máximo $41 \%$ dos entrevistados nunca coletaram (e nunca conseguiram coletar) determinado produto por motivos como, incapacidade ou medo de subir na árvore, algum problema de saúde, falta de tempo ou por não reconhecer a espécie ou seu local de ocorrência (figura II.10).

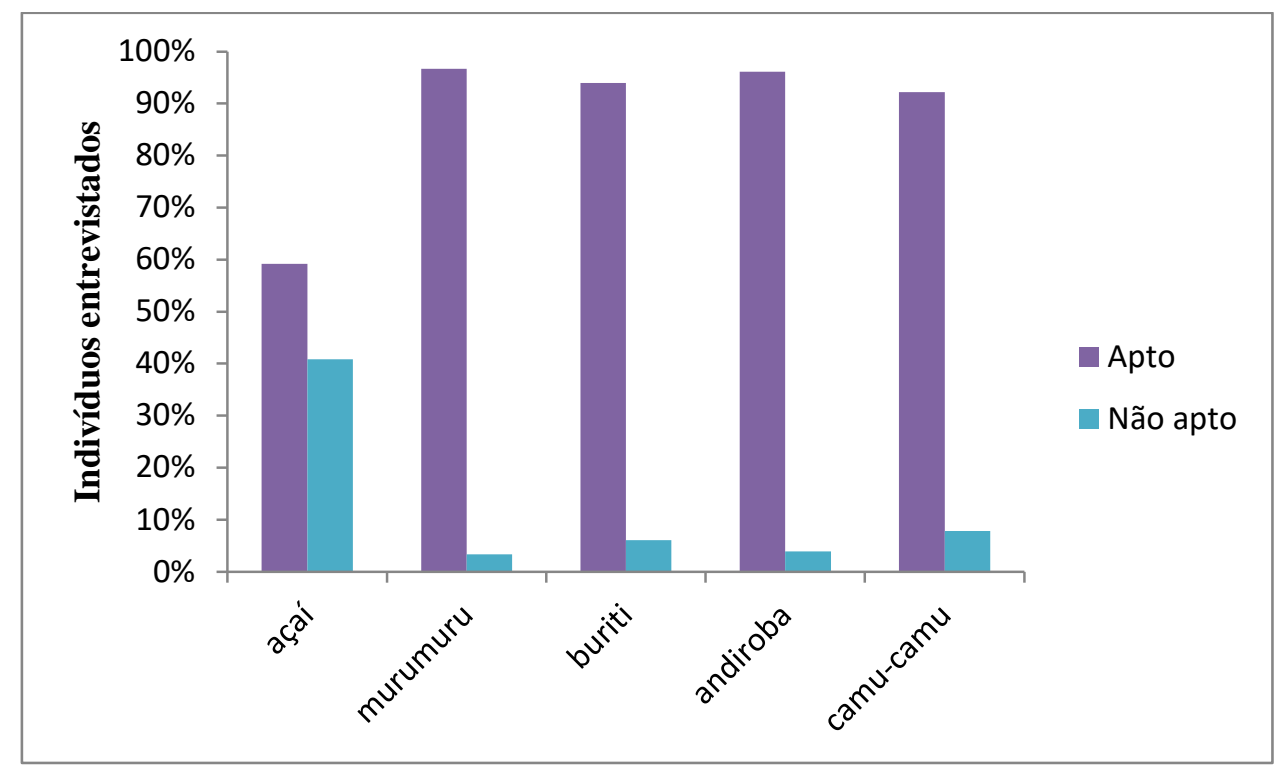

Figura II.10 - Proporção de indivíduos aptos e não aptos a coletar os cinco PFNM de importância comercial avaliados.

Na percepção dos entrevistados, a capacidade de coleta, estimada pelo número de latas (18 litros) que eles acreditam que podem coletar em um ano de boa produção de frutos e sementes, variou fortemente. A maior variação encontrada foi para o buriti, cuja capacidade variou de 2 a 3.000 latas por pessoa, com valor médio de 130,4 latas, o que corresponde a um valor monetário aproximado de $\mathrm{R} \$ 3.650,00$ ao ano, conforme o preço do quilo no mercado de Fonte Boa em 2014. Para os outros PFNM a variação também foi grande: açaí, de 2 a 1.200 latas, com média de 99,2 latas ( $\$$ \$1.984,00); murumuru, de 1 a 600 latas, com média de 70,9 
latas ( $\mathrm{R} \$ 496,30)$; andiroba, de 1 a 200 latas, com média de 26,7 latas ( $\mathrm{R} \$ 187,00)$; e camucamu, de 1 a 200 latas, com média de 16,4 latas (R \$574,00) (figura II.11).

Em média os homens declararam ter maior capacidade de coleta que as mulheres, sendo que para alguns produtos, como buriti, os homens declararam serem capazes de coletar uma quantidade seis vezes maior do que as mulheres (figura II.12).

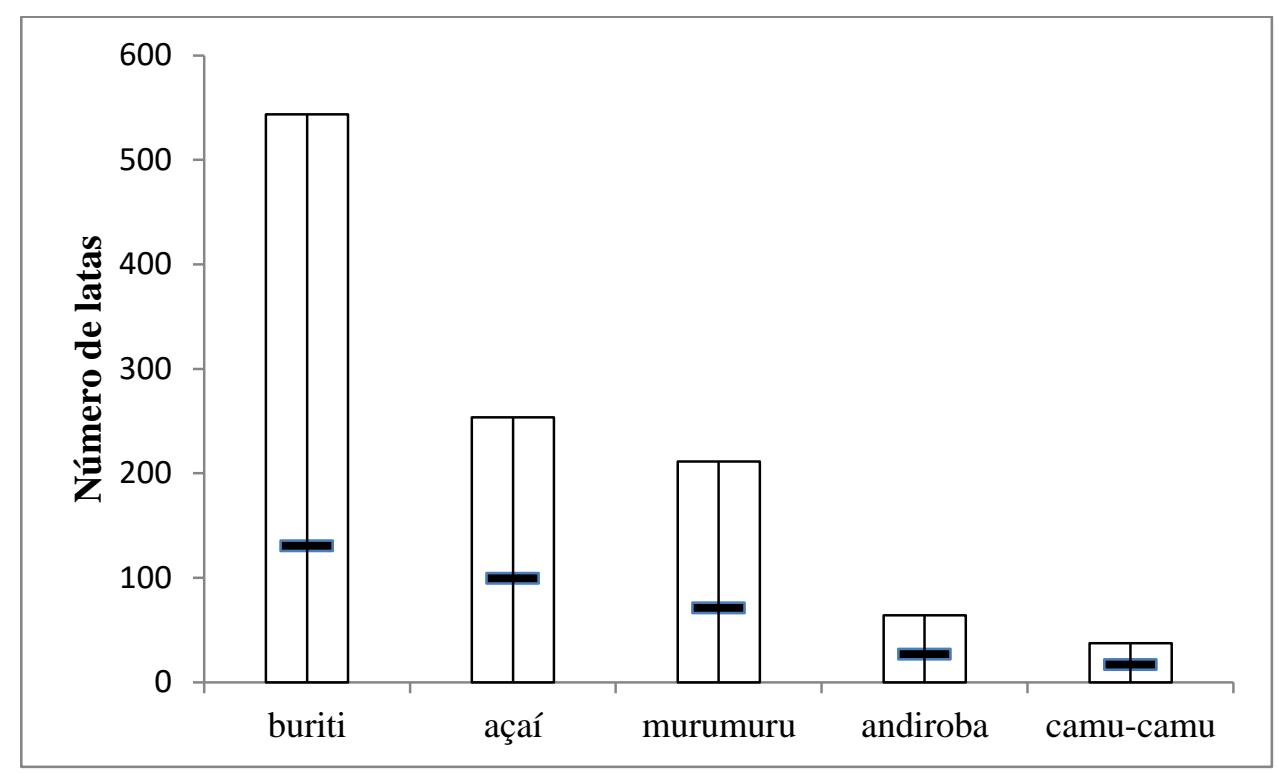

Figura II.11 - Variação da capacidade dos indivíduos em coletar os cinco PFNM avaliados.

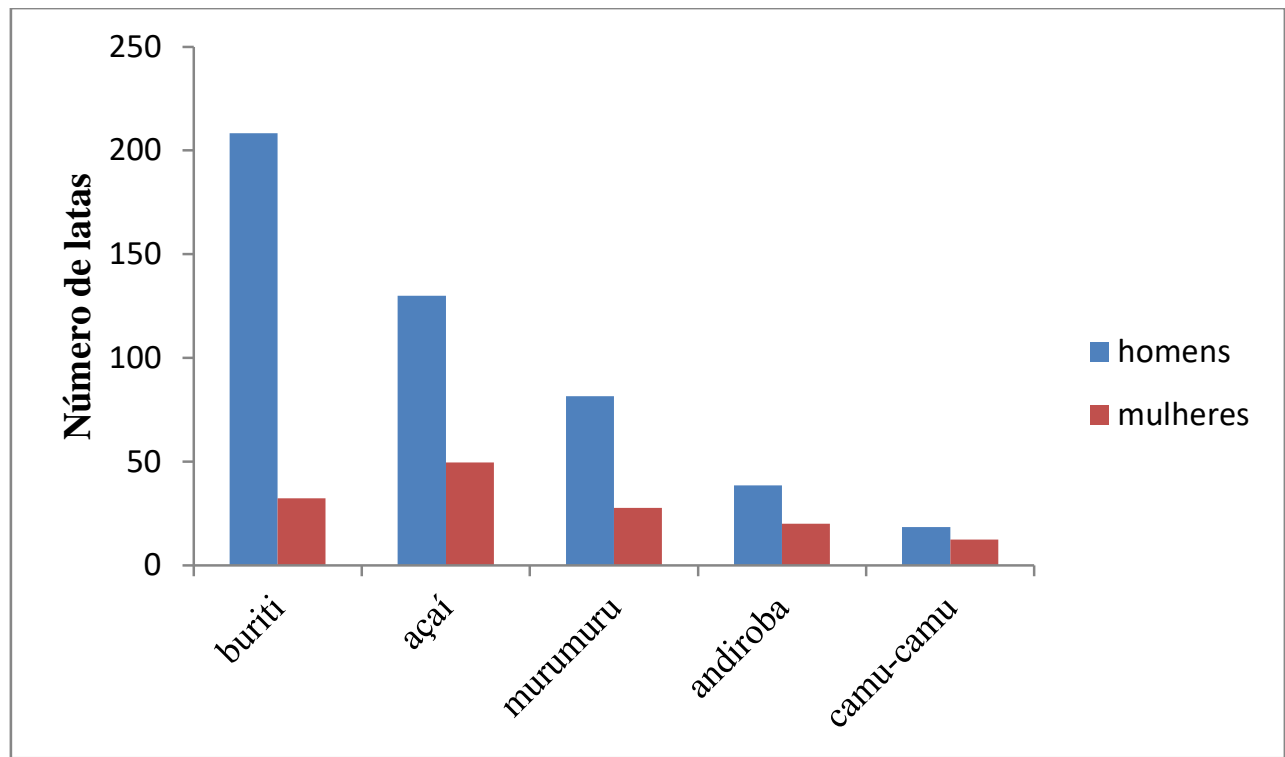

Figura II.12 - Capacidade de coleta de homens e mulheres estimada pelo número médio de latas.

Considerando o número de latas coletadas durante o último período de produção de frutos e sementes anterior à entrevista, as quantidades médias foram até 15 vezes inferiores do que a capacidade estimada por indivíduo, como no caso do buriti e murumuru (figura II.13). 
Possivelmente, parte dessa diferença se atribui ao fato de que as pessoas dedicam parte do seu tempo a outras atividades, tendo coletado somente a quantidade desejada e não aquela correspondente a sua capacidade. Além disso, a quantidade de frutos e sementes disponíveis para coleta em 2014 pode ter sido baixa, já que até $65 \%$ dos entrevistados acharam que este não foi um ano bom de produção (i.e. no caso do açaí), ou seja, as árvores não produziram muitos frutos e sementes (figura II.14).

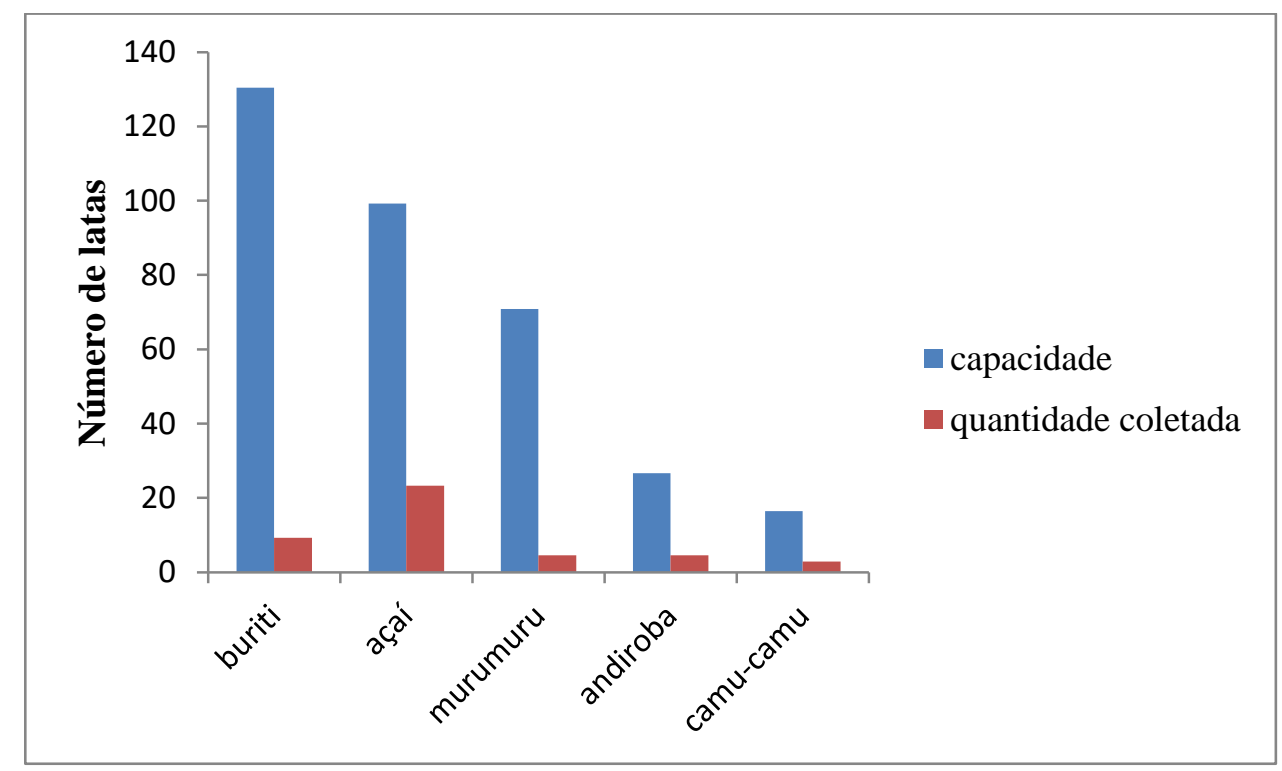

Figura II.13 - Diferença entre capacidade de coleta e quantidade coletada por produto.

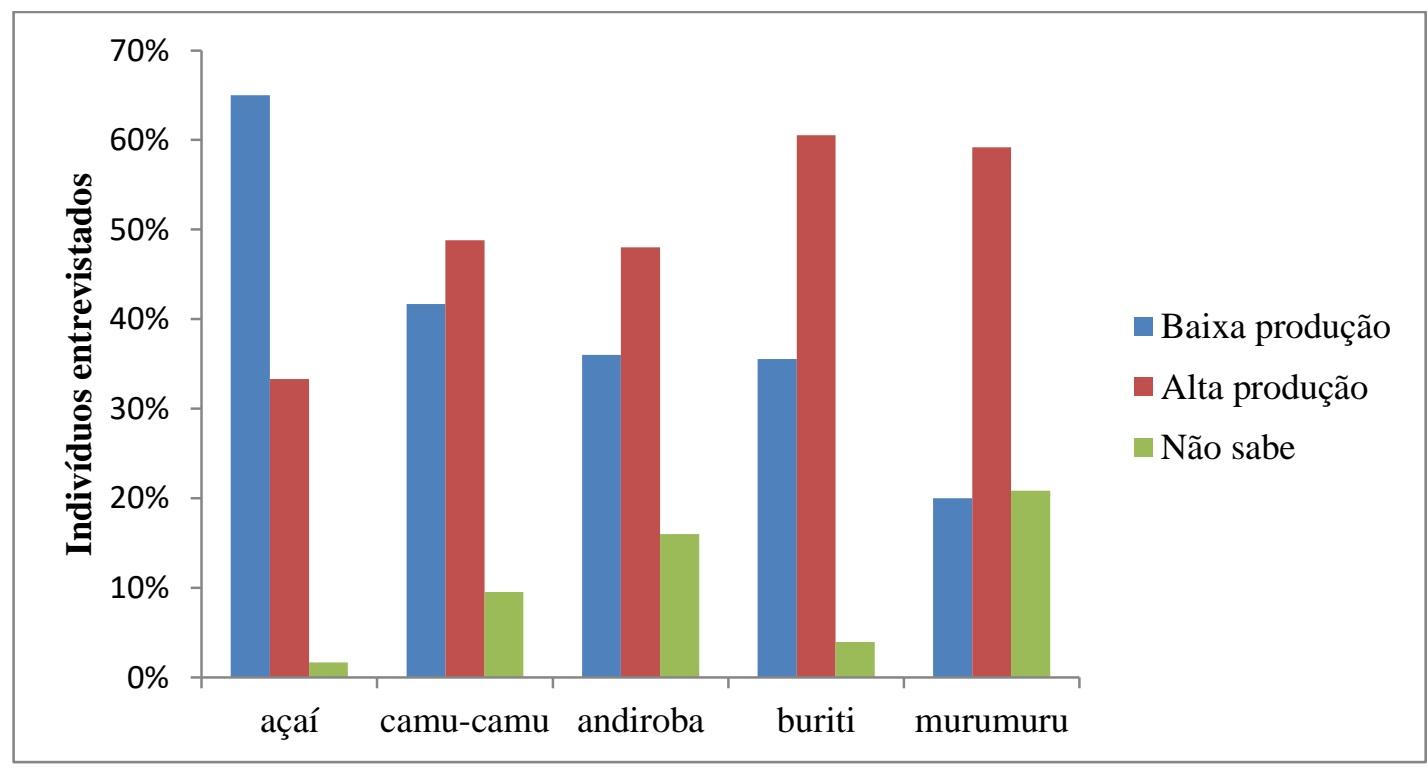

Figura II.14 - Percepção sobre a quantidade de frutos e sementes produzidos pelas árvores em 2014.

Todos os produtos avaliados já foram coletados pela maior parte dos entrevistados, com exceção do murumuru, já coletado por apenas $28 \%$ dos indivíduos. Andiroba e buriti, já 
foram coletados por respectivamente $85 \%$ e $83 \%$ dos indivíduos entrevistados; camu-camu por $75 \%$; e açaí por pouco mais da metade dos indivíduos (56\%), lembrando que neste caso este valor equivale apenas às pessoas que sobem nas palmeiras para coletar os frutos.

Além de coletados separadamente, os PFNM também podem ser coletados em conjunto. Perguntados sobre quais dos cinco produtos poderiam ser coletados no mesmo dia, isto é, durante um mesmo evento de coleta, os entrevistados responderam quais seriam as possíveis combinações de coleta e ou os motivos pelos quais não seria possível coletar determinado produto em conjunto com outro. Ao todo, foram identificadas 19 combinações entre os cinco produtos, sendo as mais comuns: açaí e camu-camu, citado por $22 \%$ dos entrevistados, murumuru e açaí (12\%), açaí, buriti e camu-camu, e açaí e buriti (ambas 8\%). As outras combinações foram citadas por no máximo $6 \%$ dos entrevistados. Contudo, a proporção de indivíduos entrevistados que acredita não ser possível coletar os produtos em conjunto é superior à proporção dos que relataram as possíveis combinações: $68 \%$ dos entrevistados que coletariam murumuru só coletariam este produto em um dia; para andiroba, camu-camu, buriti e açaí os valores foram $60 \%, 30 \%, 29 \%$ e $28 \%$, respectivamente (figura II.15).

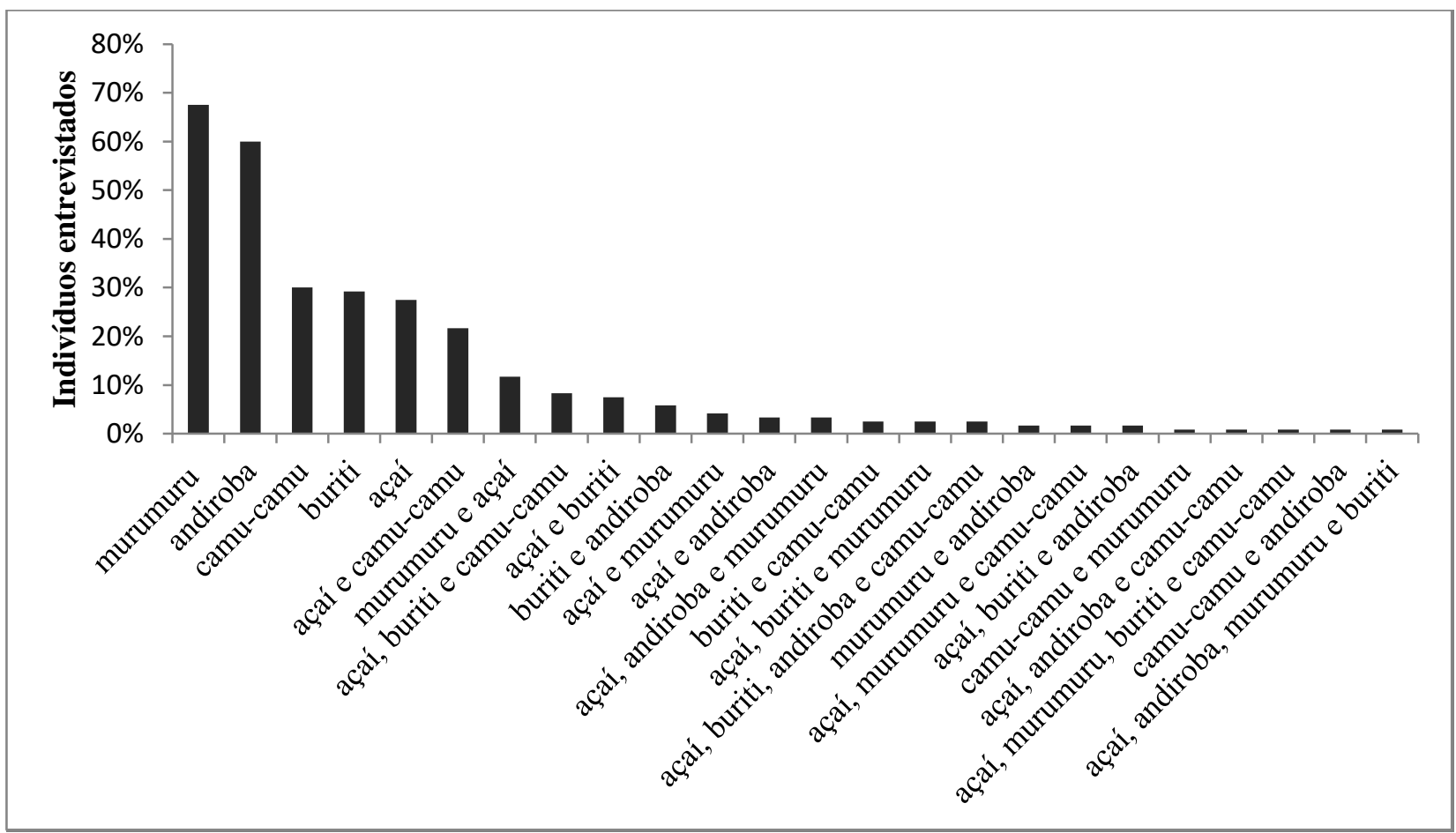

Figura II.15 - Possíveis combinações de coleta dos PFNM, segundo os entrevistados.

Os motivos pelos quais se acredita não ser possível coletar os produtos em conjunto no mesmo dia incluem: a grande distância entre a casa do coletor e a área onde o produto pode 
ser coletado; o elevado tempo gasto na coleta de um produto; as dificuldades para carregar o produto na mata; a não coocorrência com os outros produtos; e a não coincidência quanto à época em que os produtos estão disponíveis para a coleta.

O tempo médio gasto na coleta de uma lata (18 litros) variou em até cerca de duas vezes entre os produtos, sendo camu-camu aquele que demanda o maior tempo médio (53 minutos) e açaí o menor (20 minutos), de acordo com a percepção dos entrevistados (figura II.16).

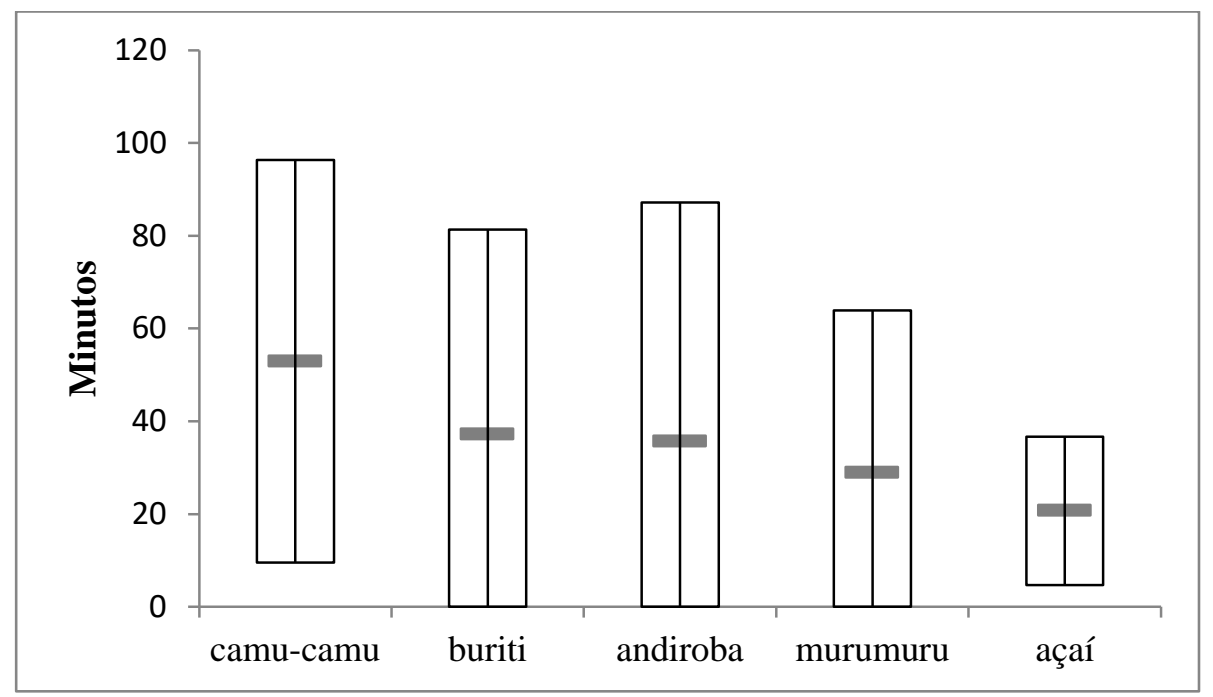

Figura II.16 - Tempo médio gasto na coleta de uma lata de cada PFNM.

Não há grande diferença entre homens e mulheres quanto ao tempo médio gasto para coletar uma lata dos PFNM, sendo que para alguns produtos, como camu-camu e buriti as mulheres demoram ligeiramente menos tempo, enquanto para outros (murumuru e açaí) os homens demoram um pouco menos, conforme a percepção dos entrevistados (figura II.17).

Quanto à frequência com que os entrevistados coletam PFNM, incluindo os cinco de importância comercial, cerca de metade dos entrevistados (53\%) declarou coletar no máximo uma vez por mês, enquanto $47 \%$ costumam coletar com mais frequência, isto é, ao menos a cada 15 dias (figura II.18). 


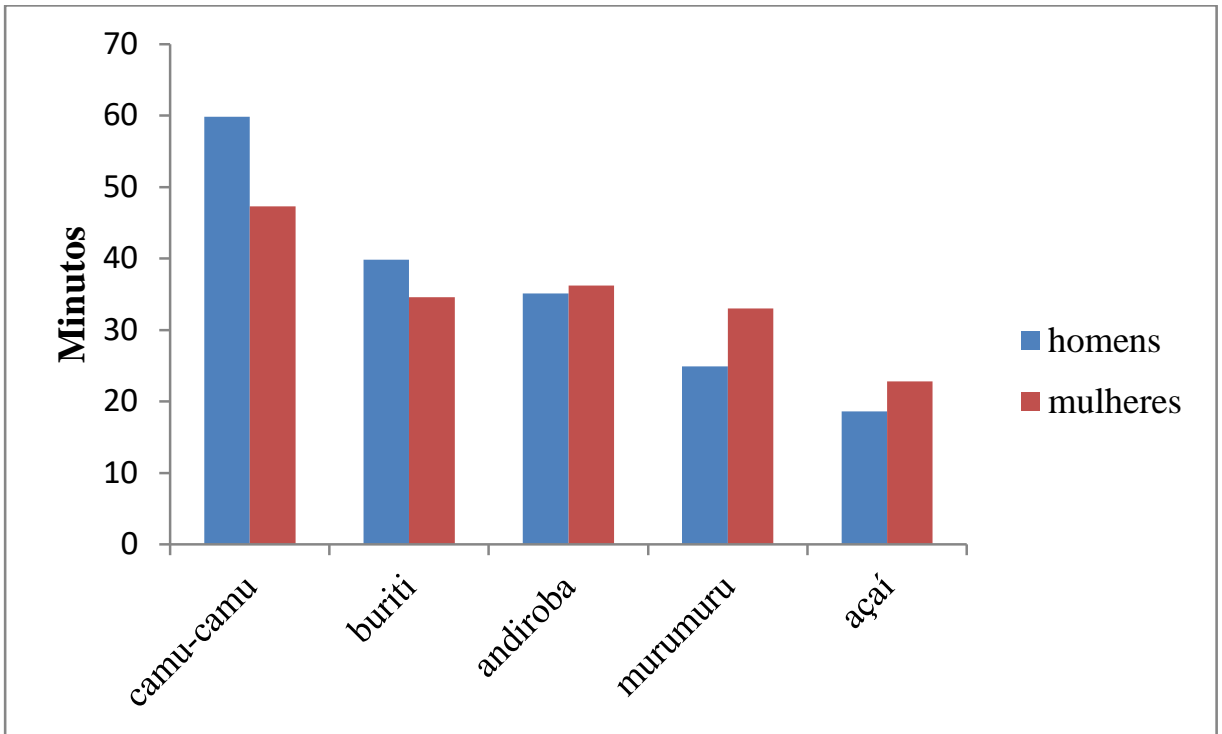

Figura II.17 - Tempo médio gasto por homens e mulheres na coleta de uma lata de cada PFNM.

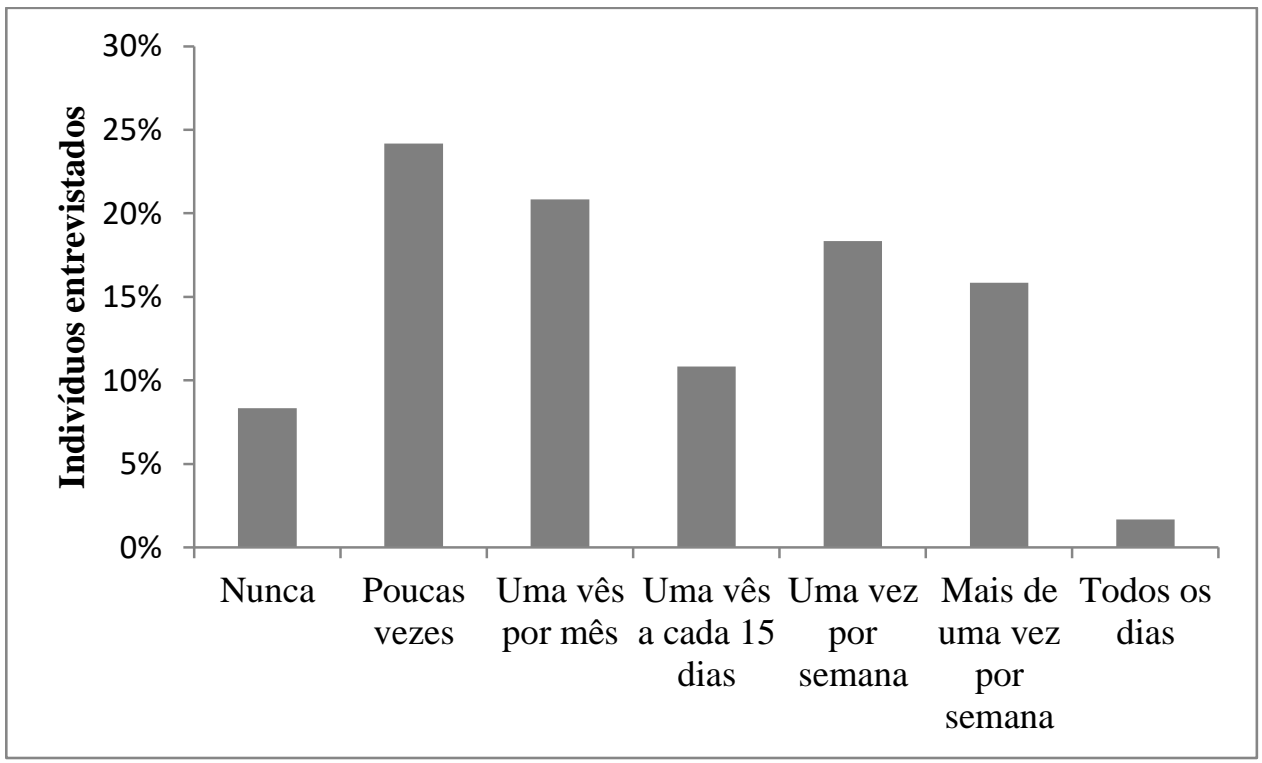

Figura II.18 - Frequência com que os entrevistados se dedicam à coleta dos PFNM. 


\section{CAPÍTULO III - DISCUSSÃO E CONCLUSÕES}

Este capítulo apresenta, em três partes, a discussão dos resultados encontrados. A primeira, discute os resultados obtidos quanto à disponibilidade (ocorrência e abundância) e o potencial econômico dos PFNM fornecidos pelas cinco espécies de importância comercial avaliadas na região das sete localidades alvo da pesquisa. Além disso, discute como os fatores ambientais podem estar relacionados às disponibilidades encontradas. A segunda parte discute os resultados obtidos quanto ao interesse dos indivíduos em coletar os cinco PFNM e sua associação com fatores socioeconômicos das unidades domésticas, e de percepção dos indivíduos. A terceira, discute os resultados obtidos sobre a capacidade, aptidão e habilidade das pessoas de coletar os produtos. Por último, são apresentadas as conclusões finais.

\section{III.1. Discussão dos principais resultados encontrados}

\section{III.1.1. Disponibilidade e potencial econômico dos PFNM}

Os resultados sobre a disponibilidade dos cinco PFNM avaliados neste estudo demonstraram que tanto a ocorrência das espécies de árvores e palmeiras investigadas, quanto a abundância dos indivíduos dessas espécies variaram entre as sete localidades amostradas da RDS Mamirauá.

A ocorrência ou número de espécies, que variou de dois a cinco entre as localidades, pode ser a primeira limitação para a exploração de múltiplos PFNM e consequentemente para alcançar os benefícios dessa atividade, como por exemplo, a geração de renda monetária. A presença de apenas uma ou duas espécies em uma determinada localidade pode representar menores condições de se adaptar às oportunidades, ameaças e riscos do mercado, quando comparada a uma maior diversidade de produtos disponíveis (CLAY; CLEMENT, 1993). Em localidades onde as pessoas dependem de poucos produtos para obtenção de renda monetária, flutuações temporárias ou mudanças permanentes na demanda desses produtos podem acarretar grandes decréscimos na renda (PENROSE, 2006).

Dentre as cinco espécies investigadas, E. precatoria e A. murumuru foram as únicas que ocorreram em todas as localidades. De acordo com estudos prévios, ambas estão entre as espécies mais comuns dentre a comunidade de palmeiras da Amazônia, ocorrendo tanto em terrenos mais elevados, como em planícies e em diferentes estratos da várzea (várzea alta e várzea baixa) (JARDIM; VIEIRA, 2001; ROCHA, 2002; ASTURIZAGA, 2005). Já M. 
flexuosa foi a menos frequente entre as três palmeiras estudadas, tendo sido encontrada somente em três localidades, sendo que em uma destas foi registrado apenas um indivíduo na amostra, o que obviamente não representa um potencial econômico significativo para esta localidade. Dentre as duas espécies arbóreas estudadas C. guianensis foi a mais frequente, tendo ocorrido na área de três localidades. E de fato, como apontado por outros estudos, essa espécie, que ocorre em toda a América Central e região amazônica, é frequente em locais alagados ou periodicamente inundados, como a várzea (BOUFLEUER, 2004; MELLINGER, 2006). Já $M$. dubia foi a mais rara entre as espécies estudadas, tendo sido registrada em apenas duas localidades, sendo que em uma delas foi amostrado um único indivíduo, não representando, neste caso, um potencial econômico significativo. A raridade desta espécie pode ser explicada por ela ocorrer preferencialmente em ambientes mais restritos das florestas de várzea, como margens de lagos e igarapés onde a altura de inundação atinge entre seis e oito metros (WITTMANN et al., 2010).

Interessante notar que foi nas áreas onde o açaí seria coletado para comercialização por ocorrer em maiores quantidades segundo os habitantes, que coocorreram mais espécies, isto é, as outras quatro investigadas. Isso sugere, portanto, que nessas áreas a coleta de múltiplos PFNM seria favorecida, ao menos em termos de diversidade de produtos. De maneira semelhante, as áreas de maior concentração de A. murumuru, assim como de $M$. flexuosa e $C$. guianensis, também apresentaram diversidade de espécies, com a coocorrência de outras três em cada caso. Em contraste, na área amostrada onde $M$. dubia ocorre em maiores quantidades segundo os habitantes, nenhuma das outras quatro espécies foi encontrada, sugerindo que locais de maiores concentrações desta espécie não são favoráveis para a coleta de múltiplos PFNM, ao menos para os outros quatro produtos investigados. Por outro lado, no transecto alocado nessa área foi observada alta concentração de indivíduos (83), a quinta maior dentre os 24 transectos estabelecidos, o que em termos de potencial econômico poderia compensar a falta de diversidade encontrada, já que uma grande quantidade de frutos poderiam ser produzidos no local e, portanto, coletados.

Entretanto, considerando todos os transectos amostrados, com suas respectivas parcelas, a abundância das espécies estudadas foi baixa, com a presença de no máximo cinco árvores e ou palmeiras em mais da metade das parcelas. Esses valores representaram uma densidade de no máximo 100 indivíduos.ha ${ }^{-1}$, cerca de seis vezes inferior à densidade de árvores e palmeiras das florestas de várzea, que chega a mais de 600 indivíduos.ha ${ }^{-1}$ (WITTMANN et al., 2011). Mesmo assim, em menor porção das parcelas amostradas (cerca de $20 \%$ ), estiveram presentes de 10 a 28 indivíduos, o que representa uma densidade de até 
560 indivíduos.ha ${ }^{-1}$. Essa estimativa evidencia a distribuição agregada, que é comum para essas espécies (PETERS; VASQUEZ, 1987; BECK; TERBORGH, 2002; ROCHA, 2002; KLIMAS et al., 2007; MACÍA, 2011). Esse padrão de distribuição, por sua vez, pode ser vantajoso para acessar os PFNM, porque sua concentração facilita as atividades de manejo, como abertura de menos trilhas, assim como a coleta dos frutos ou sementes (KLIMAS et al., 2007).

Nas sete localidades, as maiores concentrações, ou seja, as maiores abundâncias das árvores e palmeiras investigadas parecem ocorrer na várzea alta, pois a maior altura de inundação registrada dentre os 24 transectos amostrados foi por volta três metros. Contudo, a variação encontrada entre as abundâncias médias das espécies foi grande entre as localidades, que também apresentaram valores médios diferentes de altura de inundação, assim como dos outros fatores ambientais avaliados (radiação solar e matéria orgânica disponível no solo). Nota-se, portanto, que existem diferenças na distribuição de espécies dentro de uma mesma tipologia florestal da várzea, que podem ser atribuídas, ao menos em parte, aos fatores ambientais. Em outras palavras, as condições ambientais ótimas para o estabelecimento, sobrevivência e reprodução dos indivíduos (parâmetros relacionados à abundância) parecem ser diferentes pra cada espécie, ao menos no que diz respeito aos três fatores ambientais avaliados. As parcelas que apresentaram menores alturas médias de inundação e profundidade de folhiço, e maior abertura de dossel foram as que tiveram maior abundância de M. flexuosa, mas não a maior abundância das outras espécies, enquanto os maiores valores médios de altura de inundação e profundidade do folhiço, bem como a menor abertura de dossel foram observados nas parcelas de maior abundância de $M$. dubia, onde só foi encontrada esta espécie. Já E. precatoria e A. murumuru, que foram as espécies mais abundantes em todas as localidades estudadas, ocorreram em maiores concentrações em locais cujos valores médios de altura de inundação, profundidade de folhiço e abertura de dossel estimados foram intermediários, em comparação com os valores estimados nas áreas de maior abundância das outras três espécies.

Porém, os fatores ambientais parecem não ser os únicos responsáveis pela distribuição das cinco espécies investigadas. Um estudo sobre o padrão de distribuição e abundância da comunidade de plantas lenhosas de toda a bacia amazônica constatou que 227 espécies são tão comuns que juntas congregam metade de todas as plantas lenhosas da Amazônia, enquanto que as 11.000 espécies mais raras congregam somente $0,12 \%$ dessas plantas. De acordo com esse estudo, duas das espécies aqui investigadas, E. precatoria e A. murumuru, estão entre as dez espécies mais abundantes da Amazônia, sendo E. precatoria a mais abundante entre 
todas. Segundo os autores, a hiperdominância de poucas espécies (poucas em relação à riqueza do bioma) pode ser resultado não somente de sua capacidade de competição, mas também de seu amplo cultivo, realizado por populações pré-colombianas (anteriores ao ano de 1492) (TER STEEGE et al., 2013). Esses antigos habitantes da região muitas vezes decidiam quais árvores ou palmeiras deveriam crescer e onde isso deveria ocorrer, de maneira que mesmo aquelas florestas encontradas na atualidade que são aparentemente virgens, ou seja, sem interferência humana, podem ser na verdade florestas culturais ou antropogênicas, resultantes do manejo de povos antigos que favoreciam as espécies que lhes eram mais úteis, ao fornecer, por exemplo, alimento (BALÉE; ERICKSON, 2006).

A taxa anual de produção de frutos e sementes variou bastante entre as espécies e até mesmo entre indivíduos da mesma espécie. Dessa forma, a estratégia de explorar múltiplos PFNM pode ser vantajosa, pois mesmo que a produção de uma espécie seja escassa em um ano, poderá haver outros produtos a serem explorados alternativamente. Além disso, produtos sazonais, como por exemplo, frutos e sementes, podem estar disponíveis em meses alternados ao longo do ano, aumentando a frequência dos eventos de coleta e consequentemente de geração de renda (MOLNAR et al., 2007). De fato, como declararam as pessoas entrevistadas sobre a sazonalidade da coleta, durante todo o ano pode haver coleta, considerando os cinco PFNM avaliados, embora os meses entre maio e junho correspondam ao melhor período para coletar quatro dos cinco produtos. Porém, nos períodos de seca, entre os meses de julho e novembro, as sementes de murumuru podem ser coletadas alternativamente aos frutos, ou às sementes de andiroba.

A produção média por palmeira estimada para as espécies $M$. flexuosa (buriti) e $E$. precatoria (açaí) esteve dentro da variação estimada por outros estudos, ou seja, 71,0 e 21,0 $\mathrm{kg}$ de frutos, respectivamente (FOOD, 1986; MEDINA, 2005; ROSA et al., 2014). Já as outras espécies apresentaram produção bastante inferior àquela encontrada em outros estudos. A produção média de sementes de murumuru (A. murumuru) estimada por palmeira $(5,2 \mathrm{~kg})$ foi cerca da metade já apontada para a espécie (MORAIS, 2015) e para andiroba $(C$. guianensis) que foi de $5,3 \mathrm{~kg}$, a diferença foi ainda maior, cerca de dez vezes inferior ao que já fora estimado para espécie, considerando as estimativas mais baixas (MEDINA, 2005). Possivelmente, os dois meses (abril e maio) em que os dados foram coletados não foram suficientes para amostrar a maior parte dos frutos e sementes produzidos por essas duas espécies (A. murumuru e C. guianensis). Mais contrastante ainda foi o caso da produção de frutos de camu-camu (M. dubia), que apesar de estudo anterior ter estimado uma produção de 
13,0 kg de fruto por indivíduo (PETERS; VASQUEZ, 1987), nenhum dos indivíduos amostrados nesse estudo frutificou.

A variação na frutificação pode estar associada tanto à composição genética dos indivíduos e aos recursos acumulados pelas plantas (água e nutrientes), quanto aos fatores externos a estas, como doenças e herbivoria, ventos e tempestades durante a floração, polinização e desenvolvimento dos frutos. Além disso, a distribuição das chuvas e temperatura pode ser responsável pela proporção de indivíduos adultos que frutificam em determinado ano (STEPHENSON, 1981; ARES; BRAUER, 2004; KAINER et al., 2007). Essa proporção não deve ser desprezada, pois como se observou neste estudo, menos da metade dos indivíduos adultos amostrados de todas as espécies frutificaram em 2014, sendo que essa proporção foi zero para a espécie $M$. dubia. Uma localidade especializada na exploração comercial somente desta espécie teria sua renda monetária seriamente prejudicada em um ano como 2014. Por isso a exploração de múltiplos PFNM pode conferir maior segurança econômica frente às flutuações naturais na produção dos frutos e sementes.

Contudo, vale reforçar que maior diversidade de espécies não garante necessariamente maior retorno financeiro, como mostraram os resultados acerca do potencial econômico da coleta dos PFNM. Na localidade que apresentou o maior potencial econômico ocorreram somente duas das cinco espécies (açaí e murumuru), sendo que os produtos ali disponíveis estão ainda entre os mais baratos dentre os cinco avaliados. Em compensação, as espécies presentes na localidade apresentaram alta abundância de indivíduos, o que indica que este fator é de grande importância para determinar o potencial econômico em certa localidade. Essa ideia pode ser reforçada pelo fato de que tanto a abundância geral das espécies, quanto os potenciais econômicos médios estimados não variaram de maneira acentuada entre as localidades, diferentemente do potencial econômico estimado por indivíduo que variou bastante entre as espécies. Essa relação entre o potencial econômico de um PFNM e a abundância de árvores de onde o produto pode ser coletado foi também observada em estudo envolvendo outra espécie que ocorre Amazônia. Árvores de copaíba da várzea apresentaram menor rendimento econômico do que as árvores da terra firme, mas a maior abundância de árvores na várzea fez com que ambos os ambientes apresentassem potenciais econômicos similares (NEWTON, WATKINSON, et al., 2012).

Considerando todos os transectos amostrados, que correspondem às áreas de grande abundância de pelo menos uma das espécies avaliadas, o potencial retorno econômico médio com a coleta dos cinco PFNM nessas áreas foi estimado em cerca de R \$ 850,00 por hectare ao ano. Isso significa que um único hectare dessas áreas de grande abundância poderia render 
aproximadamente 3\% da renda monetária média familiar anual, sem descontar os custos com a coleta e comercialização. Possivelmente esse valor pode ainda aumentar conforme se considere outras espécies além das cinco aqui avaliadas, atingindo até seis vezes essa quantia monetária (GRIMES et al., 1994). Contudo, as estimativas mais altas do potencial econômico de PFNM em floresta de várzea devem ser consideradas com cautela, porque a disponibilidade dos PFNM depende do tipo de floresta (várzea baixa ou várzea alta) (KVIST et al., 2001), e como foi visto, pode também variar dentro de um mesmo tipo. Entre as localidades estudadas, as estimativas variaram até cerca de três vezes, sendo a mais baixa em Terra Nova, com potencial médio de $\mathrm{R} \$ 442,80$ por hectare, e a mais alta em Santa Tersa, com R $\$ 1.154,60$ por hectare, lembrando que essa diferença poderia ser menor, caso os indivíduos de camu-camu, que foram abundantes em Terra Nova, tivessem frutificado em 2014.

\section{III.1.2. Interesse em coletar múltiplos PFNM de importância comercial}

O interesse dos indivíduos em coletar variou tanto quando comparados diferentes PFNM, quanto quando comparado o interesse demonstrado em diferentes localidades, considerando-se o mesmo produto. Neste último caso, a variação encontrada entre as localidades, considerando-se o interesse em coletar o mesmo produto, pode ser atribuída às diferenças na disponibilidade (ocorrência e abundância) dos produtos, pois ao se observar as localidades onde ocorreram mais espécies, nota-se que existe uma tendência das pessoas a se interessarem em coletar mais produtos, em termos de diversidade, como mostraram os resultados. Além disso, ouviu-se, frequentemente, durante as entrevistas, que a falta de interesse em coletar determinado produto era decorrente de sua baixa disponibilidade na localidade, embora não tenha havido perguntas no questionário, relacionando a falta de interesse e a abundância. Porém, seguramente a pouca disponibilidade não é o único fator associado à falta de interesse, haja vista o caso do murumuru, produto por cuja coleta houve menos interesse, mesmo sendo o segundo PFNM mais abundante em seis das sete localidades. Neste caso, a não utilização deste produto parece ser o principal motivo pela falta de interesse em coletá-lo, já que a maioria das pessoas que declarou não ter interesse em coletar murumuru, também declarou nunca ter coletado o produto por não ter costume de utilizá-lo para o consumo e nem para a venda.

Assim como observado para o murumuru, o consumo e a venda dos outros PFNM parecem também afetar a frequência com que eles são coletados e, portanto, se relacionam ao 
interesse das pessoas em coletá-los. O produto por cuja coleta houve mais indivíduos interessados, o açaí, além de ter sido o mais abundante na região de todas as localidades, é também amplamente consumido para a alimentação das pessoas, assim como foi o produto mais comercializado pelas unidades domésticas entrevistadas, como mostram os resultados das análises exploratórias. De maneira análoga, os outros PFNM apresentaram o mesmo padrão, isto é, aqueles que são mais consumidos e foram mais vendidos (andiroba, camucamu e buriti, respectivamente) correspondem aos produtos por cuja coleta houve mais pessoas interessadas. Essa relação entre consumo e venda de PFNM, e a frequência com que são coletados também já foi observada em outros estudos (e.g., VAN ANDEL, 2006; KAMANGA et al., 2009).

Aparentemente contrastando com os resultados das análises exploratórias, os resultados das análises de regressão não indicaram associação significativa entre consumo e venda dos PFNM, e o interesse em coletá-los. Porém, ao observar mais atentamente a variação do consumo de um determinado produto entre os indivíduos da amostra, percebe-se que esta variação foi pequena ou até mesmo inexistente, como no caso do açaí, em que todos os entrevistados disseram consumir. Obviamente, as análises de regressão não apontariam nenhuma associação nesses casos em que esse fator quase não variou. Quanto à venda dos PFNM, ao se excluir a variável "gosto pela coleta" dos modelos, as regressões indicaram uma associação positiva entre a venda e o interesse em coletar dois dos cinco produtos: murumuru $(1,674 ; p<0,1 ; n=120)$ e camu-camu $(0,906 ; p<0,1 ; n=94)$. Sem a variável "gosto pela coleta", mais observações puderam ser incluídas nas análises, isto é, o tamanho da amostra se tornou equivalente ao número de observações realizadas para a variável dependente (i.e., interesse) ${ }^{5}$. Ou seja, para esses dois produtos pode-se dizer que o interesse das pessoas em coletá-los aumenta de acordo com a possibilidade de comercializá-los. Aliás, foi comum ouvir dos entrevistados, em conversas informais, que havendo comprador para determinado produto, principalmente o murumuru, muitas pessoas que não o coletam ou nunca coletaram, passariam a fazê-lo com o intuito de aumentar sua renda. Já para os outros produtos, a existência de comprador parece não ser suficiente para despertar o interesse das pessoas em coletá-los, já que se trata de produtos de menor abundância (e.g., andiroba e buriti), ou que já são coletados direta ou indiretamente pela maioria dos entrevistados (açaí). Possivelmente por

\footnotetext{
5 Os modelos empregados nas análises consideraram, além do interesse em coletar, os fatores socioeconômicos e cultural das unidades domésticas, e de percepção individual, sendo este último representado pelo gosto pela coleta. Portanto, o número de observações empregadas nas análises de regressão correspondeu ao número de indivíduos que já haviam coletado determinado produto e que puderam assim declarar o quanto gostam de coletá-lo, sendo esse número inferior à quantidade de pessoas que declarou o interesse em coletar.
} 
isso, não foi identificada nenhuma associação entre o interesse e a variável "venda" nesses casos.

Já o gosto pela coleta e o interesse em coletar se mostraram associados em todos os casos (para os cinco produtos), ou seja, quanto mais se gosta da prática de coletar determinado produto, maior o interesse em coletá-lo, o que concorda com aquilo que se pôde observar empiricamente. Para três dos cinco produtos (buriti, andiroba e camu-camu), este foi o único fator que apresentou associação significativa com o interesse, quando avaliados todos os fatores em conjunto: socioeconômicos e de percepção. Já para o açaí e murumuru, a renda e riqueza da unidade doméstica também apresentaram associação significativa com o interesse, embora nesses casos tenha sido uma associação negativa. Em geral, famílias mais ricas ou de maior renda dependem menos de PFNM, o que faz com que possuam menos interesse em coletar esses produtos (DAVIDAR et al., 2008). Todavia, a intensidade dessa associação encontrada neste estudo para o açaí e murumuru foram nulas, o que aponta que o gosto pela coleta foi mais importante para determinar o interesse em coletar.

Dentre os outros fatores que inicialmente se esperava encontrar alguma associação com o interesse em coletar os PFNM, está a escolaridade do chefe da unidade doméstica. Assim como ocorre com a renda e a riqueza, famílias de menor escolaridade têm mais interesse em PFNM, pois seu status de pobreza ou de piores condições sociais faz com que elas dependam mais desses produtos para sua subsistência (WUNDER, 2001; DAVIDAR et al., 2008). Contudo, neste estudo não foi observada associação entre escolaridade e interesse em coletar os PFNM, possivelmente pelo fato dos dados de interesse e escolaridade terem sido coletados em níveis diferentes, isto é, enquanto o primeiro foi coletado no nível do indivíduo, o segundo foi no nível da unidade doméstica. Ou seja, o interesse de um indivíduo em coletar determinado PFNM pode estar associado ao seu nível educacional, mas não necessariamente ao nível educacional do chefe de sua unidade doméstica. Por último, não foi possível avaliar a associação dos fatores culturais com o interesse, já que a origem e a identidade dos chefes das unidades domésticas quase não variaram, sendo que a maioria deles nasceu e cresceu nas próprias localidades onde ainda vivem, assim como a maioria se declarou pescador ou agricultor, que são as principais atividades produtivas dos moradores da RDS Mamirauá, ao menos nas localidades estudadas. 


\section{III.1.3. Capacidade de coleta}

A maioria dos entrevistados é capaz de coletar os cinco PFNM avaliados, incluindo o açaí, cuja coleta exige necessariamente ter que subir na palmeira, o que demanda grande habilidade. Mesmo os indivíduos que nunca coletaram os três tipos de frutos diretamente das árvores ou palmeiras, já ajudaram ou costumam ajudar na atividade, sendo na debulha dos frutos dos cachos ou reunindo-os e carregando-os do local de coleta até as casas. Portanto, a coleta de PFNM é uma atividade coletiva realizada na maioria das vezes por diversos membros de uma mesma unidade doméstica.

Em se tratando da coleta de múltiplos PFNM, até quatro dos cinco produtos avaliados poderiam ser coletados em um mesmo dia, de acordo com parte dos entrevistados. No entanto, apesar das diversas combinações possíveis de coleta conjunta que foram mencionadas, a distância percorrida e o tempo gasto para coletar, as dificuldades para carregar os frutos e sementes, a não coocorrência das espécies no mesmo local, assim como diferenças na época em que os produtos estão disponíveis, fazem com que a maioria das pessoas prefira coletar um único produto por dia. No caso da distância e tempo, um indivíduo pode demorar mais de duas horas para acessar de canoa com motor rabeta a área de coleta de um produto, conforme medido em campo, sendo que esse tempo pode dobrar na época da seca, quando não é possível percorrer todo o trajeto de canoa. Quanto à coocorrência dos produtos, de fato não é comum que eles ocorram na mesma área em grandes abundâncias, exceto no caso de açaí e murumuru, conforme observado nos transectos. Sobre a época de coleta, embora todas as espécies frutifiquem especialmente durante a cheia, as sementes costumam ser coletadas na época da seca, especialmente as de murumuru que não flutuam na água.

A capacidade das pessoas coletarem, isto é, a quantidade de latas que elas conseguem coletar pode variar bastante de um indivíduo para outro, sobretudo entre homens e mulheres. Essa diferença na quantidade de produto coletada pode estar relacionada não apenas às condições físicas do indivíduo, mas também à divisão de trabalho por gênero, que é comum em comunidades como aquelas estudadas. Atividades que exigem andar na mata, e que são preponderantemente masculinas, como a caça ou a coleta de produtos, podem favorecer os homens quanto à quantidade de frutos ou sementes coletados, acentuando a diferença de capacidade que já possa existir devido a maior força física do homem (SUNDERLAND et al., 2014).

A maioria dos indivíduos amostrados acredita ser capaz de coletar quantidades significativas, principalmente naqueles anos em que as árvores e palmeiras produzem muitos 
frutos e sementes. Levando-se em conta o número médio de latas que os entrevistados estimaram ser capazes de coletar em um ano considerado por eles de boa frutificação, cada indivíduo conseguiria coletar, em média, mais de 340 latas de 18 litros por ano, tendo-se em vista os cinco PFNM de importância comercial. Em valores monetários, caso conseguissem vender essa quantidade dos produtos in natura (i.e., frutos de açaí, buriti e camu-camu, e sementes de andiroba e murumuru) pelos preços amostrados em 2014, poderiam obter mais de $\mathrm{R} \$ 6.800,00$ por ano, o que equivale a aproximadamente $20 \%$ da renda monetária anual das unidades domésticas entrevistadas. Em média, o valor adquirido com PFNM em regiões florestais da América Latina, Ásia e África, representa essa mesma proporção da renda familiar (ANGELSEN et al., 2014; SCHAAFSMA et al., 2014).

De acordo com as estimativas médias da capacidade de coleta e do potencial econômico dos cinco PFNM na região das sete localidades, para coletar a quantidade equivalente à sua capacidade, um indivíduo precisaria explorar uma área de oito hectares. Dessa forma, e considerando-se a razão entre o tamanho da área de uso e o número de habitantes das sete localidades, possivelmente o potencial econômico estimado dos cinco PFNM de importância comercial não seria explorado em sua totalidade. Porém, para obter estimativas mais confiáveis seria necessário ter um mapeamento das diferentes fitofisionomias das várzeas de Mamirauá, já que, como visto, as maiores abundâncias das espécies avaliadas ocorrem na várzea alta. Mesmo assim, ainda que uma estimativa mais precisa do potencial econômico seja inferior àquela estimada por este estudo, possivelmente os habitantes das sete localidades não conseguiriam explorar todo o potencial, pois como mostraram os resultados, as pessoas normalmente não coletam toda a quantidade de que são capazes.

É comum haver entre os habitantes, pessoas que não conseguem subir nas árvores e ou palmeiras, ou que não reconhecem determinadas espécies de importância comercial, assim como as áreas onde elas ocorrem. Além disso, dificilmente todos os habitantes dessas localidades teriam disponível o tempo necessário para coletar as quantidades que declararam ser capazes. Como mostraram os resultados, o tempo médio gasto para coletar uma lata dos PFNM, segundo os entrevistados, é de cerca de 35 minutos, sem considerar o tempo gasto no deslocamento entre a casa e a área de coleta, que pode demorar algumas horas, o que é comum na Amazônia (NEWTON, WATKINSON, et al., 2012). Entretanto, como as abundâncias das árvores e palmeiras variam de uma localidade para outra, assim como varia a habilidade das pessoas em coletar, algumas pessoas acreditam demorar mais de quatro horas para coletar uma única lata de determinado produto. Todavia, nem sempre esse tempo está 
disponível, ao se considerar as outras atividades realizadas pelos habitantes, tanto produtivas (e.g., pesca, roça, construção), como culturais (e.g., cultos religiosos), de lazer (e.g., festejos, torneiros de futebol) e ou educacionais (e.g., frequentar a escola). Além disso, pode-se observar que os moradores das sete localidades costumam ir pra cidade ao menos uma vez por mês para comprar produtos industrializados e ou vender sua produção, seja de pescado, de produtos da roça ou florestais, entre outros. A necessidade de frequentar a escola, pois nem todas as localidades contam com salas de aula ou professores que lecionam até o ensino médio, bem como a necessidade de acessar benefícios, como bolsa família e bolsa floresta, seguro defeso, além de salários, pensões e aposentadorias, também fazem com que muitas pessoas precisem se deslocar até a cidade com frequência. Nota-se, portanto, que esse modo de vida ribeirinho, que é comum na Amazônia, é repleto de diversas atividades, sendo a coleta de PFNM, apenas uma dentre o repertório dessas populações (ALENCAR, 2010; PERALTA; LIMA, 2014).

\section{III.2. Conclusões}

O estudo buscou investigar a viabilidade da coleta de múltiplos produtos florestais não madeireiros, e se essa coleta seria capaz de incrementar a renda monetária das unidades domésticas de sete localidades ribeirinhas em florestas de várzea da Amazônia Central. Para isso, primeiramente foi avaliada a disponibilidade de cinco tipos de produtos de importância comercial na região (frutos de açaí, buriti e camu-camu, e sementes de murumuru e andiroba). Notou-se que tanto a ocorrência das espécies fornecedoras dos produtos, quanto a abundância das árvores e palmeiras, variaram entre as localidades, sendo que apenas duas espécies $(E$. precatoria e A. murumuru) são abundantes em todas as localidades. Além disso, como os produtos avaliados correspondem a frutos e sementes, sua disponibilidade também varia de acordo com a frutificação das espécies, e como mostraram os resultados, a frutificação pode ser baixa em determinado ano, com poucos indivíduos adultos produzindo frutos e sementes. Portanto, a disponibilidade de PFNM pode ser o primeiro fator limitante para geração de renda monetária com a coleta de múltiplos PFNM, pois nem todos os produtos que têm importância comercial estão disponíveis em todas as localidades estudadas.

Apesar das diferenças encontradas quanto à ocorrência das espécies nas localidades, a maior variedade de produtos disponíveis não implicou necessariamente em maiores potenciais econômicos. Observou-se que a grande abundância de indivíduos produtivos de uma espécie pode compensar a baixa variedade de produtos, pois localidades que apresentaram poucas 
espécies, porém abundantes, tiveram potencial econômico semelhante ou superior a localidades onde havia mais espécies em menores quantidades. As maiores abundâncias foram encontradas na várzea-alta, mesmo assim, variações na topografia, na quantidade de matéria disponível no solo e na radiação solar nesse tipo de ambiente parecem afetar a concentração dos indivíduos das espécies, que possuem distribuição agregada. Enquanto determinadas palmeiras se concentram em locais onde a altura de inundação e profundidade do folhiço são menores, e quantidade de clareiras é maior, certas árvores se concentram em locais mais sombreados, onde a altura de inundação e profundidade do folhiço são maiores.

Outro fator importante para o sucesso da estratégia de se explorar múltiplos PFNM, que também foi avaliado, foi o interesse das pessoas em coletar os produtos. Em todas as localidades, a maioria dos indivíduos declarou interesse em coletar os cinco PFNM pesquisados, exceto o murumuru. Neste caso, como se trata de um produto ainda pouco utilizado ou vendido, a maioria dos indivíduos não demostrou interesse em coletá-lo. Os resultados mostraram que além das pessoas terem mais interesse em coletar os produtos que são mais consumidos e vendidos, o gosto pela coleta também é importante. Gostar de coletar alguns produtos em detrimento de outros interfere na decisão dos indivíduos em desenvolver a atividade. Já a renda e riqueza das unidades domésticas, apesar de estarem relacionadas negativamente com o interesse dos indivíduos em coletar, foram menos importantes em determiná-lo.

Por último, a capacidade, aptidão e habilidade das pessoas coletarem também podem interferir na viabilidade de se explorar múltiplos PFNM, pois ainda que os produtos estejam disponíveis e exista interesse em explorá-los, eles somente trarão benefícios econômicos se as pessoas conseguirem coletá-los para o consumo e ou venda. A maioria dos indivíduos das sete localidades é apta a coletar todos os produtos avaliados, apesar das dificuldades envolvidas na coleta, como ter que se deslocar pela mata, subir nas árvores ou palmeiras e carregar os produtos coletados até em casa. No entanto, observou-se que normalmente as pessoas não coletam toda a quantidade de produto que seriam capazes, pois essa atividade é apenas uma de tantas outras praticadas por eles. Mesmo assim, ainda que os indivíduos coletassem toda a quantidade que acreditam ser capazes, o potencial econômico estimado dos cinco produtos não seria explorado em sua totalidade.

Portanto, os resultados sugerem que os principais fatores limitantes para a coleta de múltiplos PFNM nas sete localidades da RDS Mamirauá estão relacionados a pouca quantidade de árvores ou palmeiras e à falta de interesse em coletar, que é desencadeada, por 
sua vez, pela falta do gosto de coletar, assim como pelo não costume de consumir e pela dificuldade de comercializar os PFNM. 


\section{REFERÊNCIAS BIBLIOGRÁFICAS}

ALENCAR, E. F. Memórias de Mamirauá. Instituto de Desenvolvimento Sustentável Mamirauá, 2010. ISBN 8588758148.

ANGELSEN, A. et al. Environmental Income and Rural Livelihoods: A Global-Comparative Analysis. World Development, 2014. ISSN 0305-750X.

ARES, A.; BRAUER, D. Growth and nut production of black walnut in relation to site, tree type and stand conditions in south-central United States. Agroforestry systems, v. 63, n. 1, p. 83-90, 2004. ISSN 0167-4366.

ARNOLD, J. M.; PÉREZ, M. R. Can non-timber forest products match tropical forest conservation and development objectives? Ecological Economics, v. 39, n. 3, p. 437-447, 2001. ISSN 0921-8009.

AStUriZAGA, A. A. S. The Palm Community in a Terra Firme Tropical Rain Forest in the Bolivian Amazon and Factors Structuring the Beta Diversity: MSc Thesis. Department of Systematic Botany, University of Aarhus, 2005.

BALÉE, W. L.; ERICKSON, C. L. Time and complexity in historical ecology: studies in the neotropical lowlands. Columbia University Press, 2006. ISBN 0231135629.

BECK, H.; TERBORGH, J. Groves versus isolates: how spatial aggregation of Astrocaryum murumuru palms affects seed removal. Journal of Tropical Ecology, v. 18, n. 02, p. 275288, 2002. ISSN 1469-7831.

BELCHER, B.; RUÍZ-PÉREZ, M.; ACHDIAWAN, R. Global patterns and trends in the use and management of commercial NTFPs: implications for livelihoods and conservation. World Development, v. 33, n. 9, p. 1435-1452, 2005. ISSN 0305-750X.

BELCHER, B.; SCHRECKENBERG, K. Commercialisation of Non-timber Forest Products: A Reality Check. Development Policy Review, v. 25, n. 3, p. 355-377, 2007. ISSN 14677679 .

BERJANO, R. et al. A multi-year study of factors affecting fruit production in Aristolochia paucinervis (Aristolochiaceae). American Journal of Botany, v. 93, n. 4, p. 599-606, 2006. ISSN 0002-9122.

BOOT, R. G.; GULLISON, R. Approaches to developing sustainable extraction systems for tropical forest products. Ecological applications, p. 896-903, 1995. ISSN 1051-0761.

BOUFLEUER, N. T. Aspectos ecológicos de andiroba (Carapa guianensis Aublet., Meliaaceae), como subsídio ao manejo e conservação. 2004.

CARDOSO, E.; SCHIAVINI, I. Relação entre distribuição de espécies arbóreas e topografia em um gradiente florestal na Estação Ecológica do Panga (Uberlândia, MG). Revista Brasileira de Botânica, v. 25, n. 3, p. 277-289, 2002. 
CLAY, J. W.; CLEMENT, C. R. Selected species and strategies to enhance income generation from Amazonian forests. 1993.

CLAY, J. W.; PAULO DE TARSO, B. S.; CLEMENT, C. R. Biodiversidade amazônica: exemplos e estratégias de utilização. Ministerio de Ciência e Tecnologia, 2000.

CLEMENT, C. R. et al. The domestication of Amazonia before European conquest. Proc. R. Soc. B, 2015, The Royal Society. p.20150813.

DAVIDAR, P.; ARJUNAN, M.; PUYRAVAUD, J.-P. Why do local households harvest forest products? A case study from the southern Western Ghats, India. Biological Conservation, v. 141, n. 7, p. 1876-1884, 2008. ISSN 0006-3207.

DE VAUS, D. Surveys in social research. Routledge, 2013. ISBN 1134086318.

DORMANN, C. F. et al. Collinearity: a review of methods to deal with it and a simulation study evaluating their performance. Ecography, v. 36, n. 1, p. 27-46, 2013. ISSN 1600-0587.

FOOD, F. fruit-bearing forest species. Examples from Latin America. FAO Forestry Paper, v. 44, n. 3, 1986.

GARCÍA-FERNÁNDEZ, C.; RUIZ-PEREZ, M.; WUNDER, S. Is multiple-use forest management widely implementable in the tropics? Forest Ecology and Management, v. 256, n. 7, p. 1468-1476, 2008. ISSN 0378-1127.

GOLDSTEIN, H. Multilevel statistical models. John Wiley \& Sons, 2011. ISBN $111995682 X$.

GRAM, S. Economic valuation of special forest products: an assessment of methodological shortcomings. Ecological Economics, v. 36, n. 1, p. 109-117, 2001. ISSN 0921-8009.

GRIMES, A. et al. Valuing the rain forest: the economic value of nontimber forest products in Ecuador. Ambio, p. 405-410, 1994. ISSN 0044-7447.

GUARIGUATA, M. R.; SIST, P.; NASI, R. Multiple use management of tropical production forests: How can we move from concept to reality? Forest Ecology and Management, v. 263, p. 170-174, 2012. ISSN 0378-1127.

HALL, P.; BAWA, K. Methods to assess the impact of extraction of non-timber tropical forest products on plant populations. Economic botany, v. 47, n. 3, p. 234-247, 1993. ISSN 0013-0001.

HAMILTON, L. Statistics with Stata: version 12. Cengage Learning, 2012. ISBN 1285632559.

HENDERSON, A. The palms of the Amazon. Oxford University Press, 1995. ISBN 0195083113. 
HerRero-JÁUREGUI, C.; SIST, P.; CASADO, M. A. Population structure of two lowdensity neotropical tree species under different management systems. Forest Ecology and Management, v. 280, p. 31-39, 2012. ISSN 0378-1127.

HOMMA, A.; SCHWARTZMAN, S. The dynamics of extraction in Amazonia: a historical perspective. Non-timber products from tropical forests; evaluation of a conservation and development strategy. Advances in Economic Botany-New York Botanical Garden (EUA), v. 9, 1992.

JARDIM, M. A. G.; VIEIRA, I. C. G. Composição florística e estrutura de uma floresta de várzea do estuário amazônico, Ilha do Combu, estado do Pará, Brasil. 2001. ISSN 00772216.

KAINER, K. A.; WADT, L. H.; STAUDHAMMER, C. L. Explaining variation in Brazil nut fruit production. Forest Ecology and Management, v. 250, n. 3, p. 244-255, 2007. ISSN 0378-1127.

KAMANGA, P.; VEDELD, P.; SJAASTAD, E. Forest incomes and rural livelihoods in Chiradzulu District, Malawi. Ecological Economics, v. 68, n. 3, p. 613-624, 2009. ISSN 0921-8009.

KAR, S. P.; JACOBSON, M. G. NTFP income contribution to household economy and related socio-economic factors: Lessons from Bangladesh. Forest Policy and Economics, v. 14, n. 1, p. 136-142, 2012. ISSN 1389-9341.

KELES, S.; BAŞKENT, E. Z. A computer-based optimization model for multiple use forest management planning: a case study from Turkey. Scientia Forestalis, v. 39, n. 89, p. 87-95, 2011. ISSN 1413-9324.

KIM, I.-A.; TROSPER, R. L.; MOHS, G. Cultural uses of non-timber forest products among the Sts' ailes, British Columbia, Canada. Forest Policy and Economics, v. 22, p. 40-46, 2012. ISSN 1389-9341.

KLIMAS, C. A.; KAINER, K. A.; WADT, L. H. Population structure of $<\mathrm{i}>$ Carapa guianensis $</ \mathrm{i}>$ in two forest types in the southwestern Brazilian Amazon. Forest Ecology and Management, v. 250, n. 3, p. 256-265, 2007. ISSN 0378-1127.

KVIST, L. P. et al. Extraction from woody forest plants in flood plain communities in Amazonian Peru: use, choice, evaluation and conservation status of resources. Forest Ecology and Management, v. 150, n. 1, p. 147-174, 2001. ISSN 0378-1127.

LARCHER, W. O ambiente das plantas. Ecofisiologia Vegetal. São Carlos, RiMa, p. 1-65, 2000.

LIMA, D. As transformações na economia doméstica de Mamirauá. UAKARI, v. 6, n. 1, p. 9-26, 2010. ISSN 1981-4518.

MACÍA, M. J. Spatial distribution and floristic composition of trees and lianas in different forest types of an Amazonian rainforest. Plant Ecology, v. 212, n. 7, p. 1159-1177, 2011. ISSN 1385-0237. 
MÁRIO MENEZES, M. R. P., ANA CÍNTIA GUAZZELL E FÁBIO MARTINS. Cadeia produtiva do açaí no estado do Amazonas. Produtos da Floresta - açaí - Amazonas. AMAZONAS, G. D. E. Manaus: Secretaria de Estado do Meio Ambiente e Desenvolvimento Sustentável. 1: 32 p. 2005.

MEDINA, G. Frutíferas e plantas úteis na vida amazônica. CIFOR, 2005. ISBN 8588808021.

MELLINGER, L. L. Aspectos da regeneração natural e produção de sementes de Carapa guianensis Aubl.(andiroba) na Reserva de desenvolvimento Sustentável Amanã (RDSA), AM. 2006.

MOLNAR, A. et al. Community-based forest enterprises in tropical forest countries: status and potential. Rights and Resouces Initiative, 2007.

MORSELLO, C. et al. The effects of processing non-timber forest products and trade partnerships on people's well-being and forest conservation in Amazonian societies. PloS one, v. 7, n. 8, 2012. ISSN 1932-6203.

MOURA, E. A. F.; CASTRO, E. M. R. D. Mudanças sociais e gestão ecológica em questão: a experiência de mamirauá. Ambiente \& Sociedade, v. 15, n. 2, p. 23-50, 2012. ISSN 1414$753 X$.

NEUMANN, R. P.; HIRSCH, E. Commercialisation of non-timber forest products: review and analysis of research. Cifor, 2000. ISBN 979876451X.

NEWTON, P. et al. Cross-scale variation in the density and spatial distribution of an Amazonian non-timber forest resource. Forest Ecology and Management, v. 276, p. 41-51, 2012. ISSN 0378-1127.

NEWTON, P.; WATKINSON, A. R.; PERES, C. A. Spatial, Temporal, and Economic Constraints to the Commercial Extraction of a Non-timber Forest Product: Copaíba (Copaifera spp.) Oleoresin in Amazonian Reserves. Economic botany, v. 66, n. 2, p. 165177, 2012. ISSN 0013-0001.

PANAYOTOU, T.; ASHTON, P. Not by timber alone: the case for multiple use management of tropical forests. Island, Covelo, CA, 1992.

PENROSE, E. T. A teoria do crescimento da firma. Editora Unicamp, 2006. ISBN 8526807137.

PERALTA, N.; LIMA, D. D. M. A comprehensive overview of the domestic economy in Mamirauá and Amanã in 2010. UAKARI, v. 9, n. 2, p. 33-62, 2014. ISSN 1981-4518.

PETERS, C. M. et al. Oligarchic forests of economic plants in Amazonia: utilization and conservation of an important tropical resource. Conservation Biology, v. 3, n. 4, p. 341-349, 1989. ISSN 1523-1739. 
PETERS, C. M.; VASQUEZ, A. Estudios Ecológicos de Camu camu Myrciaria dubia. I. Producción de Frutos en Poblaciones Naturales. Acta amazonica, v. 16, n. 17, p. 161-173, 1987.

PINTO, A. et al. Boas práticas para manejo florestal e agroindustrial de produtos florestais não madeireiros: açaí, andiroba, babaçu, castanha-do-brasil, copaíba e unha-de-gato. Imazon/Sebrae, Belém/Manaus. Belém, PA: Imazon, 2012.

PORTER-BOLLAND, L. et al. Community managed forests and forest protected areas: An assessment of their conservation effectiveness across the tropics. Forest Ecology and Management, v. 268, p. 6-17, 2012. ISSN 0378-1127.

QUEIROZ, H. L. A reserva de desenvolvimento sustentável Mamirauá. Estudos avançados, v. 19, n. 54, p. 183-203, 2005. ISSN 0103-4014.

QUEIROZ, H. L. Protected Areas of Sustainable Use, Involvement of Social Actors, and Biodiversity Conservation in the Várzea: The Case of the Mamirauá Reserve-Sharing Conservation Benefits in Central Amazonia, Brazil. In: (Ed.). The Amazon Várzea: Springer, 2011. p.239-257. ISBN 9400701454.

RATHCKE, B.; LACEY, E. P. Phenological patterns of terrestrial plants. Annual review of ecology and systematics, p. 179-214, 1985. ISSN 0066-4162.

REVILLA, J. Apontamentos para a cosmética amazônica. SEBRAE: INPA, 2002. ISBN 8587324152.

RICKLEFS, R. E. A economia da natureza. In: (Ed.). A economia da natureza: Guanabara Koogan, 1996.

RIOS, M. N. D. S.; PASTORE JÚNIOR, F. Plantas da Amazônia: 450 espécies de uso geral. 2011. ISSN 8564593025.

ROCHA, E. Aspectos ecológicos e sócio-econômicos do manejo de Euterpe precatoria Mart.(Açaí) em áreas extrativistas no Acre, Brasil. 2002.

ROS-TONEN, M. A.; HOMBERGH, H.; ZOOMERS, A. Partnerships for sustainable forest and tree resource management in Latin America: The new road towards successful forest governance? Partnerships in Sustainable Forest Resource Management: Learning from Latin America. Brill: Cedla Latin Amercia Studies, v. 94, p. 3-37, 2006.

ROSA, R. K.; BARBOSA, R. I.; KOPTUR, S. Which Factors Explain Reproductive Output of Mauritia flexuosa (Arecaceae) in Forest and Savanna Habitats of Northern Amazonia? International Journal of Plant Sciences, v. 175, n. 3, p. 307-318, 2014.

RUIZ PÉREZ, M.; ARNOLD, J. Current issues in non-timber forest products research. Center for International Forestry Research (CIFOR), Bogor, 1996.

SCHAAFSMA, M. et al. The importance of local forest benefits: Economic valuation of Non-Timber Forest Products in the Eastern Arc Mountains in Tanzania. Global Environmental Change, v. 24, p. 295-305, 2014. ISSN 0959-3780. 
SCHMINK, M. Household economic strategies: review and research agenda. Latin American Research Review, p. 87-101, 1984. ISSN 0023-8791.

SCHRECKENBERG, K. et al. NTFP commercialization and the rural poor: more than a safety net. Commercialization of non-timber forest products: factors influencing success, lessons learned from Mexico and Bolivia, and policy implications for decision-makers. UNEP World Conservation Monitoring Centre, Cambridge, UK, p. 71-76, 2006.

SHACKLETON, S.; DELANG, C. O.; ANGELSEN, A. From subsistence to safety nets and cash income: exploring the diverse values of non-timber forest products for livelihoods and poverty alleviation. Springer, 2011. ISBN 3642179827.

SHACKLETON, S. E. The significance of the local trade in natural resource products for livelihoods and poverty alleviation in South Africa. 2005. Rhodes University

SHANLEY, P. Tapping the green market: certification and management of non-timber forest products. Earthscan, 2002. ISBN 1853838713.

SORK, V. L. Distribution of pignut hickory (Carya glabra) along a forest to edge transect, and factors affecting seedling recruitment. Bulletin of the Torrey Botanical Club, p. 494-506, 1983. ISSN 0040-9618.

SOUSA, M. Etnografia da produção de artefatos e artesanatos em comunidades da Reserva de Desenvolvimento Sustentável Amaná-Médio Solimões. UAKARI, v. 5, n. 1, p. 21-37, 2009. ISSN 1981-4518.

STEPHENSON, A. Flower and fruit abortion: proximate causes and ultimate functions. Annual review of ecology and systematics, p. 253-279, 1981. ISSN 0066-4162.

SUNDERLAND, T. et al. Challenging perceptions about men, women, and forest product use: a global comparative study. World Development, v. 64, p. S56-S66, 2014. ISSN 0305$750 X$.

TABARELLI, M.; MANTOVANI, W. Clareiras naturais e a riqueza de espécies pioneiras em uma Floresta Atlântica Montana. Revista Brasileira de Biologia, v. 59, n. 2, p. 251-261, 1999.

TER STEEGE, H. et al. Hyperdominance in the Amazonian tree flora. Science, v. 342, n. 6156, p. 1243092, 2013. ISSN 0036-8075.

TICKTIN, T. The ecological implications of harvesting non-timber forest products. Journal of Applied Ecology, v. 41, n. 1, p. 11-21, 2004. ISSN 1365-2664.

TICKTIN, T.; SHACKLETON, C. Harvesting non-timber forest products sustainably: opportunities and challenges. In: (Ed.). Non-timber forest products in the global context: Springer, 2011. p.149-169. ISBN 3642179827.

VAN ANDEL, T. AD39E Non-timber forest products. Agromisa Foundation, 2006. ISBN 9085730279. 
VEDEL-SØRENSEN, M. et al. Spatial distribution and environmental preferences of 10 economically important forest palms in western South America. Forest Ecology and Management, v. 307, p. 284-292, 2013. ISSN 0378-1127.

WITTMANN, F.; JUNK, W. J.; PIEDADE, M. T. The várzea forests in Amazonia: flooding and the highly dynamic geomorphology interact with natural forest succession. Forest Ecology and Management, v. 196, n. 2, p. 199-212, 2004. ISSN 0378-1127.

WITTMANN, F. et al. Manual de árvores de várzea da Amazônia Central: taxonomia, ecologia e uso: Editora INPA, Manaus 2010.

WITTMANN, F.; SCHÖNGART, J.; JUNK, W. J. Phytogeography, species diversity, community structure and dynamics of central Amazonian floodplain forests. In: (Ed.). Amazonian floodplain forests: Springer, 2011. p.61-102. ISBN 9048187249.

WUNDER, S. Poverty alleviation and tropical forests-What scope for synergies? World Development, v. 29, n. 11, p. 1817-1833, 2001. ISSN 0305-750X. 


\section{APÊNDICES}

APÊNDICE A - Termo de Consentimento Livre e Esclarecido assinado pelos chefes das unidades domésticas entrevistadas.

\section{TERMO DE CONSENTIMENTO LIVRE E ESCLARECIDO}

Você está sendo convidado(a) para participar, como voluntário(a), de uma pesquisa. Em caso de recusa você não será penalizado(a) de forma alguma.

\section{INFORMAÇÕES SOBRE A PESQUISA:}

Título do Projeto: Coleta de múltiplos produtos florestais não madeireiros. O caso da Reserva de Desenvolvimento Sustentável Mamirauá.

Pesquisador Responsável: Rafael de Carvalho Sposito.

Telefone para contato: 1698245.8646 / 978108.7320 / 979144.2217

Telefone da Secretaria do Comitê de Ética - (97) 3343-9716

- Esta pesquisa será realizada com os moradores de 7 comunidades da Reserva de Desenvolvimento Sustentável Mamirauá. O objetivo é avaliar se é possível coletar ao mesmo tempo diversos produtos da mata, principalmente frutas e sementes, como aquelas estudadas pelo Rafael. E pra avaliar isso, é preciso entender o interesse das pessoas na coleta dos produtos, e também a capacidade e o tempo que elas têm pra trabalhar coletando esses produtos.

- Também queremos saber quanto as famílias dessas comunidades poderiam ganhar se coletassem e vendessem os produtos que o Rafael Sposito estudou, ou seja, açaí, buriti, murumuru, urucuri, andiroba, bacuri-coroa e camu-camu. Então, pra saber isso, é preciso fazer algumas perguntas.

- As respostas que forem dadas não serão mostradas a mais ninguém, ou seja, ninguém poderá saber quem deu cada resposta.

- Sua participação voluntária é muito importante para os resultados da pesquisa, mas para que ela aconteça, precisamos da sua autorização. Caso você sinta constrangimento com alguma das perguntas, você não será obrigado a responder e caso aceite participar, não terá nenhuma despesa ou receberá algo em troca. Sua autorização poderá ser cancelada a qualquer momento e por qualquer motivo.

- Nome do pesquisador: Rafael Sposito.

\section{- CONSENTIMENTO DA PARTICIPAÇÃO DA PESSOA COMO SUJEITO}

Eu, abaixo assinado, concordo em participar do estudo Coleta de múltiplos produtos florestais não madeireiros. 0 caso da Reserva de Desenvolvimento Sustentável Mamirauá, como sujeito. Fui devidamente informado e esclarecido pelo pesquisador Rafael Sposito sobre a pesquisa, os procedimentos nela envolvidos, assim como os possíveis benefícios decorrentes de minha participação. Foi-me garantido que posso retirar meu consentimento a qualquer momento, sem qualquer prejuízo a mim.

Local data: 
APÊNDICE B - Questionários utilizados nas entrevistas.

\begin{tabular}{|c|c|}
\hline $\begin{array}{l}\text { USP-FAPESP-IDSM } \\
\text { Projeto Coleta de múltiplos produtos } \\
\text { florestais não madeireiros - o caso da } \\
\text { RDS Mamirauá }\end{array}$ & 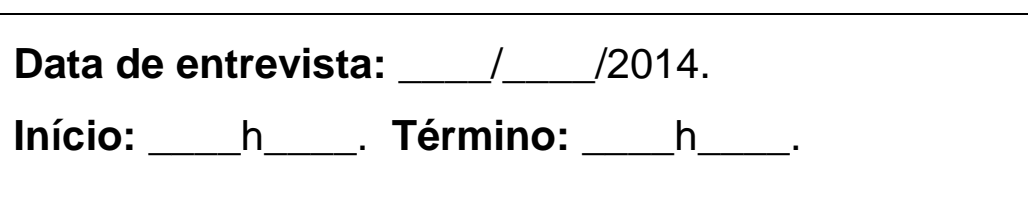 \\
\hline $\begin{array}{l}\text { MÓDULO UNIDADE } \\
\text { DOMÉSTICA }\end{array}$ & 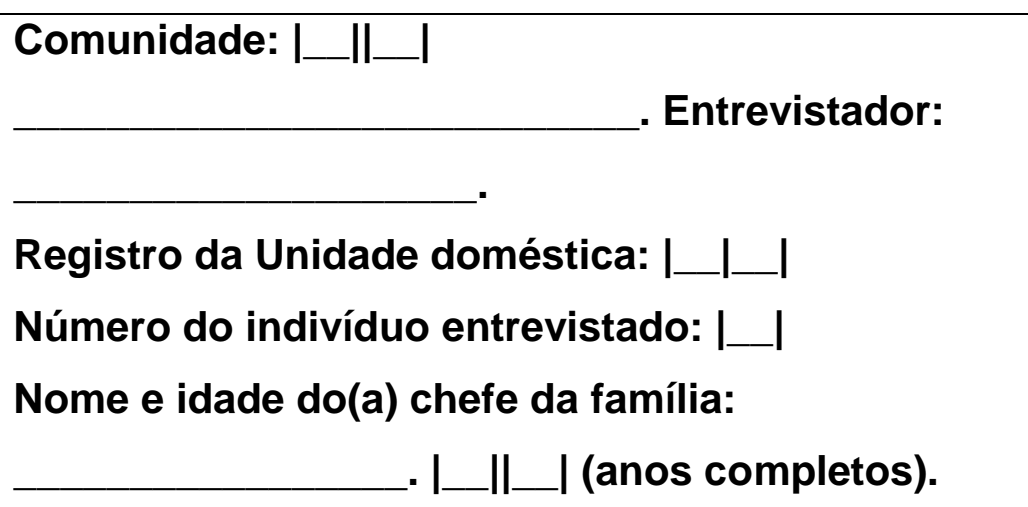 \\
\hline \multicolumn{2}{|c|}{$\begin{array}{l}\text { Nota: Os trechos em itálico são instruções ao entrevistador e não devem ser lidas ao } \\
\text { entrevistado. A introdução a seguir deve ser lida ao chefe ou à chefe da família antes do início da } \\
\text { entrevista, para informa-lo sobre os objetivos do projeto e ter seu consentimento para a } \\
\text { entrevista. Deve-se identificar o chefe da família perguntando quem é o dono ou a dona da casa } \\
\text { e solicitar se ele ou ela pode atender. }\end{array}$} \\
\hline
\end{tabular}

O objetivo desta pesquisa é avaliar se é possível coletar ao mesmo tempo diversos produtos da mata, principalmente frutas e sementes, como aquelas estudadas pelo Rafael. E pra gente entender isso, a gente precisa entender o interesse das pessoas na coleta dos produtos, e também a capacidade e o tempo que elas têm pra trabalhar coletando esses produtos.

Outra coisa que queremos tentar saber é quanto as famílias da comunidade poderiam ganhar se coletassem e vendessem aqueles produtos que o Rafael estudou, ou seja, açaí, buriti, murumuru, urucuri, andiroba, bacuri-coroa e camu-camu. Então, pra saber isso, eu vou fazer algumas perguntas a você e vou repetir as mesmas perguntas nas casas que foram sorteadas para eu conversar. As respostas que forem dadas não serão mostradas a mais ninguém, ou seja, ninguém poderá saber quem deu cada resposta. Então, se o(a) senhor(a) estiver de acordo, a gente já pode começar.

\section{NÚMERO DE COLETORES}

Pra começar, eu gostaria de saber quem são as pessoas da casa e quem tem costume de coletar produtos da mata. Aliás, se tiver pessoas que não dormem nesta casa, mas compartilham todo dia as refeições e o trabalho com o(a) senhor(a), vamos considerar com sendo todos da mesma casa, da mesma família.

\begin{tabular}{|c|c|c|c|}
\hline $\begin{array}{l}\text { 1.1. Qual o nome das pessoas da } \\
\text { casa do(a) senhor(a)? (incluir } \\
\text { o entrevistado) }\end{array}$ & $\begin{array}{l}\text { 1.2. Quantos anos } \\
\text { completos tem cada } \\
\text { uma? }\end{array}$ & $\begin{array}{l}\text { 1.3. Quais pessoas têm } \\
\text { costume de coletar pelo } \\
\text { menos uma vez por ano } \\
\text { produtos da mata, como } \\
\text { frutas, sementes, cipós, } \\
\text { cascas, óleos, breu, raiz } \\
\text { (Marcar com x as } \\
\text { pessoas que têm } \\
\text { costume) }\end{array}$ & $\begin{array}{l}\text { 1.4. Das pessoas que não } \\
\text { tem costume de coletar } \\
\text { nem uma vez por ano, } \\
\text { quais conseguiriam, ou } \\
\text { seja, seriam capazes de } \\
\text { coletar produtos da mata } \\
\text { se quisessem? (Marcar } \\
\text { com } x \text { as pessoas } \\
\text { capazes) }\end{array}$ \\
\hline & & & \\
\hline & & & \\
\hline & & & \\
\hline & & & \\
\hline & & & \\
\hline & & 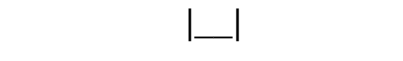 & 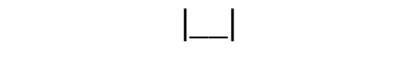 \\
\hline
\end{tabular}




\begin{tabular}{|l|l|l|l|}
\hline $\begin{array}{l}\text { 1.1. Qual o nome das pessoas da } \\
\text { casa do(a) senhor(a)? (incluir } \\
\text { o entrevistado) }\end{array}$ & $\begin{array}{l}\text { 1.2. Quantos anos } \\
\text { completos tem cada } \\
\text { uma? }\end{array}$ & $\begin{array}{l}\text { 1.3. Quais pessoas têm } \\
\text { costume de coletar pelo } \\
\text { menos uma vez por ano } \\
\text { produtos da mata, como } \\
\text { frutas, sementes, cipós, } \\
\text { cascas, óleos, breu, raiz } \\
\text { (Marcar com } x \text { as } \\
\text { pessoas que têm } \\
\text { costume) }\end{array}$ & $\begin{array}{l}\text { 1.4. Das pessoas que não } \\
\text { tem costume de coletar } \\
\text { nem uma vez por ano, } \\
\text { quais conseguiriam, ou } \\
\text { seja, seriam capazes de } \\
\text { coletar produtos da mata } \\
\text { se quisessem? (Marcar } \\
\text { com } x \text { as pessoas } \\
\text { capazes) }\end{array}$ \\
\hline & & $|L|$ & $\mid$ \\
\hline & & $|L|$ & $\mid$ \\
\hline
\end{tabular}

\section{CONSUMO PRÓPRIO}

Agora, eu gostaria de saber se vocês consomem alguns produtos da mata, para quê os produtos são usados e qual é a melhor época para coletá-los. (Fazer todas as perguntas pra um produto e depois repetir as perguntas para outro produto e assim por diante).

\begin{tabular}{|c|c|c|c|}
\hline Produto & $\begin{array}{l}\text { 2.1. Vocês usam } \\
\text { pro consumo } \\
\text { de vocês o(a) } \\
\begin{array}{l}\text { ? (ler os } \\
\text { produtos da } \\
\text { lista) }\end{array}\end{array}$ & $\begin{array}{l}\text { 2.2. Se sim, para quê } \\
\text { o(a) } \quad \text { (ler os } \\
\text { produtos da lista) é } \\
\text { usado por vocês? Para: } \\
\text { A= alimentação própria. } \\
\mathbf{R =}=\text { remédio (usado para } \\
\text { curar ou prevenir algum } \\
\text { problema de saúde). } \\
\mathbf{D}=\text { artefato de trabalho } \\
\text { (paneiro, peneira, } \\
\text { vassoura, tipiti). } \\
\text { H= artesanato (cestas, } \\
\text { tupés e outros objetos } \\
\text { de decoração ). } \\
\mathbf{C}=\text { construção, canoa, } \\
\text { remo. } \\
\text { I=isca pra peixe. } \\
\mathbf{O}=\text { outro (qual?). }\end{array}$ & $\begin{array}{l}\text { 2.3. Qual(is) o(s) melhor(es) mês(es) para coletar } \\
\text { ? (anotar somente para os sete primeiros } \\
\text { produtos da lista) }\end{array}$ \\
\hline Açaí & L_SSim L_Não & 1 L 1 & 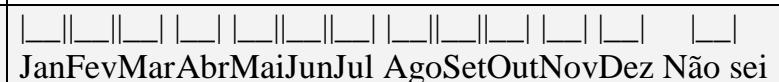 \\
\hline Urucuri & L_ISim L_Não & $\mid$ & 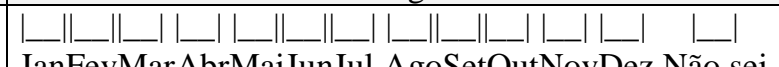 \\
\hline Murumuru & L_ISim L_Não & 1 & 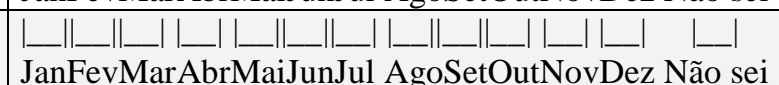 \\
\hline Buriti & L_ISim L_Não & 1 & 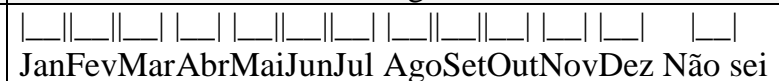 \\
\hline Andiroba & L_Sim L_Não & 1 & 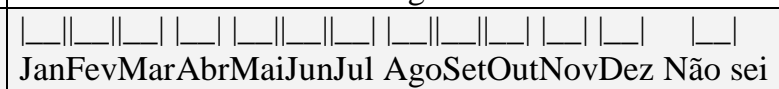 \\
\hline Bacuri-coroa & I_lSim L_|Não & $\mid$ & 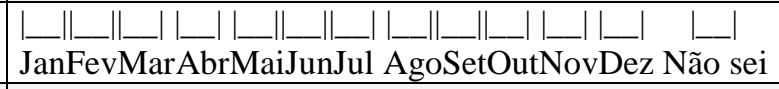 \\
\hline Camu-camu & I_ Sim L_Não & 1 & 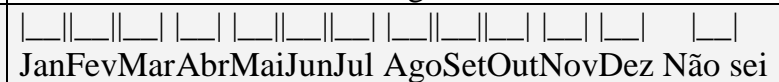 \\
\hline Abiurana & $L_{\text {L_lSim }} L_{\text {INão }}$ & 1 & \\
\hline Acapu & L_Sim I INão & $\mathrm{L}$ & \\
\hline Acapurana & $1 \ldots$ Sim $|\ldots|$ Não & 1 & \\
\hline Apuruí & L_ISim L_Não & $\mathrm{I}$ & \\
\hline Araçá & L_ISim I_ INão & 11 & \\
\hline Arapari & L_|Sim $|\ldots|$ Não & 1 & \\
\hline Arumã & 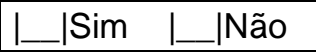 & $\mathrm{L}$ & \\
\hline Bacaba & L_ISim L_Não & $1 \mathrm{~L}$ & \\
\hline Cajurana & L__Sim L_|Não & $1 \mid$ & \\
\hline
\end{tabular}




\begin{tabular}{|c|c|c|c|c|c|}
\hline & \multicolumn{2}{|c|}{$\begin{array}{l}\text { 2.1. Vocês usam } \\
\text { pro consumo } \\
\text { de vocês o(a) } \\
\frac{r}{\text { ? (ler os }} \\
\text { produtos da } \\
\text { lista) }\end{array}$} & \multicolumn{2}{|c|}{$\begin{array}{l}\text { 2.2. Se sim, para quê } \\
\text { o(a) (ler os } \\
\text { produtos da lista) é } \\
\text { usado por vocês? Para: } \\
\text { A= alimentação própria. } \\
\mathbf{R}=\text { remédio (usado para } \\
\text { curar ou prevenir algum } \\
\text { problema de saúde). } \\
\mathbf{D}=\text { artefato de trabalho } \\
\text { (paneiro, peneira, } \\
\text { vassoura, tipiti). } \\
\text { H= artesanato (cestas, } \\
\text { tupés e outros objetos } \\
\text { de decoração). } \\
\mathbf{C}=\text { construção, canoa, } \\
\text { remo. } \\
\text { I=isca pra peixe. } \\
\mathbf{O}=\text { outro (qual?). }\end{array}$} & $\begin{array}{l}\text { 2.3. Qual(is) o(s) melhor(es) mês(es) para coletar } \\
\text { ? (anotar somente para os sete primeiros } \\
\text { produtos da lista) }\end{array}$ \\
\hline Carapanauba & Sim & INão & & & \\
\hline Caraipé & ISim & |Não & L. & & \\
\hline Cauaçu & Sim & INão & $1=$ & & \\
\hline Caxinguba & Sim & |Não & L & & \\
\hline Cipó-ambé & Sim & |Não & 1 & & \\
\hline Cipó-timbó & Sim & INão & L & & \\
\hline Cipó-titica & S Sim & INão & 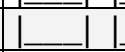 & & \\
\hline Copaíba & ISim & |Não & 1 & & \\
\hline Ingazeiro & Sim & |Não & 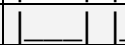 & & \\
\hline Jacitara & Sim & |Não & 1 & & \\
\hline Jauari & Sim & |Não & 1 & & \\
\hline Jenipapo & Sim & |Não & 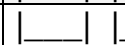 & & \\
\hline Assacu & Sim & INão & L. & & \\
\hline Macucu & ISim & |Não & . & & \\
\hline Murici & Sim & |Não & L & & \\
\hline Namui & Sim & INão & L & & \\
\hline Paracuuba & Sim & |Não & & & \\
\hline Seringueira & Sim & |Não & 1 & & \\
\hline Sucuuba & Sim & |Não & L. & & \\
\hline Taperebá & L Sim & Não & $\perp$ & & \\
\hline & $\perp_{\text {L Sim }}$ & |Não & 11 & & \\
\hline & $\ldots$ Sim & |Não & & & \\
\hline
\end{tabular}

\section{FATORES CULTURAIS}

Agora, eu gostaria de saber um pouco sobre sua origem.

3.1. Onde o(a) senhor(a) se criou, ou seja, viveu desde pequeno até completar 15 anos? |_| comunidade ribeirinha. L_ cidade. I_ outro. Qual?

3.2. Há quantos anos completos, isto é, desde o dia em que chegou até o dia de hoje, o(a) senhor(a) vive aqui na comunidade (dizer o nome da atual comunidade)?

L___ anos. I_ desde que nasceu.

3.3. Pensando nos diferentes tipos de trabalho: pescador(a), agricultor(a), caçador(a), coletor(a) de produtos da mata, funcionário(a) público, ou outro, o que o(a) senhor(a) se considera em primeiro lugar? E em segundo? (escrever por extenso).

\begin{tabular}{|l|l|}
\hline $1^{\text {a }}$ opção: & $2^{\text {a }}$ opção: \\
\hline
\end{tabular}

3.4. Até que série completa o(a) senhor(a) estudou?

3.5. Até que série completa estudou a pessoa que mais estudou aqui desta casa? 


\section{POSSIBILIDADE CONCRETA DE COMERCIALIZAÇÃO}

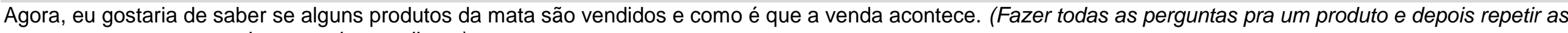
perguntas para outro produto e assim por diante).

\begin{tabular}{|c|c|c|c|c|c|c|c|c|}
\hline Produto & 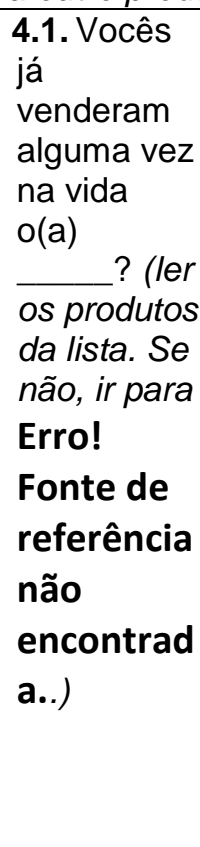 & $\begin{array}{l}\text { 4.2. Se sim, qual } \\
\text { foi a última vez } \\
\text { que venderam? } \\
\text { (Anotar mês e } \\
\text { ano). }\end{array}$ & 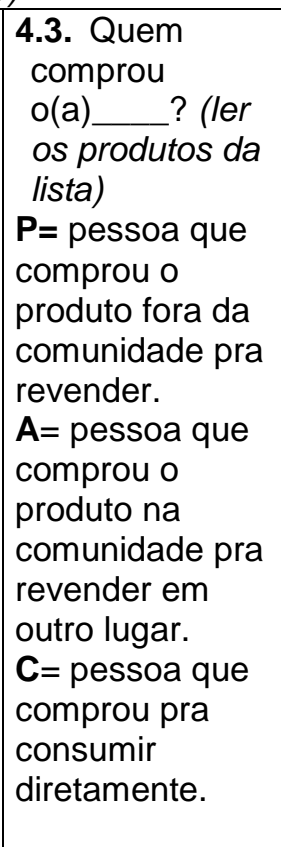 & $\begin{array}{l}\text { 4.4. Onde vocês } \\
\text { venderam } \\
\text { o ? } \\
\text { (ler os produtos } \\
\text { da lista) } \\
\text { P= na própria } \\
\text { comunidade } \\
\mathbf{F = ~ e m ~ o u t r a ~} \\
\text { comunidade. } \\
\text { Qual? } \\
\mathbf{C}=\text { na cidade. } \\
\text { Qual? } \\
\mathbf{O}=\text { Outro. Qual? }\end{array}$ & $\begin{array}{l}\text { 4.5. Existe uma quantidade } \\
\text { mínima que o(a) (ler } \\
\text { os produtos da lista) é } \\
\text { comprado, ou seja, o } \\
\text { comprador compra no } \\
\text { mínimo uma certa } \\
\text { quantidade? (Se sim, anotar } \\
\text { a quantidade e unidade com } \\
\text { o valor correspondente em } \\
\text { kg). }\end{array}$ & $\begin{array}{l}\text { 4.6. Vocês } \\
\text { gastaram } \\
\text { algum dinheiro } \\
\text { só para ir } \\
\text { vender } \\
\text { o(a)_, por } \\
\text { exemplo, com } \\
\text { combustível } \\
\text { ou de alguma } \\
\text { outra forma? } \\
\text { Qual? }\end{array}$ & $\begin{array}{l}\text { 4.7. Se sim, } \\
\text { quanto } \\
\text { vocês } \\
\text { gastaram } \\
\text { no total, em } \\
\text { reais, para } \\
\text { ir vender } \\
\text { o(a) } \\
\text { (ler os } \\
\text { produtos da } \\
\text { lista) }\end{array}$ & $\begin{array}{l}\text { 4.8. Qual foi o preço } \\
\text { que vocês venderam } \\
\text { cada produto? (Se } \\
\text { venderam em mais } \\
\text { de um local, } \\
\text { considerar o preço do } \\
\text { local mais próximo). }\end{array}$ \\
\hline Açaí & $\left.\right|_{\text {__ }}$ Sim & & | & 1 & 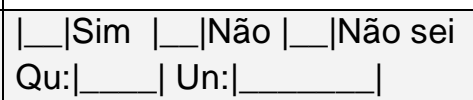 & $L_{\text {__ }}$ Sim & & Un: I \\
\hline Urucuri & _ $\mid$ Sim & & | & 1 & 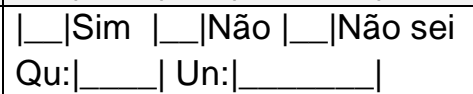 & $\left.\right|_{\text {L_ }} \mid$ Sim & & Un: I \\
\hline \begin{tabular}{|l|} 
Murumuru \\
\end{tabular} & $\left.\right|_{\text {__ }} ^{\text {INão }}$ & & 1 & 1 & 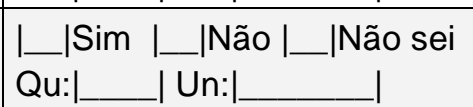 & 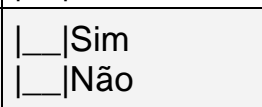 & & Un: I \\
\hline Buriti & $\left.\right|_{\text {__ }} \mid$ Sim & & | & 1 & 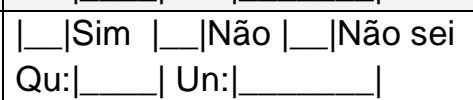 & L_ISim & & Un: \\
\hline Andiroba & $L_{\text {__ }}^{\mid}$Sim & & 1 & 1 & $\left|\_\right| \operatorname{Sim}|\ldots|$ Não |_ $\mid$ Não sei & $\left.\right|_{\text {__ }} ^{\text {ISão }}$ & & Un: 1 \\
\hline $\begin{array}{l}\text { Bacuri- } \\
\text { coroa }\end{array}$ & $\mid \begin{array}{l}\text { Sim } \\
\mid \text { INão }\end{array}$ & & l & 1 & 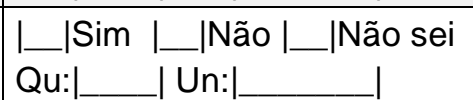 & I_ & & Un: 1 \\
\hline
\end{tabular}




\begin{tabular}{|c|c|c|c|c|c|c|c|c|}
\hline & 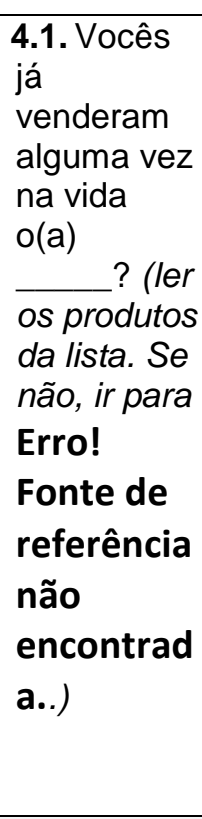 & $\begin{array}{l}\text { 4.2. Se sim, qual } \\
\text { foi a última vez } \\
\text { que venderam? } \\
\text { (Anotar mês e } \\
\text { ano). }\end{array}$ & $\begin{array}{l}\text { 4.3. Quem } \\
\text { comprou } \\
\text { o(a) ? (ler } \\
\text { os produtos da } \\
\text { lista) } \\
\mathrm{P}=\text { pessoa que } \\
\text { comprou o } \\
\text { produto fora da } \\
\text { comunidade pra } \\
\text { revender. } \\
\mathrm{A}=\text { pessoa que } \\
\text { comprou o } \\
\text { produto na } \\
\text { comunidade pra } \\
\text { revender em } \\
\text { outro lugar. } \\
\mathbf{C}=\text { pessoa que } \\
\text { comprou pra } \\
\text { consumir } \\
\text { diretamente. }\end{array}$ & $\begin{array}{l}\text { 4.4. Onde vocês } \\
\text { venderam } \\
\text { o ? } \\
\text { (ler os produtos } \\
\text { da lista) } \\
\\
\mathbf{P =} \text { na própria } \\
\text { comunidade } \\
\mathbf{F}=\text { em outra } \\
\text { comunidade. } \\
\text { Qual? } \\
\mathbf{C}=\text { na cidade. } \\
\text { Qual? } \\
\mathbf{O}=\text { Outro. Qual? }\end{array}$ & $\begin{array}{l}\text { 4.5. Existe uma quantidade } \\
\text { mínima que o(a) (ler } \\
\text { os produtos da lista) é } \\
\text { comprado, ou seja, o } \\
\text { comprador compra no } \\
\text { mínimo uma certa } \\
\text { quantidade? (Se sim, anotar } \\
\text { a quantidade e unidade com } \\
\text { o valor correspondente em } \\
\text { kg). }\end{array}$ & $\begin{array}{l}\text { 4.6. Vocês } \\
\text { gastaram } \\
\text { algum dinheiro } \\
\text { só para ir } \\
\text { vender } \\
\text { o(a) , por } \\
\text { exemplo, com } \\
\text { combustivel } \\
\text { ou de alguma } \\
\text { outra forma? } \\
\text { Qual? }\end{array}$ & $\begin{array}{l}\text { 4.7. Se sim, } \\
\text { quanto } \\
\text { vocês } \\
\text { gastaram } \\
\text { no total, em } \\
\text { reais, para } \\
\text { ir vender } \\
\text { o(a) ? } \\
\text { (ler os } \\
\text { produtos da } \\
\text { lista) }\end{array}$ & $\begin{array}{l}\text { 4.8. Qual foi o preço } \\
\text { que vocês venderam } \\
\text { cada produto? (Se } \\
\text { venderam em mais } \\
\text { de um local, } \\
\text { considerar o preço do } \\
\text { local mais próximo). }\end{array}$ \\
\hline Camu-camu & $\begin{array}{l}\text { L_Sim } \\
\text { LINão }\end{array}$ & & ا 11 ا & 1 & $\mid$ L_ISim |__Não |__|Não sei & 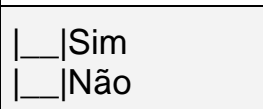 & & Un: \\
\hline
\end{tabular}




\section{RENDA}

Nesta parte, eu gostaria de saber como o(a) senhor(a) e as pessoas de sua casa conseguem os alimentos ou dinheiro. Lembro que a gente está considerando como pessoas de casa todas aquelas que moram com o(a) senhor(a) e também aquelas que compartilham todo dia as refeições e o trabalho com o(a) senhor(a), mas que

dormem em outro lugar.

\section{Renda com Produtos Florestais}

5.1. O(a) senhor(a) ou alguém de sua casa coletou algum produto da mata, como lenha, madeira (construiu ou reformou algo), semente/caroço/castanha, fruta, borracha, óleo, palha, cipó, mel, planta medicinal ou outro produto desde a última cheia, ou seja, do primeiro dia de março até hoje? |_ | Sim. produto de cada vez e aguardar a resposta. Marcar sim caso tenha coletado ao menos um produto e anotar qual, fazendo a série de perguntas da tabela abaixo. Se não, ir para 6.1).

\begin{tabular}{|c|c|c|c|c|c|}
\hline Produtos & $\begin{array}{l}\text { 5.2. Quantos vocês } \\
\text { coletaram de desde } \\
\text { o primeiro dia de abril } \\
\text { até hoje? (ler os } \\
\text { produtos da lista). }\end{array}$ & $\begin{array}{l}\text { 5.3. Quantos usaram } \\
\text { pro consumo de vocês } \\
\text { desde o início de abril } \\
\text { até hoje? (incluir } \\
\text { unidade, se pertinente) }\end{array}$ & $\begin{array}{l}\text { 5.4. Vocês } \\
\text { venderam } \\
\text { algum desses } \\
\text { produtos? }\end{array}$ & $\begin{array}{l}\text { 5.5. Se sim, quantos } \\
\text { venderam desde o início } \\
\text { de abril até hoje? (incluir } \\
\text { unidade). }\end{array}$ & $\begin{array}{l}\text { 5.6. Qual foi o preço que } \\
\text { vocês venderam cada } \\
\text { produto? Se não } \\
\text { venderam, quanto custa, } \\
\text { se vocês fossem } \\
\text { comprar? (mesma } \\
\text { unidade anterior). } \\
\end{array}$ \\
\hline & Qu:|__ Un: | & Qu:|__ Un: | & L_Sim L_Não & | Un: | & \\
\hline & Qu:|_| Un: & Qu:|_ | Un: | & L_|Sim L_Não & Un: | & \\
\hline & Qu:|_ Un: | & Qu:|__ Un: | & L_|Sim L_Não & | Un: | & \\
\hline & Qu:|_| Un: & Qu:|_| Un: & L_|Sim L_Não & Un: $\left.\right|_{1}$ & \\
\hline & _I Un: | & - Un: | & L_Sim L_Não & | Un: | & \\
\hline & Qu: & Qu:|__ Un: | & L_Sim L_Não & U Un: $\mid$ & \\
\hline & Qu:|_| Un: | & Qu:|__ Un: | & L_Sim L_Não & U Un: | & \\
\hline & Qu: & | Un: | & L_|Sim L_Não & | Un: | & \\
\hline
\end{tabular}




\section{Renda com pesca}

6.1. $\mathrm{O}$ (a) senhor(a) ou alguém de sua casa foi pescar na última semana, ou seja, de (dia da semana referente aos 7 dias anteriores à entrevista) até hoje? ___ Sim. ___ Não. (Se sim, anotar um por linha e fazer a série de perguntas da tabela abaixo. Se não, ir para 7.1).

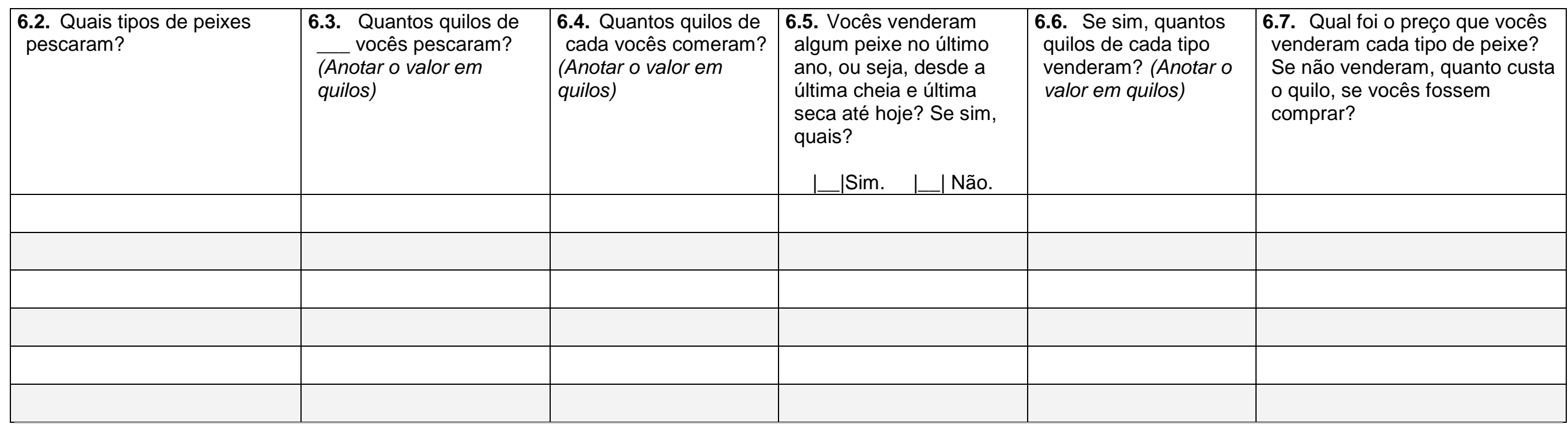

\section{Renda com produtos Agrícolas}

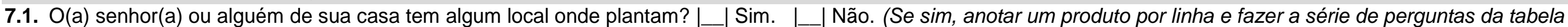
a seguir. Se não, ir para 8.1).

\begin{tabular}{|c|c|c|c|c|c|c|}
\hline 7.2. Produtos & 7.3. Têm plantado? & $\begin{array}{l}\text { 7.4. Vocês comeram } \\
\text { algum destes } \\
\text { produtos nos últimos } \\
15 \text { dias, ou seja, do } \\
\text { dia (dia da semana } \\
\text { referente aos } 15 \text { dias } \\
\text { anteriores à } \\
\text { entrevista) até hoje? }\end{array}$ & $\begin{array}{l}\text { 7.5. Quantos vocês } \\
\text { comeram? }\end{array}$ & $\begin{array}{l}\text { 7.6. Vocês venderam } \\
\text { algum produto no } \\
\text { último ano, ou seja, } \\
\text { desde a última cheia } \\
\text { e última seca até } \\
\text { hoje? Se sim, quais? } \\
\mid \text { |Sim. __ Não. }\end{array}$ & $\begin{array}{l}\text { 7.7. Quanto } \\
\text { venderam? }\end{array}$ & $\begin{array}{l}\text { 7.8. Qual foi o preço que } \\
\text { vocês venderam cada } \\
\text { produto? Se não } \\
\text { venderam, quanto custa, } \\
\text { em reais, se vocês } \\
\text { fossem comprar? } \\
\text { (mesma unidade anterior) }\end{array}$ \\
\hline Mandioca/farinha & $L_{\ldots}\left|\operatorname{Sim} L_{\perp}\right|$ Não & L_|Sim L_|Não & Qu:| & & Qu:| & \\
\hline
\end{tabular}




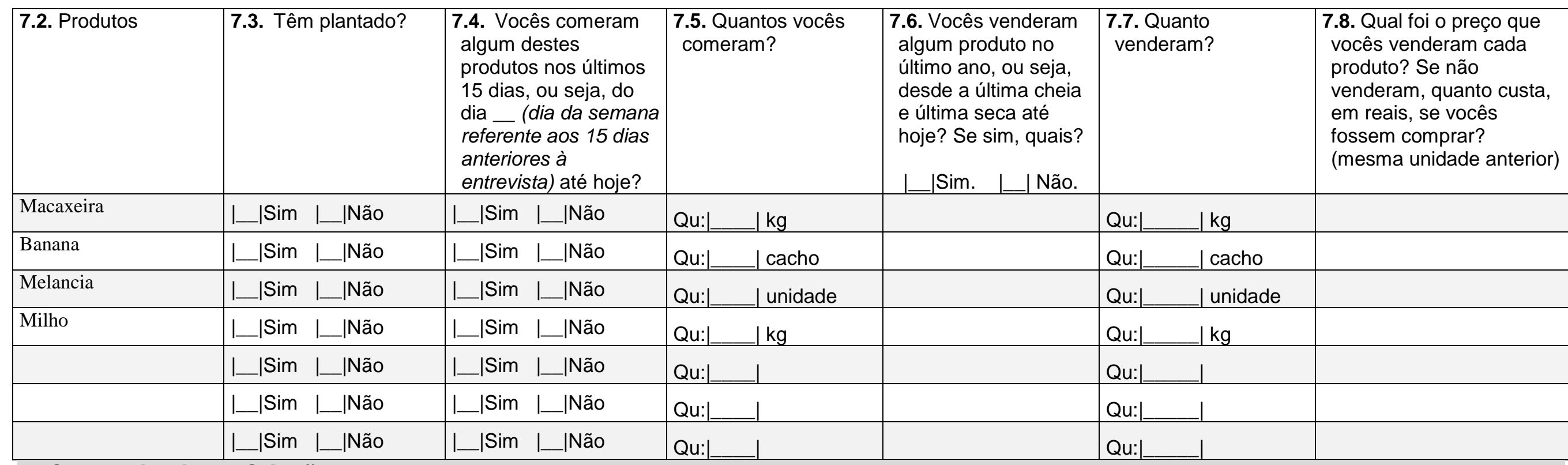

\section{Com Animais de Criação}

8.1. O(a) senhor(a) ou alguém de sua casa tem algum animal de criação? |__ Sim. I_ Não. (Se sim, anotar um por linha e fazer a série de perguntas da tabela a seguir. Se não, ir para 9.1).

\begin{tabular}{|c|c|c|c|c|c|c|}
\hline $\begin{array}{l}\text { 8.2. Animais } \\
\text { criados }\end{array}$ & $\begin{array}{l}\text { 8.3. Quantos } \\
\text { de cada } \\
\text { vocês têm? }\end{array}$ & $\begin{array}{l}\text { 8.4. Vocês } \\
\text { comeram algum } \\
\text { destes animais } \\
\text { nos últimos } 15 \\
\text { dias, ou seja, de } \\
\text { (dia da } \\
\text { semana referente } \\
\text { aos } 15 \text { dias } \\
\text { anteriores à } \\
\text { entrevista) até } \\
\text { hoje? }\end{array}$ & $\begin{array}{l}\text { 8.5. Quantos vocês comeram? } \\
\text { (incluir parte, se pertinente). }\end{array}$ & $\begin{array}{l}\text { 8.6. Vocês } \\
\text { venderam algum } \\
\text { destes animais } \\
\text { nos últimos } 15 \\
\text { dias, ou seja, de } \\
\text { (dia da } \\
\text { semana referente } \\
\text { aos } 15 \text { dias } \\
\text { anteriores à } \\
\text { entrevista) até } \\
\text { hoje? }\end{array}$ & $\begin{array}{l}\text { 8.7. Quanto venderam? (incluir } \\
\text { unidade) }\end{array}$ & $\begin{array}{l}\text { 8.8. Qual foi o } \\
\text { preço que vocês } \\
\text { venderam cada } \\
\text { animal inteiro ou } \\
\text { em parte? Se não } \\
\text { venderam, quanto } \\
\text { custa, em reais, se } \\
\text { vocês fossem } \\
\text { comprar? (mesma } \\
\text { unidade anterior) }\end{array}$ \\
\hline & & 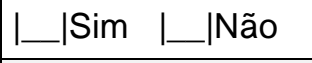 & Qu:|__ $\mathrm{Pt:} \mid$ & $L_{\text {_ }} \operatorname{Sim} L_{\ldots} \mid N a ̃ o$ & | Un: $\mid$ & \\
\hline & & L_|Sim I_|Não & Qu: $\quad$ | Pt: | & L_|Sim L_|Não & Qu: $|\quad|$ Un: $\mid$ & \\
\hline & & L_Sim L_Não & $\mathrm{Qu}:{ }_{1} \quad|\mathrm{Pt}:|$ & I_ Sim I_ Não & Qu:|_ Un: | & \\
\hline & & L_ISim I_|Não & Qu:|__ Pt: | & $L_{\perp}|\operatorname{Sim}|_{\perp} \mid N a ̃ o$ & Qu:|_ Un: | & \\
\hline
\end{tabular}




\begin{tabular}{|c|c|c|c|c|c|c|}
\hline $\begin{array}{l}\text { 8.2. Animais } \\
\text { criados }\end{array}$ & $\begin{array}{l}\text { 8.3. Quantos } \\
\text { de cada } \\
\text { vocês têm? }\end{array}$ & $\begin{array}{l}\text { 8.4. Vocês } \\
\text { comeram algum } \\
\text { destes animais } \\
\text { nos últimos } 15 \\
\text { dias, ou seja, de } \\
\quad \text { (dia da } \\
\text { semana referente } \\
\text { aos } 15 \text { dias } \\
\text { anteriores à } \\
\text { entrevista) até } \\
\text { hoje? }\end{array}$ & $\begin{array}{l}\text { 8.5. Quantos vocês comeram? } \\
\text { (incluir parte, se pertinente). }\end{array}$ & \begin{tabular}{|l|} 
8.6. Vocês \\
venderam algum \\
destes animais \\
nos últimos 15 \\
dias, ou seja, de \\
\multicolumn{1}{c|}{ (dia da } \\
semana referente \\
aos 15 dias \\
anteriores à \\
entrevista) até \\
hoje?
\end{tabular} & $\begin{array}{l}\text { 8.7. Quanto venderam? (incluir } \\
\text { unidade) }\end{array}$ & $\begin{array}{l}\text { 8.8. Qual foi o } \\
\text { preço que vocês } \\
\text { venderam cada } \\
\text { animal inteiro ou } \\
\text { em parte? Se não } \\
\text { venderam, quanto } \\
\text { custa, em reais, se } \\
\text { vocês fossem } \\
\text { comprar? (mesma } \\
\text { unidade anterior) }\end{array}$ \\
\hline & & L_|Sim L_Não & | Pt: | & I_|Sim L_Não & - Un: & \\
\hline
\end{tabular}

\section{Renda com Caça}

9.1. O(a) senhor(a) ou alguém de sua casa caçou ou pegou algum bicho de casco nos últimos 15 dias, ou seja, do dia (dia da semana referente aos 15 dias anteriores à entrevista) até hoje?

L__ Sim. L_ | Não. (Se sim, anotar um por linha e fazer a série de perguntas da tabela abaixo. Se não, ir para 10.1).

\begin{tabular}{|c|c|c|c|c|c|}
\hline $\begin{array}{l}\text { 9.2. Quais animais } \\
\text { vocês caçaram? }\end{array}$ & $\begin{array}{l}\text { 9.3. Quantos destes } \\
\text { bichos vocês } \\
\text { caçaram/pegaram } \\
\text { nos últimos } 15 \text { dias, } \\
\text { ou seja, de (dia } \\
\text { da semana referente } \\
\text { aos } 15 \text { dias } \\
\text { anteriores entrevista) } \\
\text { até hoje? }\end{array}$ & $\begin{array}{l}\text { 9.4. Quantos vocês comeram? (incluir } \\
\text { unidade, se pertinente). }\end{array}$ & $\begin{array}{l}\text { 9.5. Vocês } \\
\text { venderam algum } \\
\text { destes bichos nos } \\
\text { últimos } 15 \text { dias, ou } \\
\text { seja, do dia } \\
\text { (dia da semana } \\
\text { referente aos } 15 \\
\text { dias anteriores à } \\
\text { entrevista) até } \\
\text { hoje? }\end{array}$ & $\begin{array}{l}\text { 9.6. Quanto venderam? (incluir } \\
\text { unidade) }\end{array}$ & $\begin{array}{l}\text { 9.7. Qual foi o preço } \\
\text { que vocês venderam } \\
\text { cada tipo bicho ou } \\
\text { quanto custa a } \\
\text { unidade, em reais, se } \\
\text { vocês fossem } \\
\text { comprar? (mesma } \\
\text { unidade anterior) }\end{array}$ \\
\hline
\end{tabular}




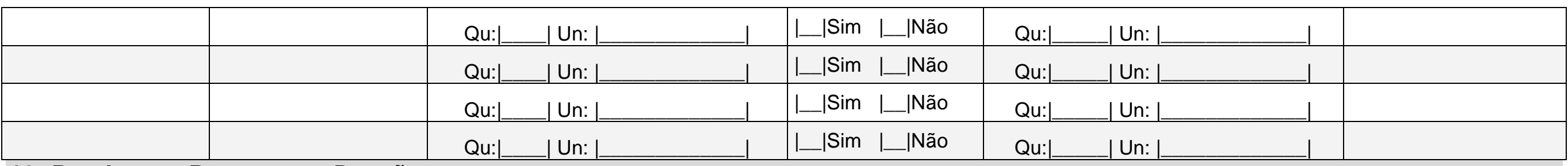

\section{Renda com Presente ou Doação}

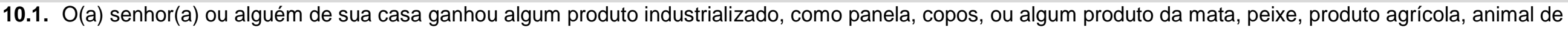

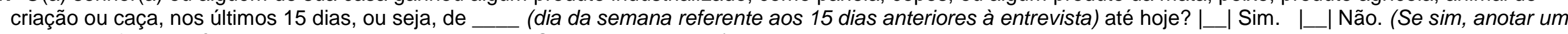
por linha e fazer a série de perguntas da tabela abaixo. Se não, ir para 12.1).

\begin{tabular}{|c|c|c|c|c|c|}
\hline \multirow[t]{2}{*}{$\begin{array}{l}\text { 10.2. Quais foram os produtos que vocês } \\
\text { ganharam nos últimos } 15 \text { dias? }\end{array}$} & \multicolumn{2}{|c|}{$\begin{array}{l}\text { 10.3. Qual foi a quantidade que vocês ganharam? (indicar } \\
\text { a unidade) }\end{array}$} & \multicolumn{3}{|c|}{$\begin{array}{l}\text { 10.4. Quanto custa a unidade desse produto, em reais, se } \\
\text { vocês fossem comprar? (indicar a unidade) }\end{array}$} \\
\hline & Qu:| & Un: & Qu:| & Un: $\mid$ & 1 \\
\hline & Qu:| & Un: & Qu:| & Un: $\mid$ & 1 \\
\hline & Qu:| & Un: & Qu:| & Un: & $\perp$ \\
\hline & Qu:| & Un: & Qu:| & Un: & \\
\hline
\end{tabular}

\section{Dívidas}

11.1. Alguém da casa tem alguma dívida pendente ou ainda está pagando crediário de algum produto? |_ | SIM | _ | NÃO. Se sim, quanto falta pagar? reais.

11.2. Tipo da casa: |_ madeira. _ _ _ alvenaria. _ _ _ madeira e alvenaria. (Observar e marcar com $x$ ).

11.3. $O(a)$ senhor(a) ou alguém que mora com o(a) senhor(a) possui casa em outra localidade?

L__ Sim. I_ Não. Se sim, onde? |. 


\section{Outros Tipos de Renda Monetária}

Agora, eu gostaria de saber sobre os tipos de renda que vocês podem ter, como salário, aposentadoria, bolsa família, trabalho temporário ou ajuda de alguém que mora fora. Eu vou ler alguns tipos e gostaria que o(a) senhor(a) me dissesse se alguém na casa recebe dessa forma e quanto.

\begin{tabular}{|c|c|c|c|c|c|c|}
\hline \multicolumn{2}{|c|}{$\begin{array}{l}\text { 12.1. Quantas pessoas entre } \\
\text { o(a) senhor(a) e } \\
\text { aqueles(as) que moram } \\
\text { com o senhor(a) } \\
\text { ganharam dinheiro no } \\
\text { último mês, isto é, dos } \\
\text { últimos } 30 \text { dias pra cá, } \\
\text { de alguma das formas } \\
\text { que vou citar? (Colocar } \\
\text { número) }\end{array}$} & \multirow[t]{2}{*}{$\begin{array}{l}\text { 12.2. Em } \\
\text { qual } \\
\text { atividade? } \\
\text { (Válido para } \\
\text { empregos e } \\
\text { prestação } \\
\text { de serviço) }\end{array}$} & \multicolumn{3}{|c|}{$\begin{array}{l}\text { 12.3. Quanto cada pessoa ganhou } \\
\text { de cada uma dessas formas? (os } \\
\text { números se referem a mais de uma } \\
\text { pessoa ganhando da mesma } \\
\text { forma) }\end{array}$} & \multirow[t]{2}{*}{ Observação } \\
\hline Tipo & $\begin{array}{l}\text { № de } \\
\text { pessoas }\end{array}$ & & 1 & 2 & 3 & \\
\hline $\begin{array}{l}\text { Emprego com } \\
\text { salário fixo }\end{array}$ & & & & & & \\
\hline $\begin{array}{l}\text { Prestação de } \\
\text { serviço }\end{array}$ & & & & & & \\
\hline $\begin{array}{l}\text { Ajuda em } \\
\text { dinheiro de } \\
\text { parentes ou } \\
\text { amions }\end{array}$ & & & & & & \\
\hline $\begin{array}{l}\text { Aposentadoria } \\
\text { por idade }\end{array}$ & & & & & & \\
\hline $\begin{array}{l}\text { Aposentadoria } \\
\text { por invalidez }\end{array}$ & & & & & & \\
\hline Bolsa família & & & & & & \\
\hline Bolsa floresta & & & & & & \\
\hline Seguro defeso & & & & & & $\begin{array}{l}\text { Mês de } \\
\text { início: }{ }_{\text {__ }} \text { | Mês }\end{array}$ \\
\hline Pensão & & & & & & \\
\hline $\begin{array}{l}\text { Usou dinheiro de } \\
\text { poupança }\end{array}$ & & & & & & \\
\hline Outro: & & & & & & \\
\hline
\end{tabular}

\section{Bens e riqueza acumulada}

Nesta parte, eu vou ler uma série de itens que o(a) senhor(a) pode ter aqui nessa casa. Gostaria que o(a) senhor(a) me dissesse quais deles vocês possuem que estejam funcionando. Caso tenham mais de um de cada, quantos.

\begin{tabular}{|c|c|c|c|c|c|c|c|}
\hline Bens & \begin{tabular}{|l} 
13.1. Tem? \\
(se \\
sim, \\
marcar \\
X).
\end{tabular} & $\begin{array}{l}\text { 13.2. Foi } \\
\text { comprado } \\
\text { (C), dado } \\
\text { (D), } \\
\text { emprestad } \\
\text { o (E) ou } \\
\text { (F) feito? }\end{array}$ & $\begin{array}{l}\mathbf{1 3 . 3 .} \\
\text { Em que } \\
\text { ano foi } \\
\text { adquirid } \\
\text { o o } \\
\text { bem? }\end{array}$ & $\begin{array}{l}\text { 13.4. Quantos } \\
\text { cada um dor } \\
\text { itens) vocês } \\
\text { têm? }\end{array}$ & $\begin{array}{l}\text { 13.5. Qual } \\
\text { é o tipo } \\
\text { do bem? } \\
\text { (escrever) }\end{array}$ & \begin{tabular}{|l|} 
Valor \\
do \\
bem
\end{tabular} & Observação \\
\hline $\begin{array}{l}\text { Antena } \\
\text { parabólica }\end{array}$ & 1 & L & & & & & \\
\hline $\begin{array}{l}\text { Aparelho } \\
\text { de som }\end{array}$ & I & L & & & & & \\
\hline $\begin{array}{l}\text { Caixa } \\
\text { amplificada }\end{array}$ & 1 & L & & & & & \\
\hline $\begin{array}{l}\text { Cama com } \\
\text { colchão }\end{array}$ & L & I & & & & & \\
\hline
\end{tabular}




\begin{tabular}{|c|c|c|c|c|c|c|c|}
\hline Bens & $\begin{array}{l}\text { 13.1. Tem? } \\
\text { (se } \\
\text { sim, } \\
\text { marcar } \\
\text { X). }\end{array}$ & $\begin{array}{l}\text { 13.2. Foi } \\
\text { comprado } \\
\text { (C), dado } \\
\text { (D), } \\
\text { emprestad } \\
\text { o (E) ou } \\
\text { (F) feito? }\end{array}$ & $\begin{array}{l}\mathbf{1 3 . 3} . \\
\text { Em que } \\
\text { ano foi } \\
\text { adquirid } \\
\text { o o } \\
\text { bem? }\end{array}$ & $\begin{array}{l}\text { 13.4. Quantos } \\
\text { (ler } \\
\text { cada um dos } \\
\text { itens) vocês } \\
\text { têm? }\end{array}$ & $\begin{array}{l}\text { 13.5. Qual } \\
\text { é o tipo } \\
\text { do bem? } \\
\text { (escrever) }\end{array}$ & $\begin{array}{l}\text { Valor } \\
\text { do } \\
\text { bem }\end{array}$ & Observação \\
\hline Canoa & L & $\mathrm{L}$ & & & & & \\
\hline $\begin{array}{l}\text { Casa de } \\
\text { farinha }\end{array}$ & | & L & & & & & \\
\hline Celular & I & $\mathrm{L}$ & & & & & \\
\hline $\begin{array}{l}\text { Tanque } \\
\text { d'água }\end{array}$ & L & L & & & & & \\
\hline DVD & L_ & $\mathrm{L}$ & & & & & \\
\hline $\begin{array}{l}\text { Arma de } \\
\text { fogo }\end{array}$ & I & L & & & & & \\
\hline Filtro & I_ & L & & & & & \\
\hline Fogão a & L & L & & & & & \\
\hline Freezer & I_l & $\mathrm{L}$ & & & & & \\
\hline Geladeira & L_ & L_ & & & Tamanho: & & \\
\hline $\begin{array}{l}\text { Máquina } \\
\text { de bater }\end{array}$ & I & L_ & & & & & \\
\hline $\begin{array}{l}\text { Máquina } \\
\text { de lavar }\end{array}$ & L & L & & & & & \\
\hline Moto-serra & L & 1 & & & & & \\
\hline $\begin{array}{l}\text { Motor de } \\
\text { centro }\end{array}$ & L & L & & & & & \\
\hline $\begin{array}{l}\text { Motor de } \\
\text { luz }\end{array}$ & I & L & & & & & \\
\hline $\begin{array}{l}\text { Motor } \\
\text { rabeta }\end{array}$ & L_ & I_ & & & & & \\
\hline Roçadeira & 1 & $\mathrm{~L}$ & & & & & \\
\hline Sofá & 1 & 1 & & & & & \\
\hline Telefone & L & 1 & & & & & \\
\hline Televisão & L & 1 & & & & & \\
\hline Ventilador & L & L & & & & & \\
\hline $\begin{array}{l}\text { Bote de } \\
\text { voadeira }\end{array}$ & L & I & & & & & \\
\hline
\end{tabular}




\section{USP-FAPESP-IDSM}

Projeto Coleta de múltiplos produtos florestais não madeireiros - o caso da RDS Mamirauá
Data de entrevista:

/

/2014.

Início: $\mathrm{h}$

Término:

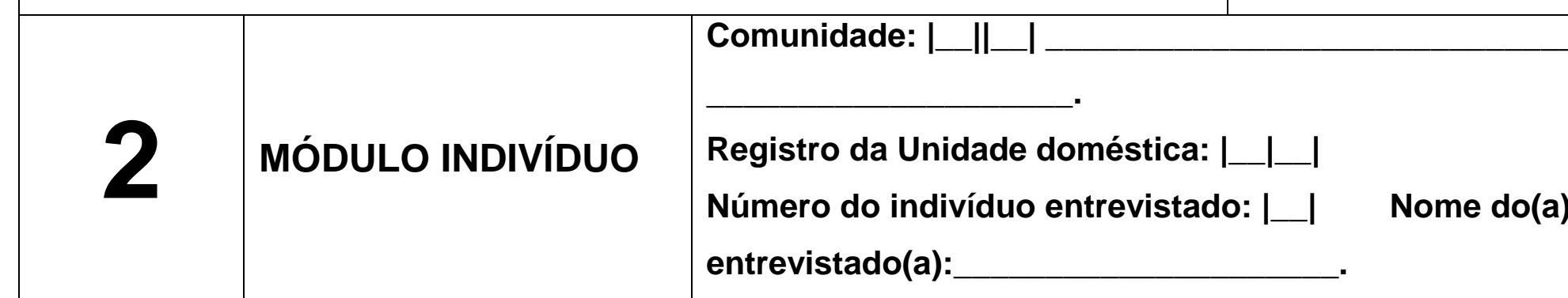

Nota: Os trechos em itálico são instruções para entrevistador e não devem ser lidas ao entrevistado. A introdução a seguir deve ser lida ao entrevistado antes do início da entrevista, para informá-lo sobre os objetivos do projeto e ter seu consentimento para a entrevista.

O objetivo desta pesquisa é avaliar se é possível coletar ao mesmo tempo diversos produtos da mata, principalmente frutas e sementes, como aquelas estudadas pelo Rafael. E pra gente entender isso, a gente precisa entender o interesse das pessoas na coleta dos produtos, e também a capacidade e o tempo que elas têm pra trabalhar coletando esses produtos. Eu tenho aqui uma lista de perguntas e vou perguntar a mesma coisa em todas as casas onde eu for conversar. As respostas que forem dadas não serão mostradas a mais ninguém, ou seja, ninguém poderá saber quem deu cada resposta. Então, se você estiver de acordo, a gente já pode começar.

\section{INTERESSE}

Pra começar, eu gostaria de saber o interesse do(a) senhor(a) em coletar alguns produtos da mata. Para isso, nós vamos usar este desenho (mostrar o desenho e ler a explicação do Interesse).

1.1. Eu vou ler alguns produtos e vou pedir pro(a) senhor(a) indicar somente seu interesse em coletar aqueles que existirem aqui na área de uso da comunidade, ou seja, aqueles que não existirem não é pra apontar. Então, o(a) senhor(a) pode apontar no desenho, por favor, qual é o seu interesse, ou seja, sua vontade ou intenção de ir pra mata na próxima safra pra coletar (ler os produtos da lista)? 


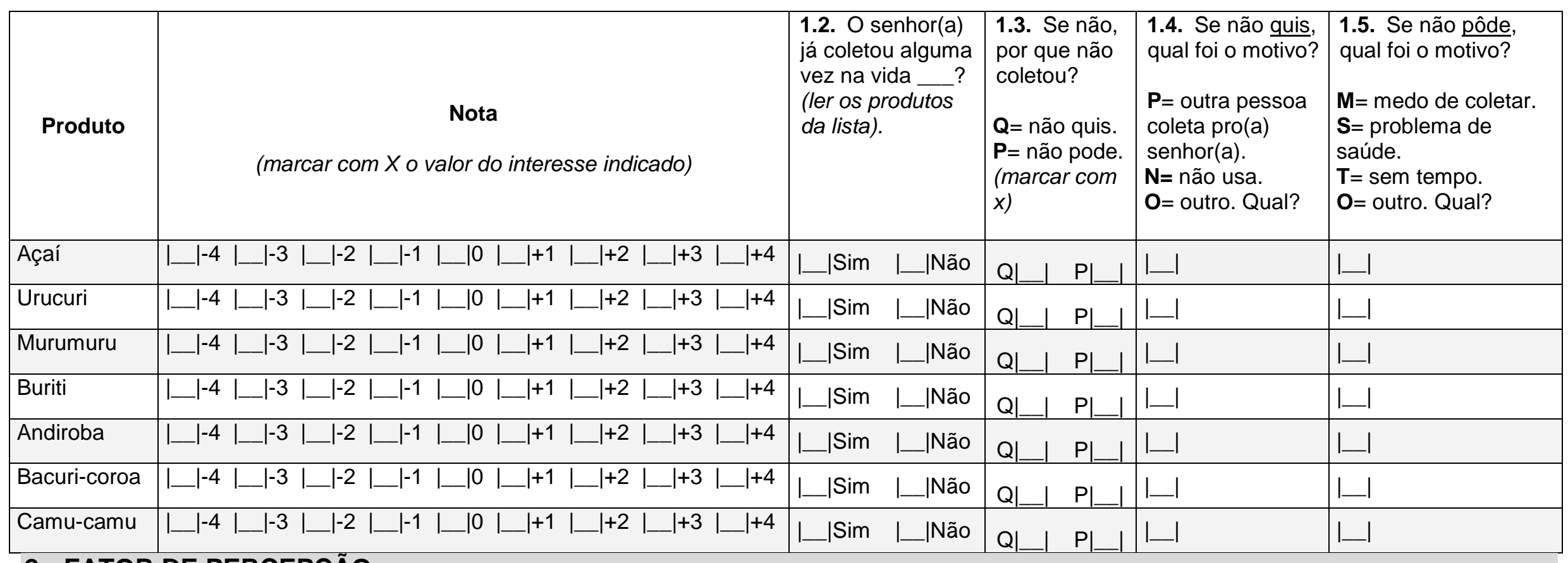

\section{FATOR DE PERCEPÇÃO}

Agora, eu gostaria de saber se o(a) senhor(a) gosta de coletar alguns produtos da mata. Nós vamos usar novamente este desenho (mostrar o desenho e ler a explicação do Gostar).

2.1. Então, o(a) senhor(a) pode apontar no desenho, por favor, o quanto o(a) senhor(a) gosta de coletar, ou seja, o quanto acha bom coletar ? (ler os produtos da lista que o entrevistado já coletou).

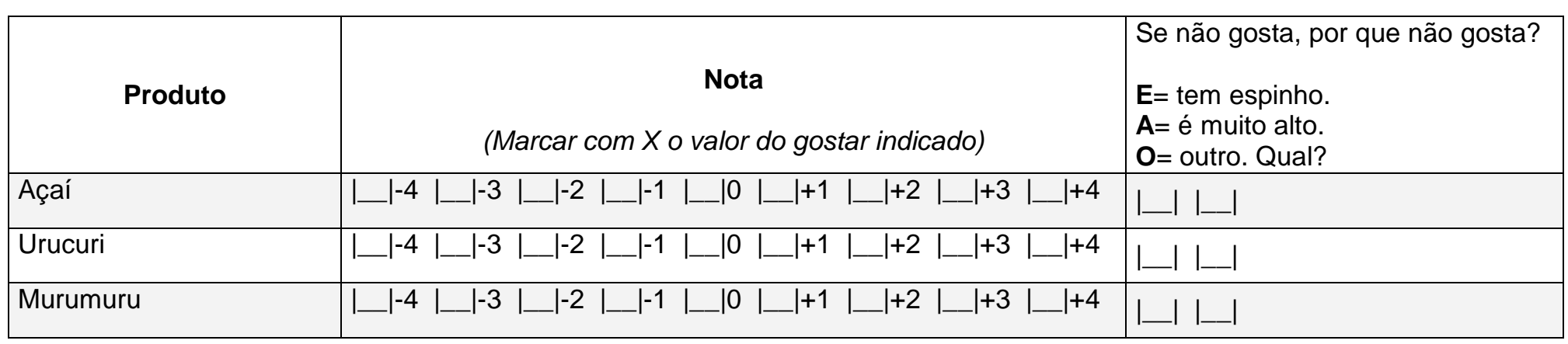




\begin{tabular}{|c|c|c|}
\hline Buriti & 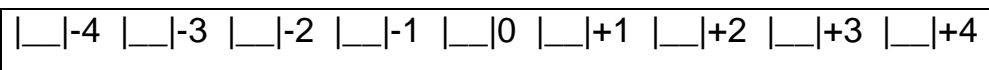 & $1 \ldots 1$ \\
\hline Andiroba & 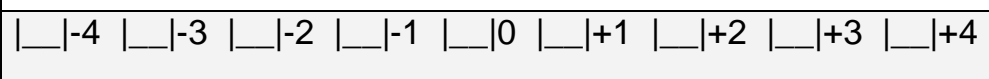 & | \\
\hline Bacuri-coroa & $\left|\_\right|-4\left|\_\right|-3\left|\_\right|-2\left|\_\right|-1\left|\_\right| 0\left|\_\right|+1\left|\_\right|+2\left|\_\right|+3\left|\_\right|+4$ & | \\
\hline Camu-camu & 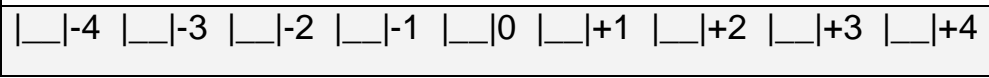 & 1 \\
\hline
\end{tabular}

\section{DISPONIBILIDADE DE RECURSOS E CAPACIDADE}

Agora, eu gostaria de saber a quantidade que o(a) senhor(a) consegue coletar de algumas frutas e sementes que são encontradas aqui na área de uso da comunidade. O que não tiver aqui não precisa dizer. (Fazer todas as perguntas pra um produto e depois repetir as perguntas para o outro e assim por diante).

\begin{tabular}{|c|c|c|c|c|c|c|c|}
\hline Produto & Açaí & Urucuri & Murumuru & Buriti & Andiroba & $\begin{array}{l}\text { Bacuri- } \\
\text { coroa }\end{array}$ & Camu-camu \\
\hline $\begin{array}{l}\text { 3.1. O(a) senhor(a) coletou ou ajudou coletar na última } \\
\text { safra }\end{array}$ & $\begin{array}{l}\text { LISim } \\
\text { I_Não }\end{array}$ & —_Sim & $\begin{array}{l}\text { L_Sim } \\
\text { __|Não }\end{array}$ & —_Sim & L_Sim & I_|Sim & $\mid \begin{array}{l}\text { L_Sim } \\
\text { L_INão }\end{array}$ \\
\hline $\begin{array}{l}\text { 3.3. Se sim, quantas sacas ou latas coletou de } \ldots \text {. Se } \\
\text { não, quantas acha que poderia ter coletado se quisesse? } \\
\text { (incluir a medida utilizada). }\end{array}$ & 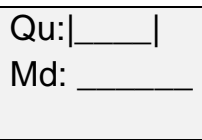 & Qu: & $\begin{array}{l}\text { Qu: } \\
\text { Md: }\end{array}$ & $\begin{array}{l}\text { Qu: } \\
\text { Md:__ }\end{array}$ & $\begin{array}{l}\text { Qu: } \\
\text { Md:__ }\end{array}$ & $\begin{array}{l}\text { Qu: } \\
\text { Md:__ }\end{array}$ & $\begin{array}{l}\text { Qu: } \\
\text { Md: }\end{array}$ \\
\hline \multicolumn{8}{|l|}{$\begin{array}{l}\text { 3.4. Se coletou, quanto tempo gastou, depois que chegou } \\
\text { no lugar onde tem } \\
\text { ou lata? (Anotar quantas horas ou minutos). Se não } \\
\text { coletou, quanto tempo o(a) senhor(a) acha que gastaria? }\end{array}$} \\
\hline
\end{tabular}




\begin{tabular}{|c|c|c|c|c|c|c|c|}
\hline $\begin{array}{l}\text { 3.6. Se a última safra teve uma produção ruim, quantas } \\
\text { sacas ou latas o(a) senhor(a) imagina que poderia coletar } \\
\text { na melhor safra possível? Ou quanto o(a) senhor(a) mais } \\
\text { coletou na vida numa safra? }\end{array}$ & Qu:|__ & Qu: & Qu:___ & Qu:___ & Qu:| & Qu:|__ & Qu:|__ \\
\hline $\begin{array}{l}\text { 3.7. Se não coletou na última safra, o(a) senhor(a) é } \\
\text { capaz, ou seja, o(a) senhor(a) consegue coletar se quiser? }\end{array}$ & L_|Sim & L_|Sim & L_|Sim & L_ & L_|Sim & L__Sim & $\mid \begin{array}{l}\text { Lim } \\
\mid \text { INão }\end{array}$ \\
\hline $\begin{array}{l}\text { 3.8. Quais desses produtos que existe aqui na área de uso } \\
\text { (Escrever os produtos que dá pra coletar numa mesma ida, }\end{array}$ & da comun & o(a) ser & a) acha qu & pra colet & ntos, num & scma ida $r$ & nata? \\
\hline
\end{tabular}




\section{ATIVIDADES PRODUTIVAS}

Agora, eu gostaria de saber quanto que o(a) senhor(a) se dedica a alguns trabalhos na época da cheia, o seja, de fevereiro até o final de julho. Para cada trabalho que eu disser eu vou ler algumas opções e o(a) senhor(a) me diz qual é a opção que melhor se encaixa no seu caso.

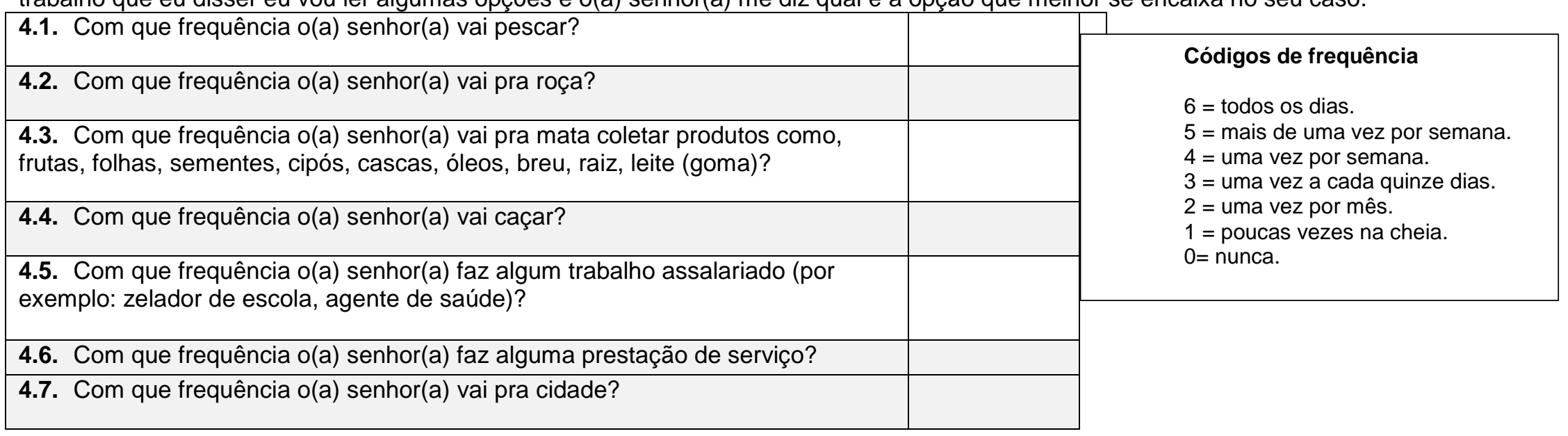

4.8. Se o(a) senhor(a) pudesse escolher, qual é a primeira atividade que o(a) senhor(a) preferiria fazer pra ganhar dinheiro? E a segunda? E a terceira? (escrever por extenso).

\begin{tabular}{|l|}
\hline $1^{\text {ap}}$ preferência: \\
\hline 2 $^{\mathrm{a}}$ preferência: \\
\hline 3ªpreferência: \\
\hline
\end{tabular}

